\title{
NEXT GENERATION TURBINE PROGRAM
}

\section{TECHNICAL PROGRESS REPORT}

FINAL REPORT

PERIOD OF PERFORMANCE: 16 AUGUST 2000 TO 14 JUNE 2002

\author{
Prepared for \\ National Energy Technology Center \\ U.S. Department of Energy \\ AAD Document Control M/S 921-107 \\ P.O. Box 10940 \\ Pittsburgh, PA 15236 \\ Prepared under \\ Contract DE-AC26-00NT40847 \\ Prepared by \\ Pratt \& Whitney \\ Advanced Engine Programs \\ 400 Main Street \\ East Hartford, CT 06108
}

\section{DISCLAMER NOTICE}

THIS REPORT WAS PREPARED AS AN ACCOUNT OF WORK SPONSORED BY AN AGENCY OF THE U.S. GOVERNMENT. NEITHER THE U.S GOVERNMENT NOR ANY AGENCY THEREOF, NOR ANY OF THEIR EMPLOYEES, MAKES ANY WARRANTY, EXPRESS OF IMPLIED, OR ASSUMES ANY LEGAL LIABILITY OR RESPONSIBILITY FOR THE ACCURACY, COMPLETENESS, OR USEFULNESS OF ANY INFORMATION, APPARATUS, PRODUCT, OR PROCESS DISCLOSED, OR REPRESENTS THAT ITS USE WOULD NOT INFRINGE PRIVATELY-OWNED RIGHTS. REFERENCE HEREIN TO ANY SPECIFIC COMMERCIAL PRODUCT, PROCESS, OR SERVICE BY TRADE NAME, TRADEMARK, MANUFACTURER, OR OTHERWISE DOES NOT NECESSARILY CONSTITUTE OR IMPLY ITS ENDORSEMENT, RECOMMENDATION, OR FAVORING BY THE U.S. GOVERNMENT OR ANY AGENCY THEREOF. THE VIEWS AND OPINIONS OF AUTHORS EXPRESSED HEREIN DO NOT NECESSARILY STATE OR REFLECT THOSE OF THE U.S. GOVERNMENT OR ANY AGENCY THEREOF. 


\section{ABSTRACT}

The Next Generation Turbine (NGT) Program's technological development focused on a study of the feasibility of turbine systems greater than $30 \mathrm{MW}$ that offer improvement over the 1999 state-of-the-art systems. This program targeted goals of 50 percent turndown ratios, 15 percent reduction in generation cost $/ \mathrm{kW}$ hour, improved service life, reduced emissions, 400 starts/year with 10 minutes to full load, and multiple fuel usage. Improvement in reliability, availability, and maintainability (RAM), while reducing operations, maintenance, and capital costs by 15 percent, was pursued. This program builds on the extensive low emissions stationary gas turbine work being carried out by Pratt \& Whitney (P\&W) for P\&W Power Systems (PWPS), which is a company under the auspices of the United Technologies Corporation (UTC). This study was part of the overall Department of Energy (DOE) NGT Program that extends out to the year 2008. A follow-on plan for further full-scale component hardware testing is conceptualized for years 2002 through 2008 to insure a smooth and efficient transition to the marketplace for advanced turbine design and cycle technology. This program teamed the National Energy Technology Laboratory (NETL), P\&W, United Technologies Research Center (UTRC), kraftWork Systems Inc., a subcontractor on-site at UTRC, and Multiphase Power and Processing Technologies (MPPT), an off-site subcontractor.

Under the auspices of the NGT Program, a series of analyses were performed to identify the NGT engine system's ability to serve multiple uses. The majority were in conjunction with a coal-fired plant, or used coal as the system fuel. Identified also was the ability of the NGT system to serve as the basis of an advanced performance cycle: the humid air turbine (HAT) cycle. The HAT cycle is also used with coal gasification in an integrated cycle HAT (IGHAT). The NGT systems identified were:

- Feedwater heating retrofit to an existing coal-fired steam plant, which could supply both heat and peaking power (Block 2 engine)

- $\quad$ Repowering of an older coal-fired plant (Block 2 engine)

- Gas-fired HAT cycle (Block 1 and 2 engines)

- Integrated gasification HAT (Block 1 and 2 engines).

Also under Phase I of the NGT Program, a conceptual design of the combustion system has been completed. An integrated approach to cycle optimization for improved combustor turndown capability has been employed. The configuration selected has the potential for achieving single digit $\mathrm{NO}_{\mathrm{x}} / \mathrm{CO}$ emissions between 40 percent and 100 percent load conditions. A technology maturation plan for the combustion system has been proposed.

Also, as a result of Phase I, ceramic vane technology will be incorporated into NGT designs and will require less cooling flow than conventional metallic vanes, thereby improving engine efficiency. A common $50 \mathrm{~Hz}$ and $60 \mathrm{~Hz}$ power turbine was selected due to the cost savings from eliminating a gearbox. A list of ceramic vane technologies has been identified for which the funding comes from DOE, NASA, the U.S. Air Force, and P\&W. 


\section{ACKNOWLEDGEMENTS}

The Program Manager for the DOE was Kanwal Mahajan, from the beginning of the contract in July 2000 until July 2001. Kanwal moved to a different job within DOE and was replaced by Chuck Alsup.

On the contractor side, the work involved a great many people in different component groups. The leaders of the major efforts are as follows; all are from $\mathrm{P} \& \mathrm{~W}$ except as noted.

Program Manager - Bill Day

Performance - Jill Kelly

Compression System - Norm Jacques

Combustion System - Steve Morford

Combustion Modeling - Paul Van Slooten (UTRC)

Ceramic Materials - Gary Linsey and Ellen Sun (UTRC)

Turbine Systems - Rajendra Agrawal and Hector Pinero

Mechanical Systems - Wes Surowka

Rotor Dynamics - Lisa Marquis

Systems Integration - Mike Babu

Balance of Plant - Brian Donnelly

Bottoming Cycle - Lance Hays Douglas Energy)

Bottoming Cycle - Ted Bond (MPPT)

Market Study - Stan Blazewicz and Dinesh Agarwal (Arthur D. Little Company [ADL])

Advanced Cycles - Fred Robson (kraftWork Systems)

Program Administration - Marc Lamoureux

Contracts - Leigh Fournier. 


\section{CONTENTS}

Section

Page

ABSTRACT ii

ACKNOWLEDGEMENTS .iii

EXECUTIVE SUMMARY .

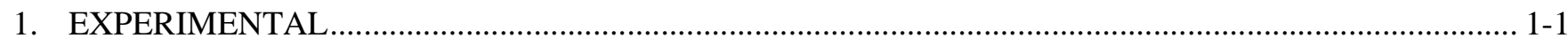

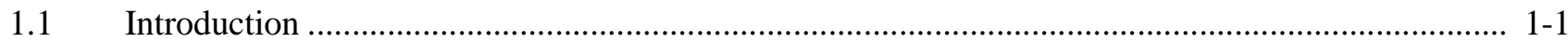

1.2 Overall System Description and Attributes ..................................................................... 1-1

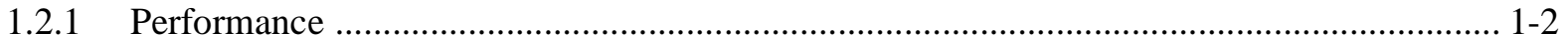

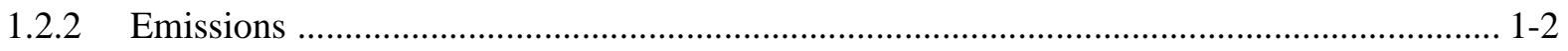

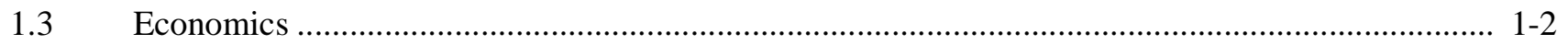

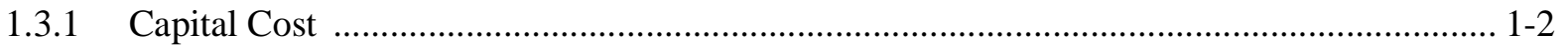

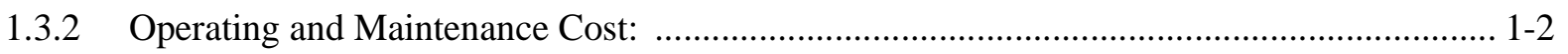

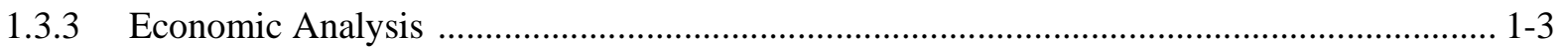

$1.4 \quad$ Reliability, Availability, and Maintainability …................................................................ 1-4

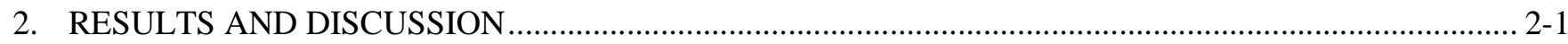

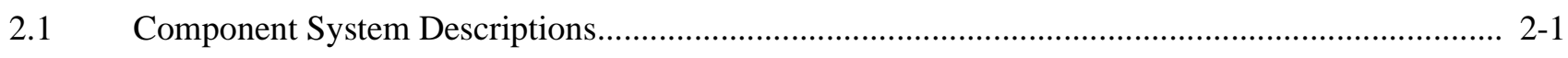

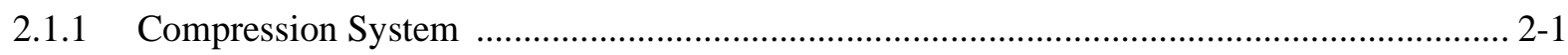

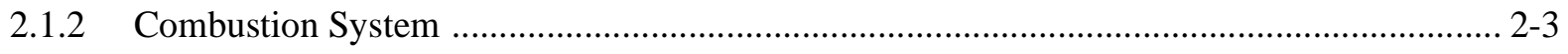

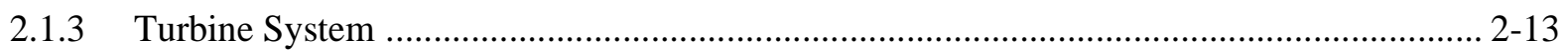

2.1.4 Ceramic Turbine Vanes and Ceramic Matrix Composite Liners .................................... 2-16

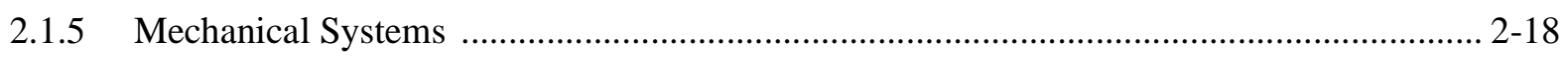

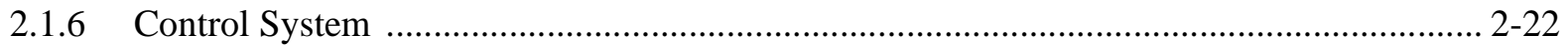

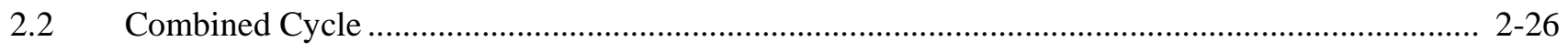

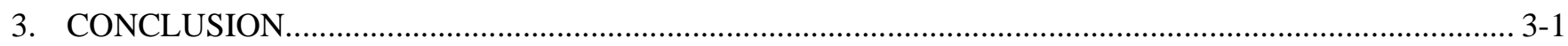

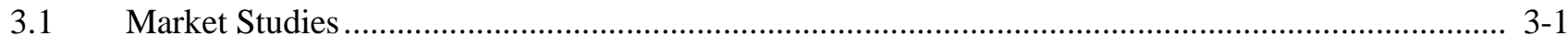

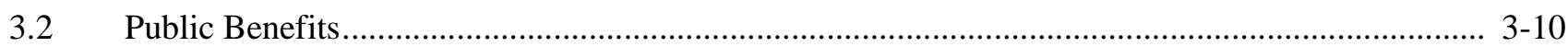

3.2.1 The System's Ability to Serve Multiple Uses .............................................................. 3-10

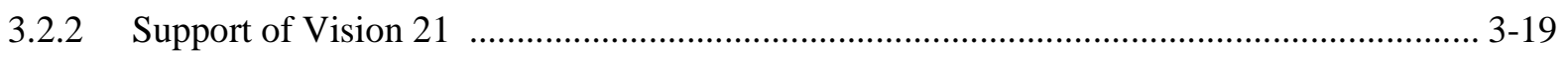

3.2.3 Next Generation Turbine/Fuel Cell Hybrids ................................................................... 3-19

3.2.4 Comments on Public Benefits of the Vision 21 Application ............................................ 3-20

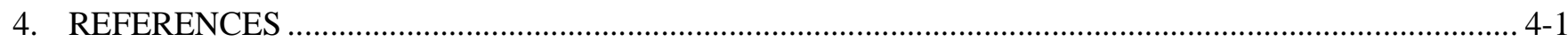




\section{FIGURES}

1-1. Intercooler Cycle $1-1$

1-4. Combined Cycles Cost Considerably More Than Simple Cycles .......................................................... 1-2

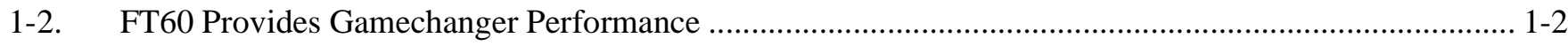

1-3. Market Price Trends Lower With Larger Size ............................................................................... 1-2

1-5. NGT Is Competitive Over a Wide Range of Operating Hours ....................................................... 1-3

1-6. Comparison of the Relative Attractiveness of NGTs By Calculating the NPV of Production Cost $/ \mathrm{kW}$ for Each Unit Over a 15-Year Investment Horizon ........................................ 1-4

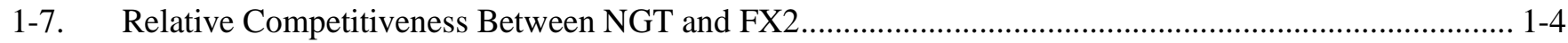

1-8. Aeroderivatives With Lease Engines Have High Reliability and Availability ..................................... 1-4

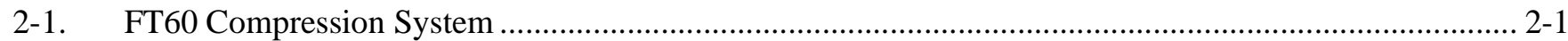

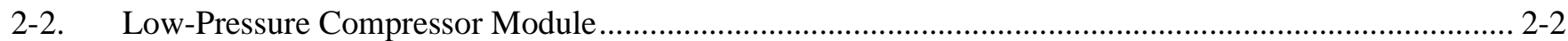

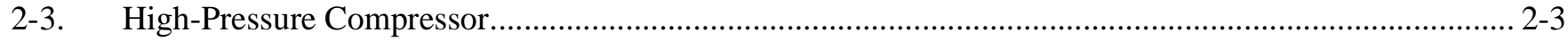

2-4. Typical $\mathrm{NO}_{\mathrm{x}}$ Emissions Versus Flame Temperature …............................................................... 2-4

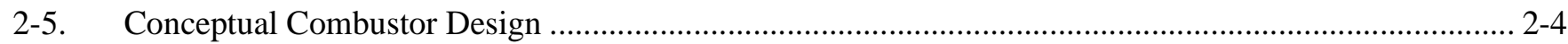

2-6. Effect of Compressor Inlet Guide Vane Modulation and Low-Compressor Bleed On Combustor Exit Temperature Versus Load .................................................................................... 2-5

2-7. Flame Temperature Distribution Versus Load.................................................................................... 2-5

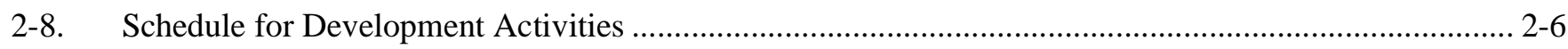

2-9. Computational Cost Estimate for a Hybrid Finite Volume/Full Composition-PDF Method ................... 2-8

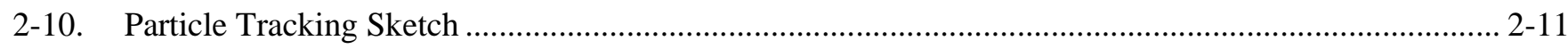

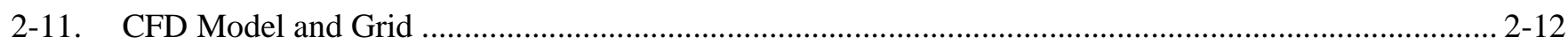

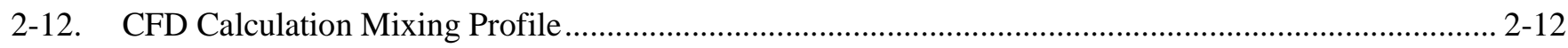

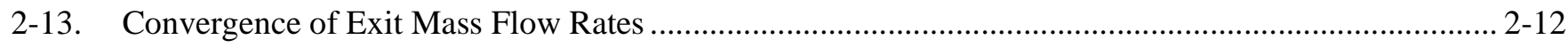

2-14. Convergence of Mean Mixture Fraction at Selected Vertex ............................................................. 2-12

2-15. Convergence of Mixture Fraction Variance at Selected Vertex ......................................................... 2-13

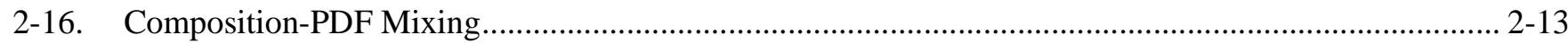

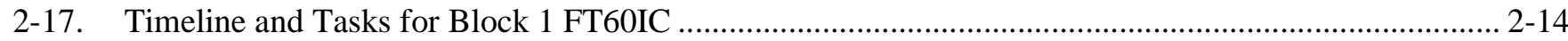

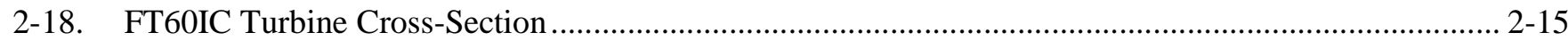

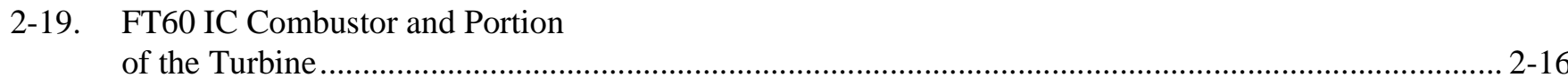

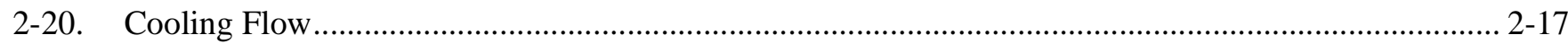

2-1. Increased Revenue With Ceramic and CMC Components ................................................................ 2-18

2-21. Isometric View of the FT60 IC With a Water-Cooled Intercooler .................................................... 2-25 
2-22. Plan View of the FT60 IC With a Water-Cooled Intercooler

2-25

2-23. Isometric View of the FT60 IC With an Air-Cooled Intercooler..........................................................2 2-25

2-24. Plan View of the FT60 IC With an Air-Cooled Intercooler.............................................................. 2-26

2-25. Biphase Combined-Cycle Boasts System Efficiency ....................................................................... 2-27

2-26. Heat Transfer for the Biphase Bottoming Cycle ........................................................................ 2-28

3-1. Framework of the Scenarios for the ADL Analysis................................................................... 3-2

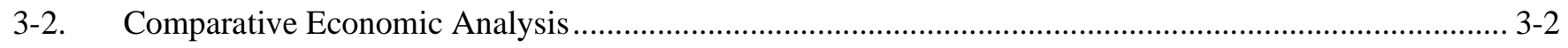

3-3. Market for New Generating Capacity in the U.S...................................................................... 3-3

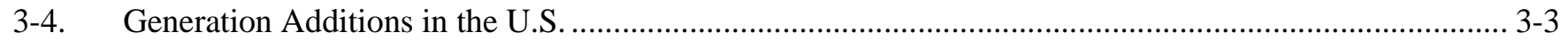

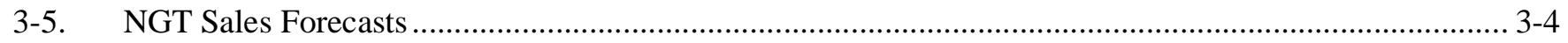

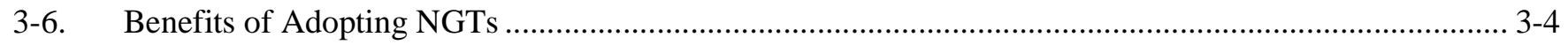

3-7. Savings Were Generated Using Market Projections .......................................................................... 3-5

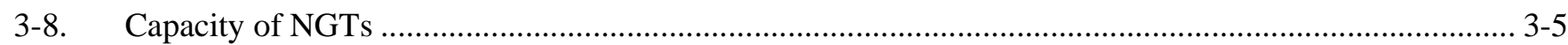

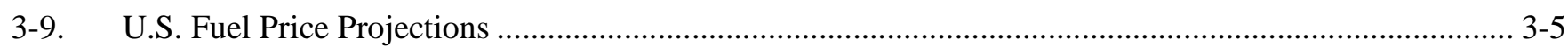

3-10. Efficiencies, Emission Factors, and Displaced Generation Technologies .......................................... 3-6

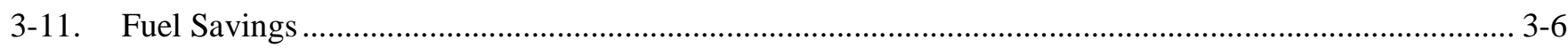

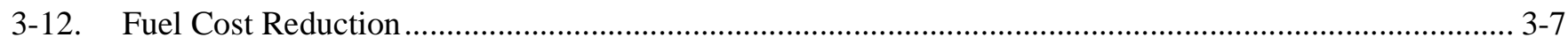

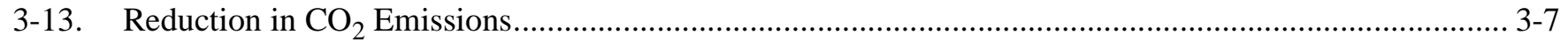

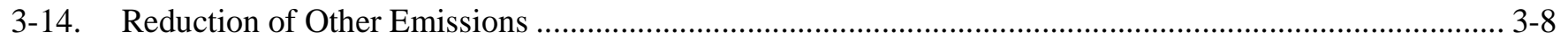

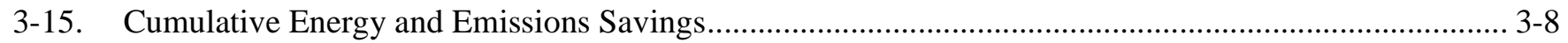

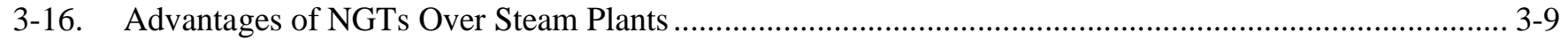

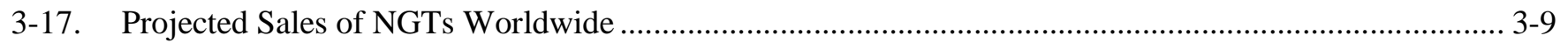

3-18. Typical Daily Load Factor for Feedwater Heating Plant .................................................................... 3-10

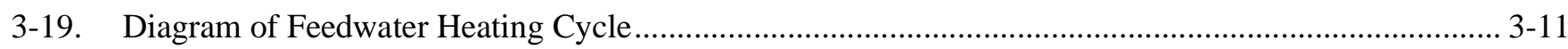

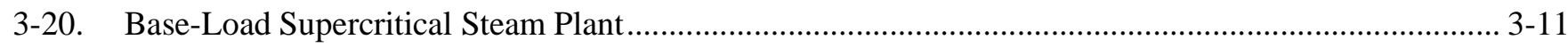

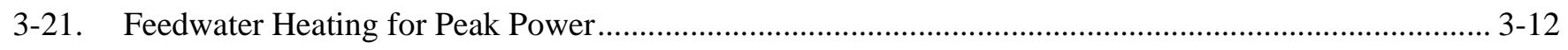

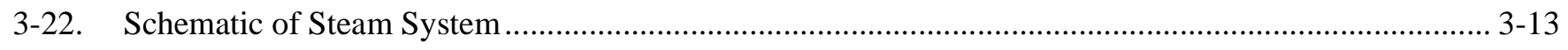

3-23. Schematic of Repowered Plant ….......................................................................................... 3-13

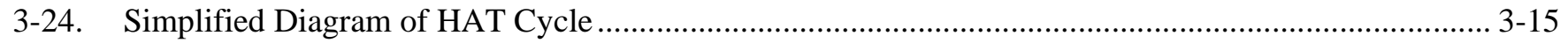

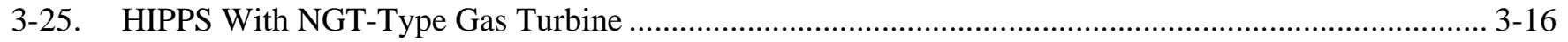

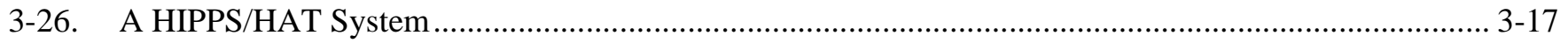

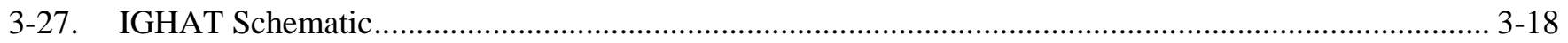

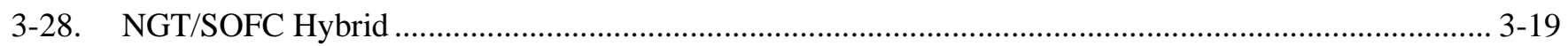




\section{TABLES}

Table

Page

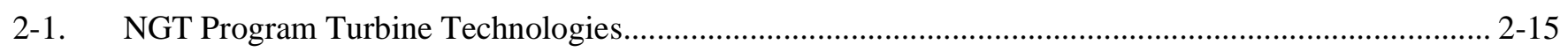

2-2. Data Comparing the Pressure Drops Data Calculated for These Two Header Options........................... 2-25

3-1. NGT Market Potential in U.S. (2007 to 2020) ............................................................................. 3-3

3-2. NGT Market Potential in the Rest of World (2005 to 2020) …........................................................ 3-4

3-3. FT60 IGHAT Performance Estimates (Texaco HEQ Gasifier) ........................................................ 3-18 


\section{Acronyms}

A

ADL

ATS

CFD

CMC

COE

DLE

DOE

EBC

HAT

HEQ

HHV

HIPPS

HPC

HPT

HRSG

IGCC

IGHAT

JIC

LES

LFL

LHV

LPC

LPS

LPT

Arthur D. Little Company

Advanced Turbine Systems

C

Computational Fluid Dynamics

Ceramic Matrix Composite

Cost of Electricity

D

Dry Low Emissions

Department of Energy

\section{E}

Environmental Barrier Coating

H

Humid Air Turbine

High-Efficiency Quench

High Heat Value

High-Performance Power Systems

High-Pressure Compressor

High-Pressure Turbine

Heat Recovery Steam Generator

I

Integrated Gasification Combined Cycle

Integrated Humid Air Cycle

J

Jet-In-Crossflow

$\mathbf{L}$

Large Eddy Simulations

Lower Flammable Level

Lower Heating Value

Low-Pressure Compressor

Low-Pressure Shaft

Low-Pressure Turbine 


\section{Acronyms}

M

MPPT

NETL

NGT

NPV

O\&M

P\&W

PWPS

RAM

SOFC

UTC

UTRC
Multiphase Power and Processing Technologies

\section{$\mathbf{N}$}

National Energy Technology Laboratory

Next Generation Turbine

Net Present Value

\section{0}

Operating and Maintenance

\section{$\mathbf{P}$}

Pratt \& Whitney

Pratt \& Whitney Power Systems

R

Reliability, Availability, and Maintainability

$\mathrm{S}$

Solid Oxide Fuel Cells

U

United Technologies Corporation

United Technologies Research Center 


\section{EXECUTIVE SUMMARY}

This report is a summary of work conducted by P\&W on behalf of the DOE's NETL. For the NGT Program, $\mathrm{P} \& \mathrm{~W}$ performed a feasibility and program planning study of turbine systems greater than $30 \mathrm{MW}$ in preparation for the development of an advanced gas turbine system that would allow for improvement over 1999 state-of-the-art systems while meeting the following objectives:

- Increase lower heating value net system efficiency by 15 percent or more

- Improve turndown ratios (using a turbine at partial capacity) by 50 percent or more

- Improve service life

- Reduce emissions of carbon and nitrogen oxide gases

- Reduce operations, maintenance, and capital costs by 15 percent or more

- Offer flexibility for at least 400 starts per year and $10 \mathrm{~min}$ to full load from the start of command

- Improve RAM

- Provide the capability to use multiple fuels.

An intercooled cycle was selected as the basis for the study. Conceptual design work was done on this cycle in enough detail to determine that it was feasible and would meet the objectives of the program. With an output of 140 to $170 \mathrm{MW}$ at low-capital cost, and an efficiency of 49 to 50 percent, this product has considerable advantages over existing systems in a wide range of peaking and intermediate load applications. This was borne out by the market study and economic analysis conducted by ADL.

The intercooled cycle can also serve multiple uses involving coal. Using the heat from the intercooler and turbine exhaust for feedwater preheating the intercooled cycle improves the efficiency of new or existing coal-fired plants and enables the owner to sell power in on-peak, as well as base load, markets. This enhances the economic competitiveness of conventional coal-fired plants.

Using the same compressors and intercooler, the intercooled cycle can be converted to a HAT cycle configuration; the combustor and turbine would be enlarged to accommodate the additional moisture. Integrated with a coal gasifier, the HAT cycle would produce efficiencies as high as an integrated gasification combined cycle (IGCC), but at reduced capital cost, thereby addressing an issue with IGCC that has slowed market penetration in coalbased applications. The moisture in the HAT cycle retards emissions, as shown in tests at DOE facilities under the HAT Cycle Technology Development Program that is part of the Advanced Turbine Systems (ATS) Program. ${ }^{1}$ The moisture could also enable a lean premix combustor for the HAT cycle in a coal gasification cycle, which is not feasible with a conventional IGCC due to the hydrogen content in the coal gas. This would further reduce emissions from the coal gasification-based cycle.

Longer term, the HAT cycle and coal gasifier can be integrated with fuel cells in a hybrid cycle to meet the 60 percent efficiency goal of the Vision 21 Program.

Technological developments required for the intercooled cycle are in the areas of high-pressure combustion, ceramic materials, advanced alloys and coatings, and intercooler and compressor integration. Extending the intercooled cycle to the HAT cycle integrated with a coal gasifier requires combustion development for the high moisture and coal gas fuel, and development testing of turbine materials and coatings to accommodate the high moisture content.

\footnotetext{
1 DOE contract number DE-AC21-96MC33084
} 


\section{EXPERIMENTAL}

\subsection{INTRODUCTION}

The NGT Program focuses on turbine systems greater than $30 \mathrm{MW}$ that improve on the 1999 state-of-the-art systems. Program goals include a 15 percent improvement in efficiency, a 15 percent reduction in operating, maintenance, and capital cost, a reduction in generation cost $/ \mathrm{kW}$ hour, improved service life, reduced emissions, 400 starts/ year with $10 \mathrm{~min}$ to full load with multiple fuel usage, and a 50 percent improvement in turndown ratios. Improvement is also sought in RAM. The current contract concerns Phase 1 , feasibility study and program planning.

The technical approach chosen to meet the goals of the NGT Program is to use the intercooled cycle, depicted schematically in Figure 1-1.

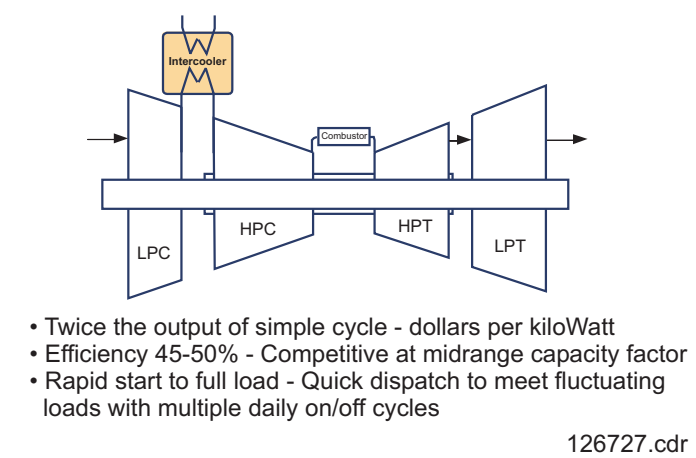

Figure 1-1. Intercooler Cycle

The initial direction of the NGT Program was to use an aircraft engine high-pressure compressor (HPC) as the basis for the industrial gas turbine. This would have resulted in an intercooled cycle in the 60-MW output class. The NGT Program direction changed following a program review with PWPS technical management in December 2000 and subsequent discussions with P2 Energy, the sales and marketing arm of PWPS. The decision was made to increase the size of the industrial gas turbine to over $100 \mathrm{MW}$ in order to meet what is believed to be the market demand. This demand was confirmed by the market survey carried out by ADL and P2 Energy. The resulting system, called the FT60 IC, offers considerable public benefit in providing very high efficiency at low-capital cost in an output class that meets the needs of the major power generators for peaking and intermediate load power.

\subsection{OVERALL SYSTEM DESCRIPTION AND ATTRIBUTES}

Figure 1-1 features a low-pressure shaft (LPS) driving the generator directly at 3,600 rpm. The HPC will be designed only for industrial gas turbine requirements. This makes the job considerably lower risk than developing an HPC that must also meet aircraft engine requirements of maneuver loads, sudden accelerations, light weight and HPC discharge temperature. The HPC case can be made compatible with the combustor case, which must be heavier than that of an aircraft engine due to the large cans required for dry low emissions (DLE). Thus, the backbone of the machine can be made strong enough to support the combustor, without compromising an aircraft engine HPC.

The LPS has relatively low inertia, since the low-pressure compressor (LPC) has only four stages; therefore, the starting motor can accelerate the LPS relatively quickly to achieve fast starts.

The combustors are individual cans, each with its own convectively-cooled transition piece connecting to the 1st-stage vanes.

The FT60 IC will be developed in phases. In the Block 1 configuration, the combustor exit temperature is in the $1316^{\circ} \mathrm{C}\left(2400^{\circ} \mathrm{F}\right)$ class with conventional materials and coatings. The airflow is about $224 \mathrm{~kg} / \mathrm{sec}(600 \mathrm{lb} / \mathrm{sec})$ and the overall pressure ratio is in the 50 to 55 range. The LPC discharge of the FT60 IC is about 0.304 Mpa (3 atm). The exhaust temperature is below $371^{\circ} \mathrm{C}\left(700^{\circ} \mathrm{F}\right)$.

The Block 2 configuration uses the same compression system as in Block 1, but represents an uprate of the hot section to a combustor exit temperature in the $1482^{\circ} \mathrm{C}\left(2700^{\circ} \mathrm{F}\right)$ class and the introduction of ceramic vanes and advanced metallic blade materials with advanced thermal barrier coatings. The exhaust temperature is $438^{\circ} \mathrm{C}$ $\left(820^{\circ} \mathrm{F}\right)$ to $449^{\circ} \mathrm{C}\left(840^{\circ} \mathrm{F}\right)$. 


\subsubsection{Performance}

From Figure 1-2 it can be seen that the efficiency is about 49 percent for Block 1 and 50 percent for Block 2. The output increases considerably from Block 1 to Block 2, from about $140 \mathrm{MW}$ to about $170 \mathrm{MW}$. This reduces the dollars $/ \mathrm{kW}$ cost after accounting for increased materials cost.

Compared to 1999 state-of-the-art systems, as reported in the Gas Turbine World 1999-2000 Handbook, the efficiency of the FT60 IC Block 2 is more than 20 percent higher than the most efficient aeroderivatives and 33 percent higher then the most efficient frame-type gas turbines.

\subsubsection{Emissions}

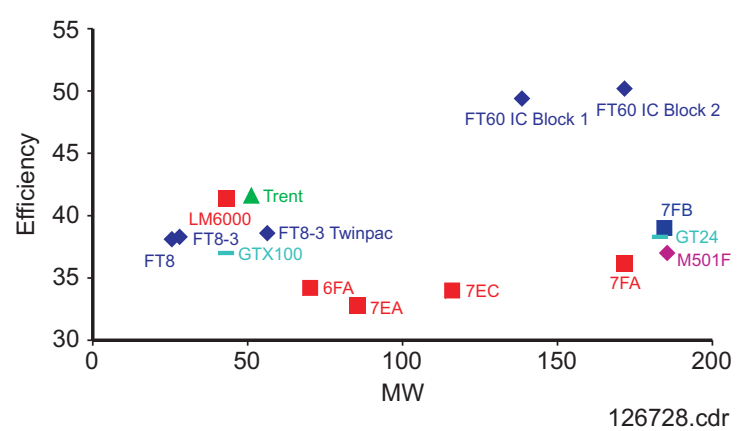

Figure 1-2. FT60 Provides Gamechanger Performance

The objective is to achieve $9 \mathrm{ppm} \mathrm{NO}_{\mathrm{x}}$ emissions after an introductory period at $25 \mathrm{ppm} \mathrm{NO} \mathrm{NO}_{\mathrm{x}}$ emissions, on gas fuel, and $25 \mathrm{ppm} \mathrm{NO}_{\mathrm{x}}$ emissions with water injection on liquid fuel. The very low exhaust temperature of the FT60 IC provides an advantage in meeting stringent emissions requirements at reasonable cost, because it accommodates the use of a conventional selective catalytic reactor with no need to reduce the exhaust temperature by outside air dilution or a bottoming cycle; this enables $\mathrm{NO}_{\mathrm{x}}$ emissions of less than $3 \mathrm{ppm}$. This is particularly important for the FT60 IC, since its high efficiency will drive the economic dispatch point well into midrange capacity factor for many installations, where local emissions caps in tons per year often require extremely low $\mathrm{NO}_{\mathrm{x}}$.

\subsection{ECONOMICS}

\subsubsection{Capital Cost}

From a capital cost standpoint, the target market price (cost to the end user) is in the same range as that of frametype gas turbines (for Gas Turbine World scope, including the intercooler, see Figure 1-3). This price range is considerably lower then that of combined cycles (Figure 1-4).

\subsubsection{Operating and Maintenance Cost:}

The largest single piece of operating and maintenance $(\mathrm{O} \& \mathrm{M})$ cost is typically the repair and replacement of turbine airfoils that amounts to about half the total. Compared to large frame-type gas turbines, the FT60 IC has differences in the design that favorably affect $O \& M$ cost.

The FT60 IC is being designed for a hot gaspath inspection at 25,000 hr and a major inspection at 50,000 hr. The high-pressure turbine (HPT) airfoils will require coating refurbishment at 25,000 $\mathrm{hr}$ and replacement at 50,000 hr. Cyclic life will be at least 5,000 cycles. For the low-pressure turbine (LPT), airfoil coating refurbishment will be required at 50,000 hr, where coatings are present and the design life is $100,000 \mathrm{hr}$. Cyclic life is 15,000 cycles for LPT airfoils. Based on experience with the FT4 and FT8, which operate with similar exhaust temperatures to the FT60 IC, the last two stages will not need coatings, and maintenance action is not needed for these stages at inspection intervals. At 4,000 hr of full load operation and 400 starts per year, the first hot

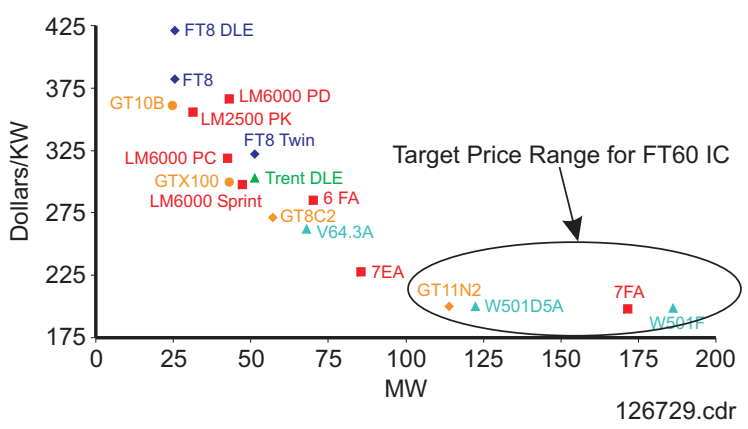

Figure 1-3. Market Price Trends Lower With Larger Size

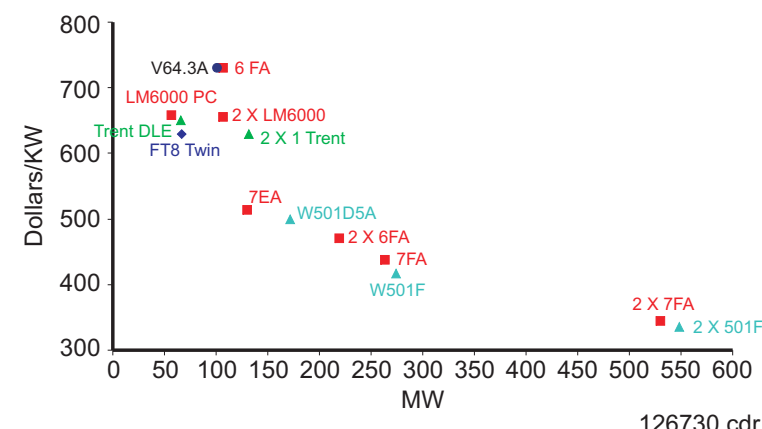

Figure 1-4. Combined Cycles Cost Considerably More Than Simple Cycles 
gaspath inspection occurs at 6.25 years. The first major inspection occurs at 12.5 years, by which time, the airfoils have accumulated 5,000 cycles and the HPT airfoils would need to be replaced.

Frame-type gas turbines are typically not designed for high-cyclic duty. In cyclic duty, E-class frame types can typically last 3 years between hot gaspath inspections, where most turbine airfoils must be repaired and some replaced. F-class frame types typically cannot go more then 2 years at 400 starts per year before a hot gaspath inspection.

The cost to refurbish or replace a turbine blade is strongly correlated to the size of the blade, for comparable materials and technology. The 1st-stage turbine blades of the FT60 IC are nearly the same size as those of a large aircraft engine and much smaller then those of a large frame-type gas turbine. As an illustration, the sizes of the airfoil sections of 1st-stage turbine blades are compared for the FT60 IC, the PW4090 large aircraft engine and an Fclass frame-type gas turbine in the same output class as the FT60 IC:

\begin{tabular}{lccc}
\hline & FT60 IC & PW4090 & F-Class Frame Type \\
\hline AirfoiL Height (in.) & 3.0 & 2.90 & 6.2 \\
\hline Axial Chord (in.) & 1.10 & 1.15 & 4.20 \\
\hline
\end{tabular}

We believe that O\&M costs on a dollars/MW-hr basis will be favorable compared to those of frame-type gas turbines.

\subsubsection{Economic Analysis}

As part of the market study, ADL did an economic analysis of the FT60 IC compared to the following frame-type gas turbines: 7EA, 7FA, and a $2 \times 1$ combined cycle 7FX-2 (two gas turbines and one steam turbine), representing a more advanced combined cycle than the $2 \times 1$ combined cycle 7FA, which is widely used today. The performance of this powerplant is estimated at $590 \mathrm{MW}$ and 58.5 percent net efficiency. This was done to make a comparison against the types of equipment that may be offered for peaking and intermediate service at the time that the FT60 IC could be made available to end users. A conventional pulverized coal powerplant was also used in the comparison. Figure 1-5 and Figure 1-6 show the

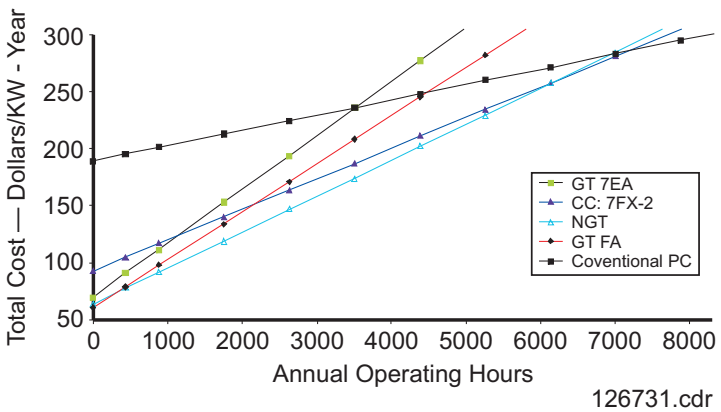

Figure 1-5. NGT Is Competitive Over a Wide Range of Operating Hours results.

In Figure 1-5, the FT60 IC (NGT in the figures) provides the lowest cost of electricity (dollars/kW/yr) when operated from about 500 to over $6,000 \mathrm{hr} / \mathrm{yr}$. The peak savings occurs at 2,200 hr/yr (e.g. $8.8 \mathrm{hr} / \mathrm{day}, 5$ days/week, 50 weeks/year), at which point the FA simple cycle and FX-2 combined cycle each cost $\$ 150 / \mathrm{kW}$-year, while the FT60 IC costs $\$ 130 / \mathrm{kW}$-year. This amounts to costs of electricity of 6.8 and 5.9 cents per $\mathrm{kW} / \mathrm{hr}$ respectively: a savings of 13.2 percent. The savings are greater when compared to 1999 state-of-the-art instead of the anticipated advanced combined cycle.

It is important to note that the combined cycle in this comparison has more than three times the output of the FT60 IC, so the combined cycle enjoys a head start in economy of scale. The FT60 IC would have more flexibility than the combined cycle in terms of the size of the commitment necessary on the part of the end user. 


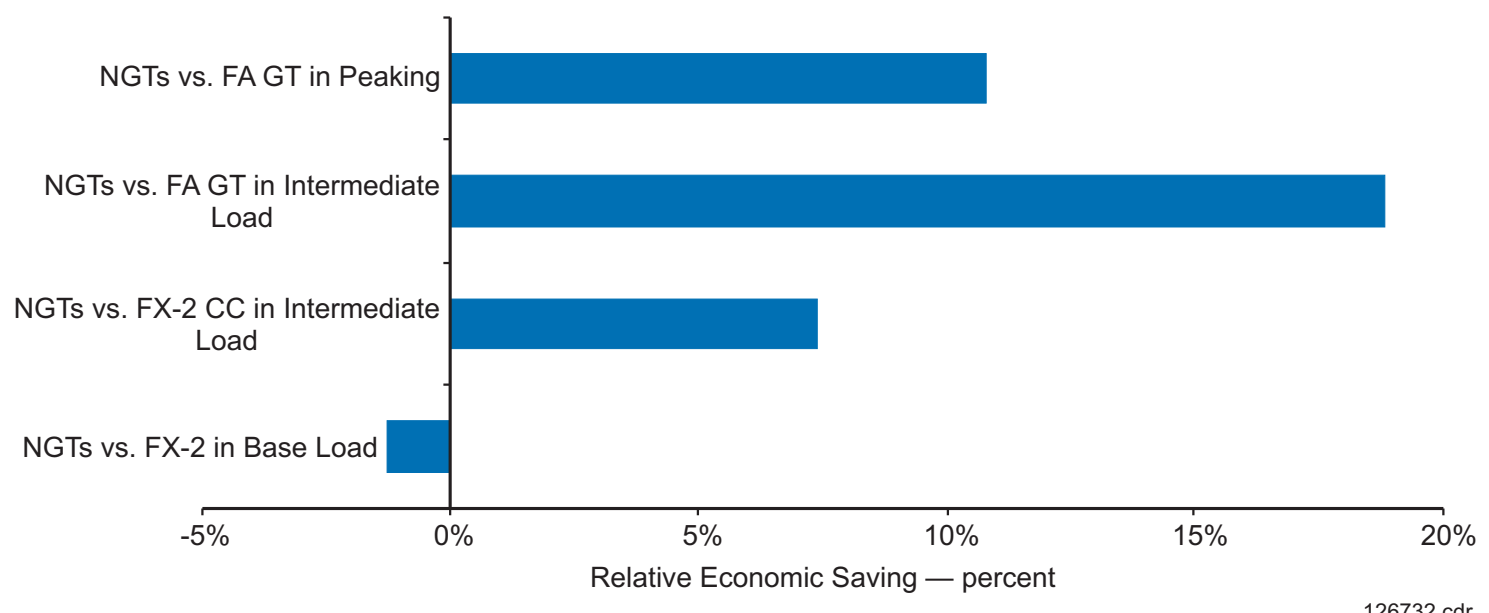

Figure 1-6. Comparison of the Relative Attractiveness of NGTs By Calculating the NPV of Production Cost/kW for Each Unit Over a 15-Year Investment Horizon

As an illustration of value to the end user, Figure 1-6 shows that the FT60 IC provides savings of 8 to 18 percent compared to conventional gas turbines in net present value (NPV) when operated in peak to intermediate load. Figure 1-7 shows that the FT60 IC remains attractive in the intermediate load range against the large combined cycle, even at high gas prices.

NGT is competitive over a wide range of operating hours for peaking and intermediate load applications; they become even more attractive when operational flexibility (one key customer feedback) is factored in.

We compared the relative attractiveness of NGTs by calculating the NPV of production cost per $\mathrm{kW}$ for each unit over a 15-year investment horizon.

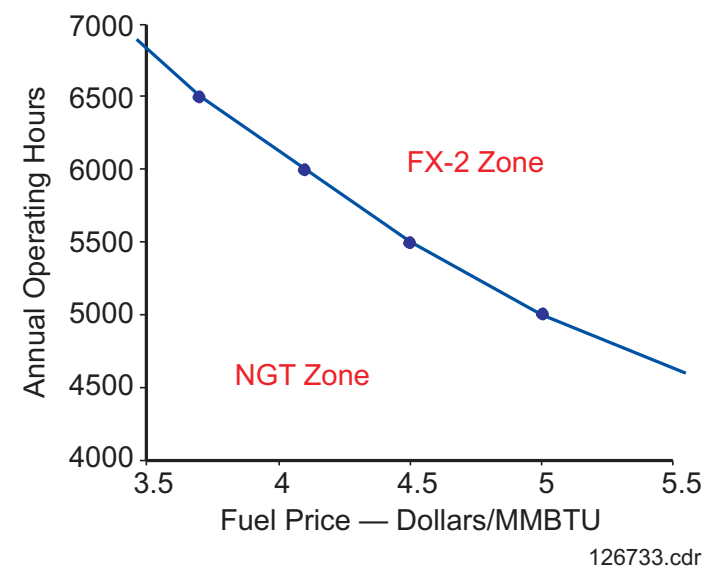

Figure 1-7. Relative Competitiveness Between NGT and FX2

\subsection{RELIABILITY, AVAILABILITY, AND MAINTAINABILITY}

The FT60 IC will be designed to accommodate cyclic duty from the outset, which will be an advantage in reliability compared to typical frame-type gas turbines in cyclic duty. In addition to the turbine airfoil design discussed in Section 1.3.2, the cases and disks will be designed for both fast start and high-cyclic duty.

Another favorable attribute for the FT60 IC is that the core (HPC, combustor, HPT) section of the machine is small enough to be readily shipped to a service shop for maintenance while a replacement core is inserted to allow the end user to continue operating. The core of the FT60 IC is no larger that the FT8 gas generator, which is shipped routinely to service shops in the same way. The FT60 IC core is about 9-ft diameter maximum (at the DLE combus-

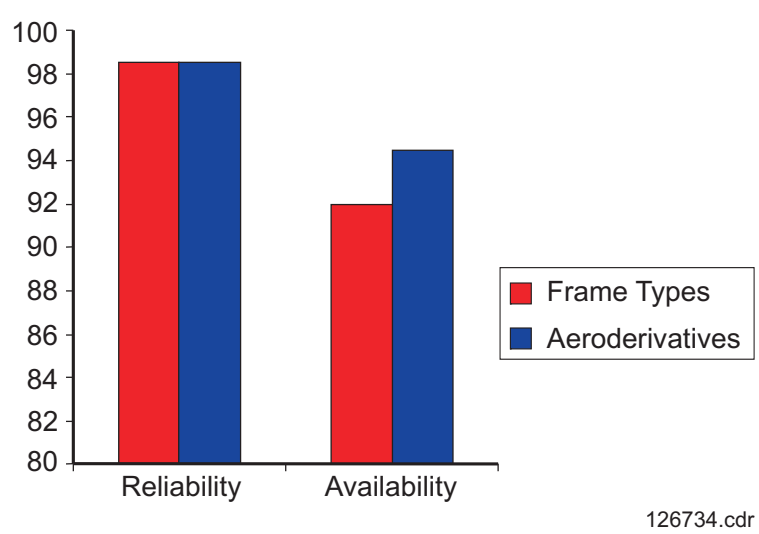

Figure 1-8. Aeroderivatives With Lease Engines Have High Reliability and Availability tor) and 8.4-ft long, while the GG8 (gas generator for a $25 \mathrm{MW}$ aeroderivative) is 5.3-ft diameter and 13.3-ft long. The core is similar to the gas generator of an aeroderivative in being the largest source of down time in the gas turbine. This method of minimizing downtime is a proven way of improved availability for aeroderivatives, as illustrated in Figure 1-8. 
The replacement core feature also improves maintainability, since the core can be shipped readily to a service shop instead of requiring maintenance in the field. This is unusual for a gas turbine in the over $100 \mathrm{MW}$-size class. 


\section{RESULTS AND DISCUSSION}

\subsection{COMPONENT SYSTEM DESCRIPTIONS}

This section of the report is a series of component system descriptions that are the result of test and evaluation under the NGT Program, and were prepared by the design groups in PWPS who are responsible for those components.

\subsubsection{Compression System}

The FT60 IC compression system shown in Figure 2-1 will consist of a 4-stage LPC and a 13-stage HPC, employing the following state-of-the-art aerodynamic features.

- Low loss controlled diffusion airfoils

- Multiple circular arc (MCA) high Mach number rotors

- Radial bowed stators

- Contoured blade platforms

- Rotor tip stability bleeds.

The controlled diffusion airfoils will be designed with calibrated computational fluid dynamics (CFD) analysis tools. The rotor system will incorporate an aerodynamic engine style rotor system to minimize rotor inertia to achieve quick start to sync idle and full power. Low-cost material and construction techniques will also be incorporated to achieve low cost.

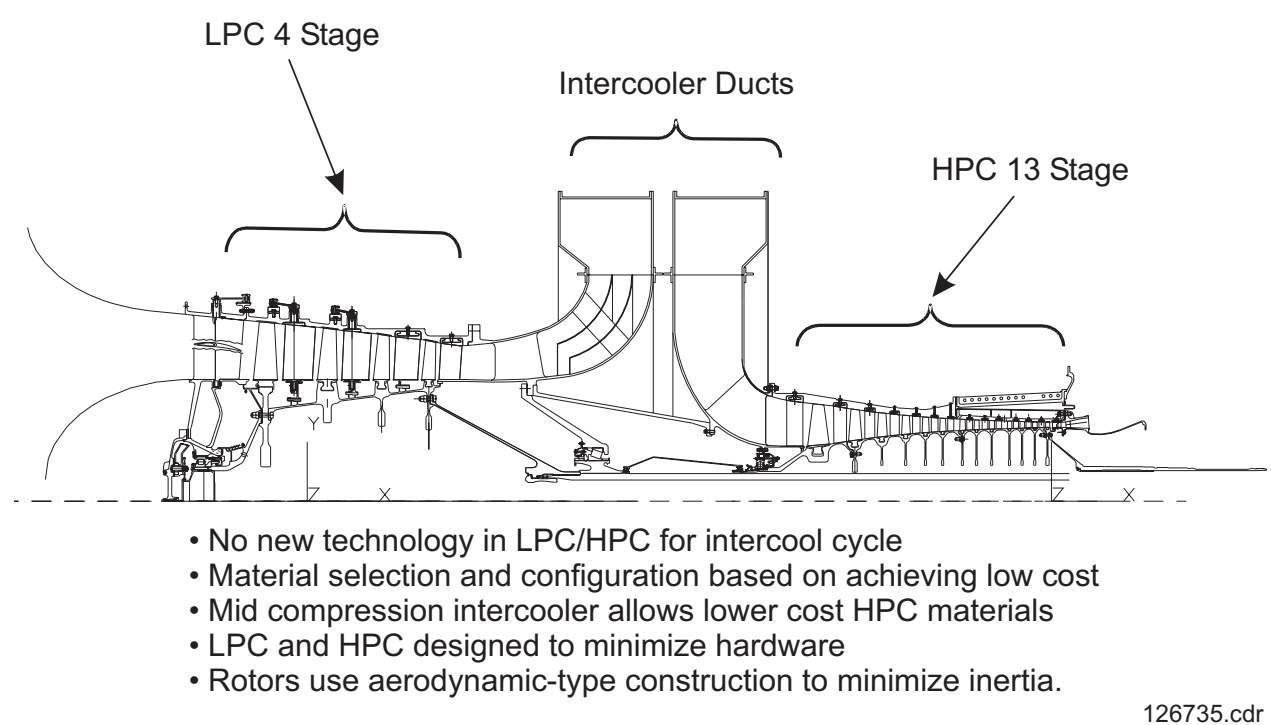

Figure 2-1. FT60 Compression System

\subsubsection{Low-Pressure Compressor}

The LPC rotor construction (Figure 2-2) is planned to have a bolted 1st-stage disk/hub using an axial blade attachment. The following three stages will be a welded drum with tangential blade attachments. The low 3,600 $\mathrm{rpm}$ N1 rotor speed allows use of a steel low rotor drum construction. This construction provides a low cost rotor system that also minimizes blade attachment leakage and rotor inertia. Rotor rim cavities will be minimized and the rotor shell placed as close as practicable to the inner flowpath wall to reduce the bending stresses on the tangential blade attachment rails. The low compressor will have three stages of variable vanes with inner shrouds to reduce vane deflection and bending loads on the variable vane trunnions. The slope or convergence of the inner flowpath wall will be determined by both aerodynamic and cost concerns but will be set to achieve acceptable flowpath wall 


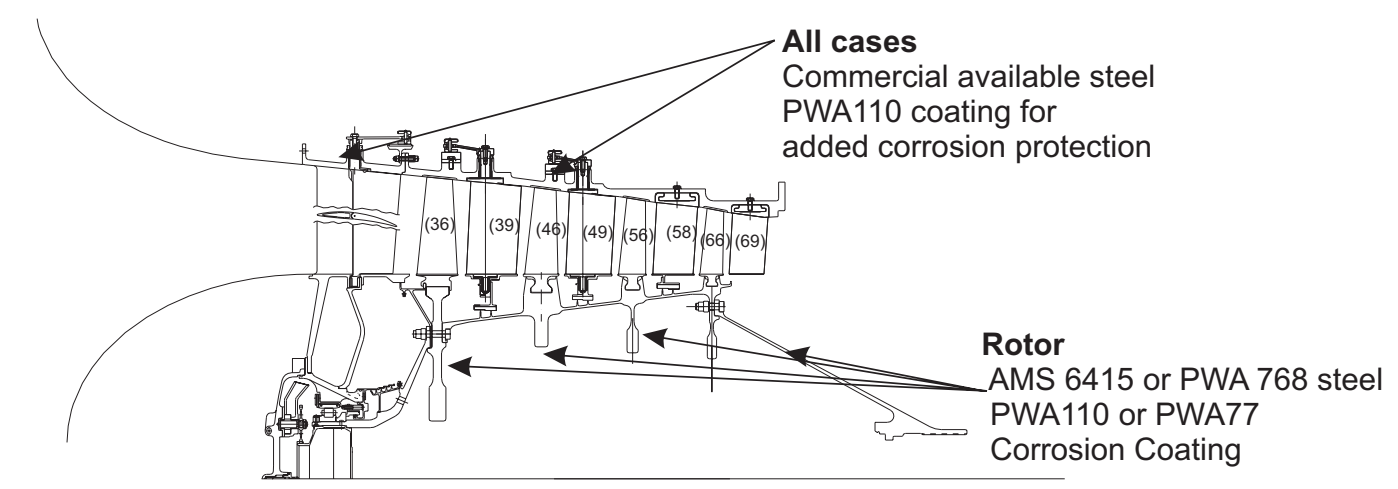

Blades and Vanes:

- Variable and fixed vanes AMS 5613

- Stator ID seal rings - AMS 6304

- PWA77 or PWA110 coating for corrosion protection

- Blades AMS 5613 coated with PWA77 for corrosion protection.
Low Cost Rotor:

- Welded drum rotor (AMS 6415 or PWA768) steel

- Eliminates disk/spacer flanges

- Eliminates integral disk wings or separate rim spacers

- 3 stages - Tangential blade attachments

- Reduces leakage

- Reduces machining cost

Figure 2-2. Low-Pressure Compressor Module

126738.cdr

loading. The variable vanes will use large diameter outer circular platforms and large diameter vane trunnion posts to minimize deflection and wear concerns at the variable vane bushings. The LPC case will be split axially at the horizontal centerline for assembly purposes. This construction also serves to facilitate compressor field maintenance. Materials selection is based on achieving low cost and meeting corrosion protection requirements. Disks are planned to be wrought alloy steel PWA 768 or AMS 6415, and will require a corrosion protective coating of either PWA77 or PWA110-2. The blades are proposed to be AMS5613 or 410 SST with the same corrosion coating used on the disks. The compressor case will be cast AMS5613, 410 SST or 347 SST. Cases, if 410 SST, may also be coated but this would be only for cosmetic purposes. The 300 series SST would maintain its appearance without special coatings. This case will be heavy wall and not subject to stress corrosion concerns.

\subsubsection{Intercooler Ducts}

The intercooler ducts are planned to be cast quarter-segment ducts welded to form a transition from a full annulus with a duct diverting flow to 180-degree horizontal ducts leading to the intercoolers. The exit and return ducts have low-pressure loss aerodynamic and structural struts tying the inner and outer walls together and providing a load path for the No. 2 and No. 3 bearing supports for the LPC rear bearing and the HPC front bearings, respectively. Choice of material for the ducting remains under review. Candidate materials are cast aluminum and cast 410 SST. Cost and stiffness of these ducts will dictate material choice.

\subsubsection{High-Pressure Compressor}

The FT60 IC HPC (Figure 2-3) will be a scaled constant meanline compressor based on test experience with our JT10D-2 and ATE compressors. The rotor will be a low inertia aerodynamic engine-style compressor to meet quick start and low-cost objectives. The rotor aft end will be a welded drum with tangential blade attachments for low cost. The drum construction reduces bolted flange interfaces and eliminates bolt hole machining and close tolerance snap fits. The elimination of these features also reduces customer maintenance cost for wear at these interface locations. The shell of the drum will be located at the inner flowpath wall, thereby eliminating rotor rim cavities. This construction requires that the fixed vanes be cantilevered, without inner vane shrouds. The cantilevered vane construction again offers opportunity to reduce stator costs. The forward fixed vane stages will require inner vane shrouds because of the sloped inner flowpath forward wall. The forward drum will be a welded construction similar to the aft drum. Tangential blade attachments will be used as far forward as practicable to reduce machining costs. The rotor rim cavities, at the forward stages of the HPC, however, will limit use of tangential blade attachments to the smaller blades in the aft end of the front drum. The rim cavities shift the drum shell inward 


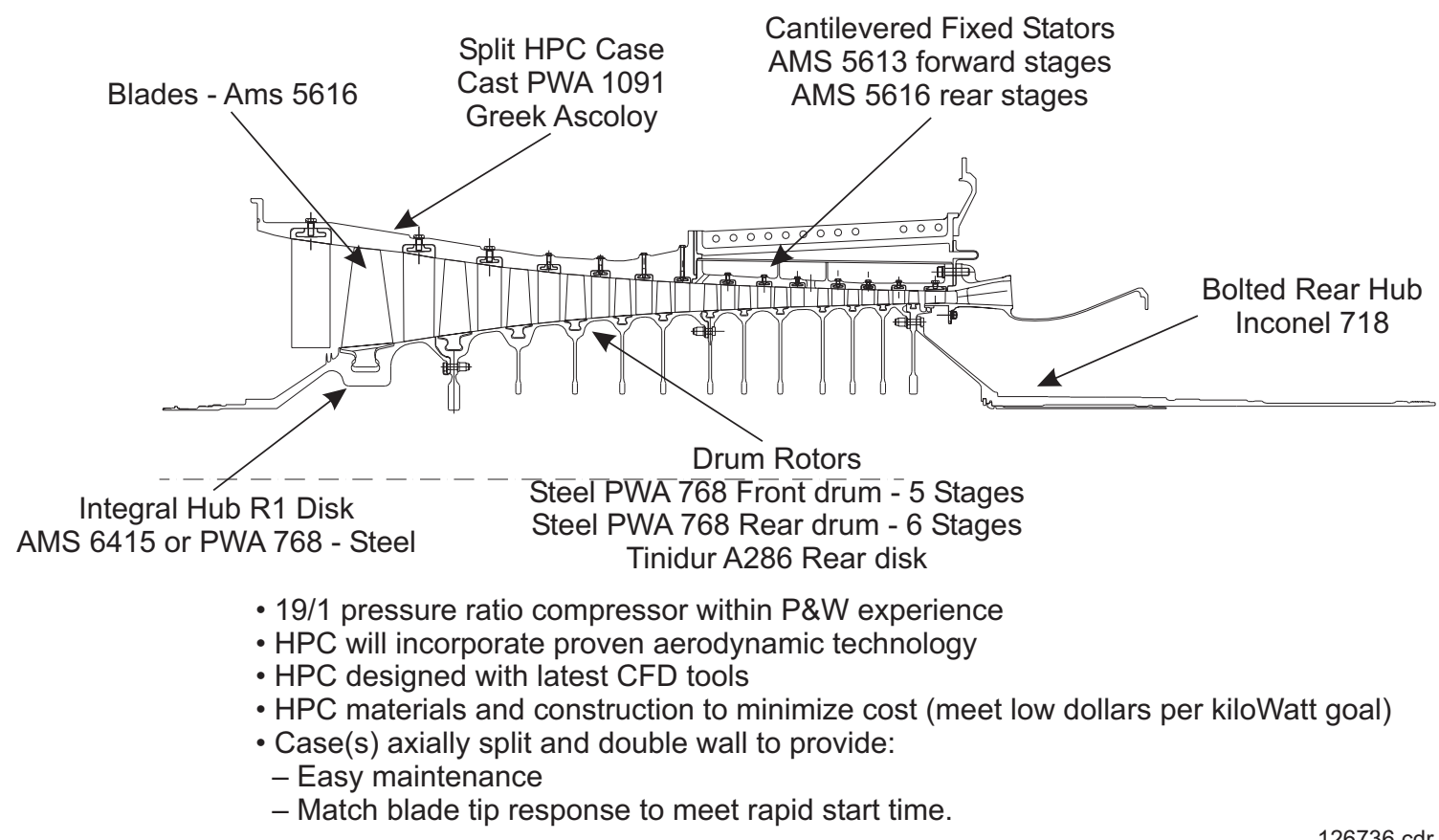

Figure 2-3. High-Pressure Compressor

and thus increase drum rail rolling deflection, blade tip deflection, and results in thicker rails to reduce bending stresses in the drum attachment rails. Further trade study of rotor inertia and drum weight versus cost is necessary to determine the stage location where the switch over to axial blade attachments should occur.

The drum rotor construction requires the HPC cases to be split axially at the horizontal centerline for assembly purposes. This construction also permits field maintenance of rotor and stator hardware, similar to the LPC plan. An additional low cost and improved maintenance feature is planned for the fixed vane attachment in the HPC case. The case will have 360-degree turned grooves to accept segmented tee-shaped vane retention hooks, which will be radial and bolted to the case. These segments will be replaceable or serviceable for wear control. This will eliminate wear refurbishment of the large split compressor cases and reduce customer maintenance cost.

The aft end stages, 7 through 13, will have a separate blade outer airseal case that will be structurally and thermally isolated from the outer structural case. This double-wall case construction will allow the blade outer airseals and case to respond to the flowpath temperatures to achieve the necessary blade tip clearance control required for improved performance and quick start capability. The outer structural case will serve to carry the case bending loads. The case stiffness will be matched to the forward intercooler, LPC case, and the aft combustor case. Rotor and case dynamics will set stiffness and mass of these cases.

The intercooled cycle permits steel- or iron-based alloys to be used throughout the HPC. The plan, as with the LPC, is to use AMS 5613 and AMS 5616 for blade and vane material. The rotor disks and drum is to be wrought alloy steel, PWA 768 or AMS 6415. These materials will need corrosion protective coatings such as PWA 77 or PWA 110-2 for all disks and blades. The compressor cases will be cast 410 SST and will also need corrosion protection for cosmetic purposes.

\subsubsection{Combustion System}

A robust, reliable, DLE combustor is key to the development of these NGTs. Technical issues associated with DLE combustion chambers include combustion-induced pressure oscillations, limited cooling air, achieving near perfect premixing of fuel and air, and maintaining nearly constant combustion reaction temperature over a wide range of power settings and ambient temperatures. The NGT Program further exacerbates these issues by effec- 
tively reducing the state-of-the-art in aerodynamic derivative $\mathrm{NO}_{\mathrm{x}}$ and $\mathrm{CO}$ emissions by a factor of two with increased turndown capability, and improved start-up and response time.

The activities for the combustion system performed under Phase 1 of the NGT Program included the following:

- Conceptual design of the combustion system

- Cycle optimization for improved combustor turndown capability

- Definition of a proposed plan to mature the combustion system.

\subsubsection{Combustion System Conceptual Design}

The thermodynamic cycle selected for the NGT Program features an overall pressure ratio of $5.57 \mathrm{Mpa}(55 \mathrm{~atm})$ and a combustor exit temperature of $1510^{\circ} \mathrm{C}\left(2750^{\circ} \mathrm{F}\right)$ at standard day base load operation. The $\mathrm{NO}_{\mathrm{x}}$ emissions characteristic versus flame temperature of a typical premixer is illustrated in Figure 2-4. The cycle, along with the program goals for $\mathrm{NO}_{\mathrm{x}}$ emissions, dictates that approximately 95 percent of the combustor airflow be used for premixing with the natural gas fuel prior to combustion.

The combustion system selected for the NGT Program is illustrated in Figure 2-5. The configuration is a fuel-staged

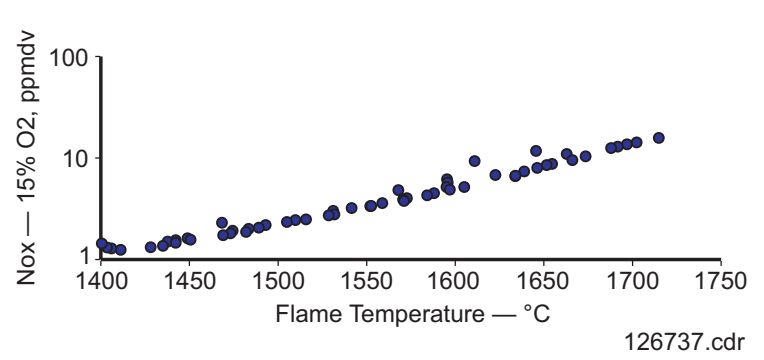

Figure 2-4. Typical $\mathrm{NO}_{x}$ Emissions Versus Flame Temperature can annular combustion system. The configuration features a primary combustion zone that serves to provide flame stabilization, light off, and low-power emission control. The secondary combustion zone, defined by the position of the secondary fuel-air injection point, serves to provide a distributed heat release for reduced combustion pressure fluctuations and a modulating flame temperature capability for emissions turndown.

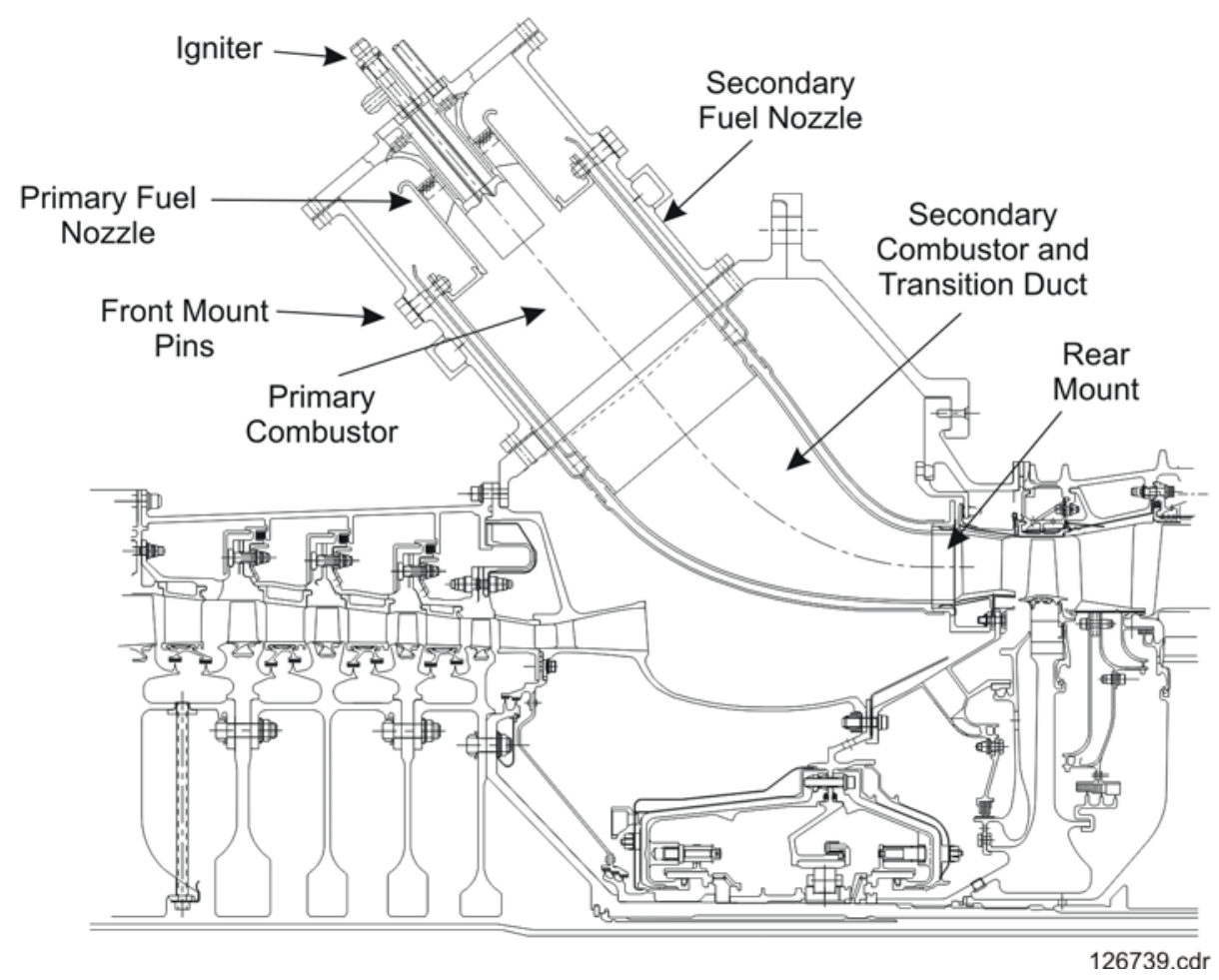

Figure 2-5. Conceptual Combustor Design 
During typical operation, the primary combustion zone would be maintained at a nearly constant flame temperature, while the secondary combustion zone temperature would vary over the gas turbine load range. The actual turndown capability of the combustion system is dictated by the combustor exit temperature lapse rate at part load conditions. A trade study has been conducted to evaluate the impact of combustor exit temperature schedule.

The compressor inlet guide vane position and LPC bleed fraction were the two main parameters selected for variation. Figure 2-6 illustrates the lapse of normalized combustor exit temperature, exit temperature normalized by the exit temperature at 100 percent load, versus load.

Schedule 2 depicts the combustor exit temperature consistent with 0 -deg inlet guide vane position and minimum LPC bleed. The resulting variation in combustor exit temperature is $287^{\circ} \mathrm{C}\left(550^{\circ} \mathrm{F}\right)$ between 40 percent and 100 percent load conditions.

Schedule 11 illustrates the combustor exit temperature consistent with a combination of inlet guide vane modulation and LPC bleed. The resultant combustor exit temperature variation is approximately $149^{\circ} \mathrm{C}\left(300^{\circ} \mathrm{F}\right)$.

The combustion chamber flame temperature distributions for the two exit temperature schedules are presented in Figure 2-7. It is interesting to note that the same combination of flame temperatures can be achieved at 25 percent lower load with inlet guide vane modulation than without.

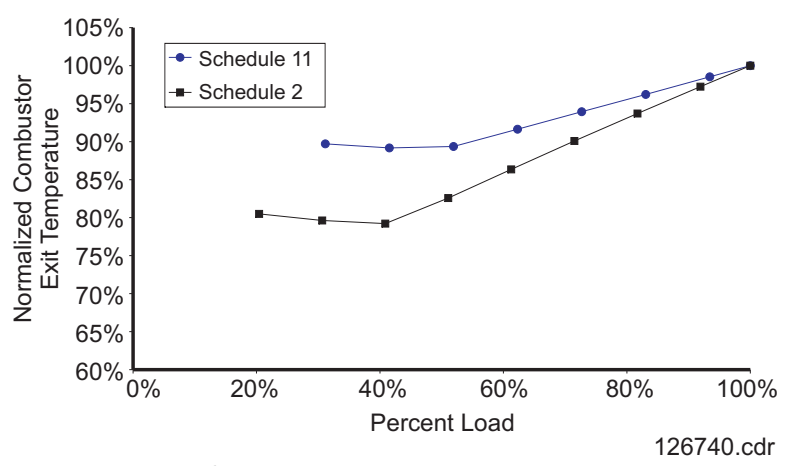

Figure 2-6. Effect of Compressor Inlet Guide Vane Modulation and Low-Compressor Bleed On Combustor Exit Temperature Versus Load

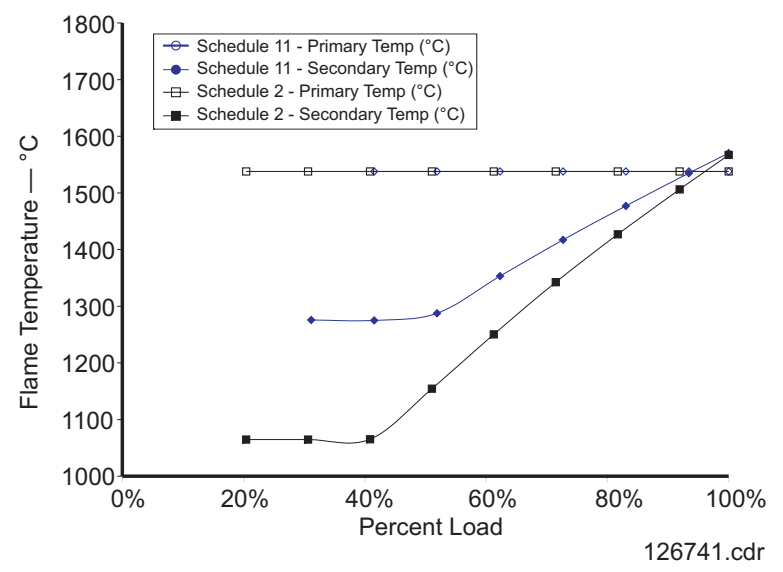

Figure 2-7. Flame Temperature Distribution Versus Load

\subsubsection{Combustor Cooling and Material Selection}

With 95 percent of the airflow dedicated to combustion, insufficient airflow remains to actively cool the combustor structure. Therefore, a regenerative cooling system that first uses the combustion air to cool the structure prior to mixing with fuel has been incorporated into the design. A detailed study of the regenerative cooling system and selection of combustor materials is presented in advanced materials section of the report.

\subsubsection{Proposed Plan to Mature Combustion System}

The cycle operating conditions of the NGT Program present a significant challenge to the development of the combustion system. Specifically, very few combustion facilities have the ability to simulate full engine pressure conditions. The facilities possessing full pressure capability are extremely expensive and thus prohibit conducting all of the development work at these conditions. Therefore, the proposed plan relies on conducting the majority of development activities at reduced scale pressure, typically $2.03 \mathrm{Mpa}$ (20 atm), with selected touch-the-wall confirmation tests conducted at full conditions.

\subsubsection{Technical Approach}

The technical approach proposed consists of focusing on three major challenges to achieving the program emissions and reliability goals. The challenges are fuel-air mixture uniformity, thermoacoustic instability induced pressure fluctuations, and combustion system durability. An approximate schedule is presented in Figure 2-8. 


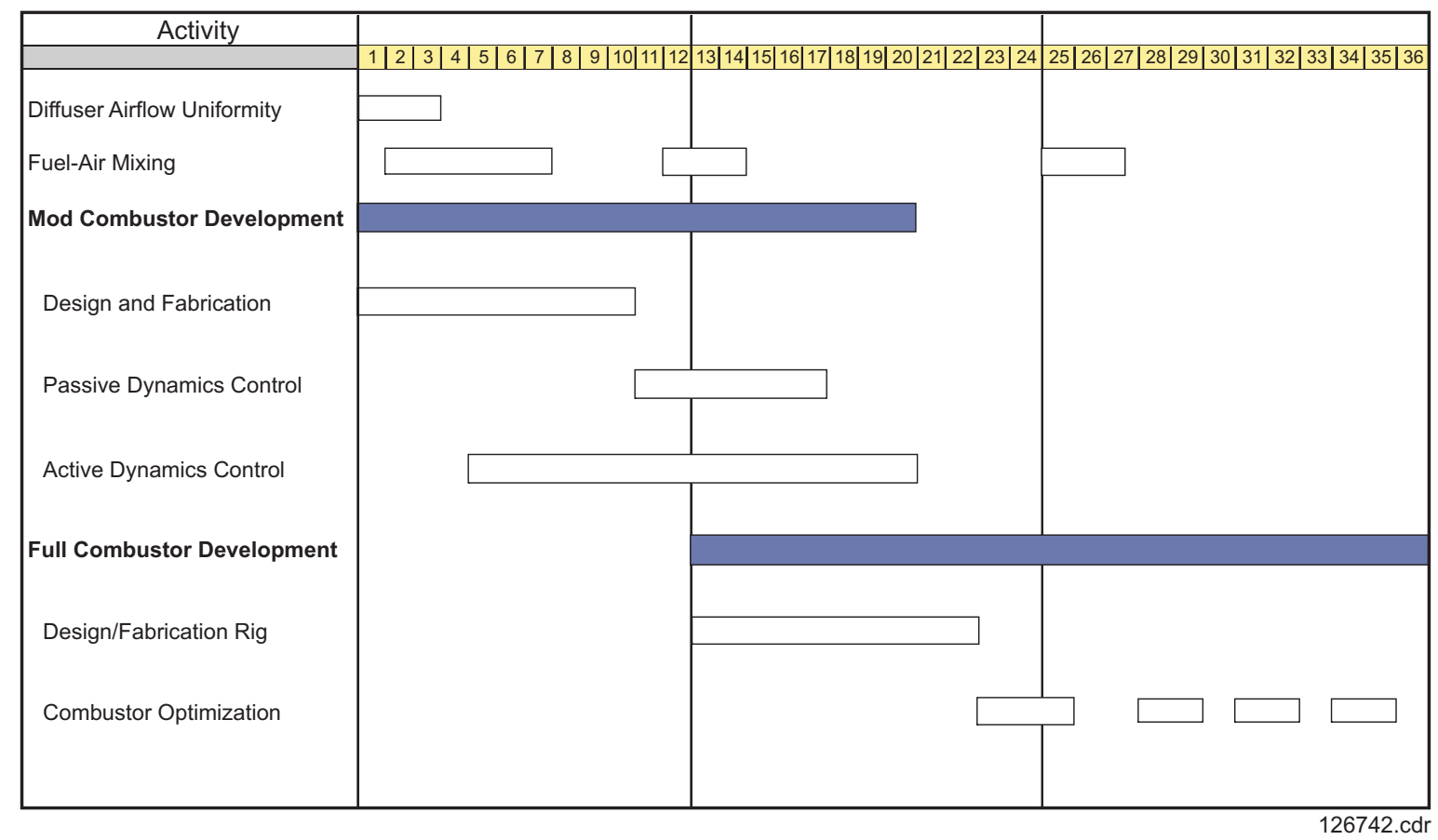

Figure 2-8. Schedule for Development Activities

\subsubsection{Diffuser and Combustor External Airflow Uniformity}

A single can sector of the gas turbine combustion section will be fabricated using low cost stereolithography models and Plexiglas. Atmospheric testing of the combustor diffuser section will be based on Mach number simulation. Assessment of combustor section pressure distribution and airflow uniformity will be made through static and total pressure measurements and flow visualization techniques. Heat transfer characteristics of the regenerative cooling configuration will be validated by the use of single change temperature sensitive paint and semi-infinite wall analytical techniques.

\subsubsection{Fuel-Air Mixing}

Spatial and temporal fuel-air mixing development will be conducted with planar laser-induced fluorescence imaging using low cost stereolithography models of premixer designs. Steady and unsteady CFD analyses will be employed to guide fuel-air mixing development.

\subsubsection{Moderate Pressure Combustion System Development}

A single can sector rig of the gas turbine combustion section will be designed and fabricated for testing at UTRC. Combustion testing under moderate pressure conditions, 2.03 Mpa (20 atm), will be conducted to develop combustion system performance. Assessment of combustor system performance will be made through measurements of emissions, dynamic pressure, vibratory stress, and temperature distribution over simulated operating range. Verification of premixer robustness to flashback/auto-ignition will be conducted through doping natural gas fuel with higher order hydrocarbons.

\subsubsection{Passive Combustion Dynamics Control}

\section{Convective Phase Angle Optimization}

One and three dimension acoustic models of the combustion and fuel system will be constructed. Linearized analysis of combustion system stability will be performed. Fuel injection location(s) will be defined. Combustion rig tests will be conducted to verify predictions and guide selection of final fuel injection locations. 


\section{Acoustic Damper}

One dimension model of coupled combustor, Helmholtz resonator system, will be constructed. Parametric assessment of resonator designs will be conducted. Combustion rig tests will be conducted to verify predictions and guide selection of final resonator design.

\subsubsection{Active Combustion Dynamics Control}

\section{Actuator Sizing and Development}

Valve bodies for use with MOOG drivers will be designed and fabricated. A set of MOOG model B74898 linear force motors and drive electronics will be procured. A test to determine dynamics response of actuator sized for full mean flow will be conducted. Time-phased PLIF imaging of fuel-air mixture at the premixer exit plane in a single-nozzle test rig will be conducted to quantify resulting fuel-air ratio modulation.

\section{Fuel System Dynamic Assessment}

An analytical model of the rig and engine fuel system to investigate fuel system response to the ACC system will be developed. A mock-up of the rig and engine fuel system complete with actuation valves to verify analytical predictions of fuel system response, will be constructed, if needed, based on analytical study results

\subsection{Combustion Rig Demonstration}

ACC components on the single sector combustion rig will be installed. Testing will be conducted to determine the ability to control each of the acoustic modes individually and simultaneously.

\subsection{Control System Integration}

Design and construct a control system that is compatible with the gas turbine control system to ensure safe and effective operation. Conduct simulations of the engine control system and the ACC system to analytically predict system level response of the integrated system

\subsubsection{Full Pressure Combustion System Development}

A single can sector rig of the gas turbine combustion section will be designed and fabricated for testing at Arnold Engineering Development Center. Combustion testing under full-pressure conditions will be conducted to verify combustion system performance. Assessment of combustor system performance will be made through measurements of emissions, dynamic pressure, vibratory stress, and temperature distribution over simulated operating range.

The architecture of the combustion system shown in Figure 2-5 is to have separate combustion cans, each with a separate convectively-cooled transition piece. The combustor control system uses compressor inlet guide vanes to modulate the airflow to the combustor to achieve part load operation (Figure 2-6).

\subsubsection{Physics Based Modeling of Combustors for Emission Predictions}

One of the principal technical issues for meeting the NGT Program requirements is the development of a lowemissions combustor. The high cost of combustor testing has lead to the incorporation of computer simulations into the design process at $\mathrm{P} \& \mathrm{~W}$; design decisions are made from CFD predictions of flow splits, temperature exit profiles, and emissions. Therefore, the accuracy and reliability of the computational models are of crucial importance.

The coupled chemical and fluid-dynamic processes occurring within a gas turbine combustor are extremely complex. Due to a huge range of both length and time scales within the turbulent flow field, direct numerical simulations of the known governing equations are not feasible and will remain so into the foreseeable future. Thus, physics-based models of these combustion processes are required. 
A hierarchy of turbulence and combustion models exists based on model fidelity and computational efficiency. To achieve reliable and accurate predictions of emissions in a gas turbine combustor over a variety of operating conditions, there are three key requirements for the computational model:

1. High-fidelity representation of the combustor geometry (grid)

2. Turbulence model for highly turbulent, swirling flows with mixing

3. Combustion model that includes a chemical kinetics mechanism and a treatment of turbulence-chemistry interactions.

The standard design process at $\mathrm{P} \& \mathrm{~W}$ incorporates the use of three-dimensional, unstructured tetrahedral meshes in its CFD calculations (Malecki, et al., 2001). With this grid topology, the complex geometric features from diffuser exit to turbine inlet are readily modeled in a CAD-to-grid process that allows local grid refinement. The closure of turbulence is achieved through standard approaches such as two-equation models (k-e, q-w), Reynolds stress models, or large-eddy simulations (LES). It has been demonstrated that turbulence models at the Reynolds-stress level provide improved results in strongly swirling flows over standard k-e models (Hogg and Leschziner, 1989).

The calculated composition probability density function (Composition-PDF) method is an advanced model for turbulent combustion that incorporates arbitrarily complex chemical kinetics mechanisms without assumption in the highly nonlinear reaction term. Thus, it provides a natural treatment of turbulent-chemistry interactions. The solution of the Composition-PDF, a high-dimensionality field, is calculated through a statistical approach (Monte Carlo method) that uses particles that are viewed as independent realizations of the underlying turbulent flow. The particle code is coupled to standard CFD finite-volume codes through the heat release or density variables.

The computational costs of the Composition-PDF method are higher than current moment closure combustion models, but recent hybrid finite-volume/Composition-PDF approaches (Muradoglu, et al., 1999; and Jenny, et al., 2000), coupled with in-situ adaptive tabulation (ISAT, Pope, 1997) and automated reduced mechanism techniques, have significantly reduced

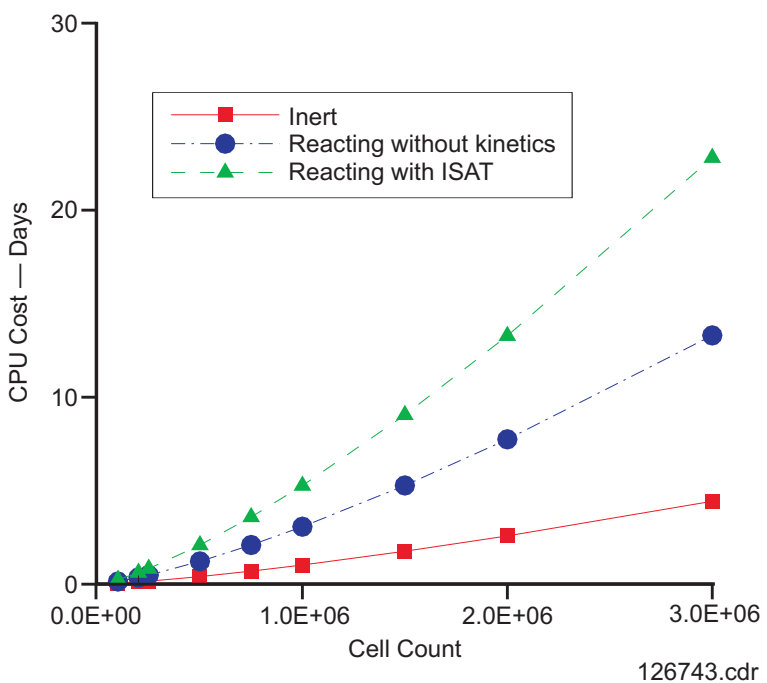

Figure 2-9. Computational Cost Esimate for a Hybrid Finite Volume/Full Composition-PDF Method computational times. An initial estimate of the cost per unit as a function of cell count for such an approach is provided in Figure 2-9, which assumes a 16 species to 41 reaction-kinetics mechanism and parallel implementation on 48 Sun Sparc Ultra2s with 70 percent parallel efficiency.

\section{Algorithm Development}

The computational cost of Compositional-PDF methods has limited its application in combustor design calculations. With recent Composition-PDF algorithm advancements and the increase in computational speed of computers, the development of a Composition-PDF approach with three-dimensional, unstructured grid capabilities would mark a significant advance with potential to directly impact the combustor design process. The first step in this development is the creation of a particle Composition-PDF code for the mixing of passive scalars. In inert flows, the feedback coupling mechanism between the particle code and the CFD code (heat release) does not exist, and the focus may be placed on the development and testing of efficient numerical algorithms and accurate physical models. The areas to be addressed may be classified as general physical/numerical issues concerning Composition-PDF methods, such as particle evolution, local time-stepping, correction algorithms, and mean flow 
estimation; or as specific algorithms concerning three-dimensional unstructured grid implementation of the Composition-PDF method, such as particle tracking, domain decomposition, and particle boundary conditions.

\section{General Composition-PDF Algorithms}

The governing equation for the Composition-PDF varies in a high-dimensional space, which makes traditional approaches for solving partial differential equations (e.g., finite differences) impractical. A Monte Carlo, or statistical, approach whose cost varies linearly with the dimensionality is required. The approach is based on stochastic differential equations that govern the evolution of notional particles from which a Composition-PDF can be derived. This density function is the modeled representation of the density function derived from the governing equation.

For the Composition-PDF approach, the fundamental particle properties are the mass $m^{*}$, position $\mathrm{X}^{*}$, and species $\phi^{*}$, of the particle that evolve through

$$
\begin{gathered}
d m^{*}=0 \\
d \mathbf{X}^{*}(t)=\left(\tilde{\mathbf{U}}+\frac{1}{\langle\rho\rangle} \nabla D_{T}\right) d t+\left(\frac{2 D_{T}}{\langle\rho\rangle}\right)^{1 / 2} d \mathbf{W} \\
\text { and } d \phi^{*}=\mathrm{M}\left(\phi^{*}, \ldots\right) d t+S\left(\phi^{*}\right) d t
\end{gathered}
$$

where $\widetilde{U}$ is the Favre means velocity, $\langle\rho\rangle$ is the mean density, and $D_{T}$ is the turbulent diffusion coefficient (Pope, 1985). These quantities are specified by the finite-volume code. Also, $d \boldsymbol{W}$ is an increment of an isotropic, vectorvalued Wiener process, and $\boldsymbol{M}$ and $\boldsymbol{S}$ are symbolic representations of the mixing and reactive processes, respectively. In the current work, the mixing model implemented is the interaction by exchange with the mean (IEM) model, while the reaction term is zero (non-reacting flow).

A two-step, mid-point numerical formulation was selected to provide second-order accuracy in the weak sense for the particle position evolution equation. The particle species equation is solved by a first-order, splitting algorithm. In this algorithm, the processes of mixing and reaction are split and calculated independently. To achieve higher accuracy would require multiple evaluations of the reaction step, a computationally prohibitive prospect. The complete algorithm is provided below.

Additionally, a local time-stepping algorithm for statistically stationary flows was developed and tested. In a typical combustor grid, the grid size may range over an order of magnitude with relatively large skewness and high expansion factors. The ability to scale the particle time step to the local conditions is critical to achieving an efficient algorithm. The algorithm developed is detailed in Muradoglu and Pope (2001), and is based on constructing an appropriate evolution equation for the normalized particle mass $m^{*}=m_{0} \mu^{*}$,

$$
d \mu^{*}=\beta \mu^{*} d t
$$

where $\beta$ is defined with respect to a global time scale $s$ such that

$$
\frac{\partial}{\partial s}[\mu(s) / \gamma(\mathbf{X}[s], s)]=0
$$

where $\gamma(\boldsymbol{x}, s) \equiv \Delta t(\boldsymbol{x}, s) / \Delta s$ is the mapping from the global uniform time step to the local non-uniform time step. The local time step is proportional to the minimum of the convective, turbulent diffusive, and turbulent time scales, as defined from finite-volume CFD quantities. At steady state, the variable time-step (mass) modeled CompositionPDF converges to the constant time-step (mass) modeled composition PDF; the local time-step formulation converges in pseudo-time to the proper steady-state solution. The method was tested on a non-reacting bluff-body flow, and was found by Muradoglu and Pope (2001) to "accelerate the global convergence of the hybrid method by as much as an order of magnitude" and to "improve significantly the robustness of the hybrid method." 
As described in Muradoglu, et al. (2001), the hybrid finite-volume/particle PDF approach is consistent at the level of the governing equations (or physical model), but may entail inconsistencies at the level of the numerical algorithm. The inconsistencies arise from duplicate information contained within the particle and finite-volume mean fields and can lead to unacceptable levels of numerical errors, particularly bias. Correction algorithms are developed to force consistency. For the inert flows considered in a Composition-PDF approach, only the position correction algorithm of Muradoglu, et al. (2001) is required. This algorithm enforces the consistency between the time-averaged mean particle and particle mass densities (the particle mass density is defined by the volume of the cell and the mass of the particles contained in it). The algorithm calculates a correction velocity $\boldsymbol{U}^{c}$ from a damped oscillator equation driven by the normalized density difference and a correction potential calculated from the normalized density difference.

The final discretized algorithm for the particle evolution is then expressed, with $\mathbf{X}^{0} \equiv \mathbf{X}^{*}(s), \phi^{0} \equiv \phi^{*}(s)$, and $\mu^{0} \equiv \mu^{*}$ as

1. Half step in position

$$
\mathbf{X}^{\frac{1}{2}} \equiv \mathbf{X}^{0}+\left\{\left(\frac{1}{2} \Delta t\right)\left[\tilde{\mathbf{U}}+\mathbf{U}^{C}(s)+\frac{1}{\langle\rho\rangle} \nabla D_{T}\right]\right\}_{\mathbf{X}^{0}}+\left\{\left(\frac{1}{2} \Delta t\right) \frac{2 D_{T}}{\langle\rho\rangle}\right\}_{\mathbf{X}^{0}}^{1 / 2} \xi
$$

2. Mixing of species

$$
\phi^{M} \equiv \alpha\left(\mathbf{X}^{\frac{1}{2}}\right) \phi^{0}+\left[1-\alpha\left(\mathbf{X}^{\frac{1}{2}}\right)\right] \tilde{\phi}^{*}\left(\mathbf{X}^{\frac{1}{2}}\right)
$$

3. Reaction of species

$$
\phi^{*}(s+\Delta s) \approx \phi^{1} \equiv \mathbf{R}\left(\phi^{M},[\Delta t,\langle p\rangle]_{\mathbf{X}^{\frac{1}{2}}}\right)
$$

4. Full step in position

$$
\mathbf{X}(s+\Delta s) \approx \mathbf{X}^{1} \equiv \mathbf{X}^{0}+\left\{\Delta t\left[\tilde{\mathbf{U}}+\mathbf{U}^{C}(s)+\frac{1}{\langle\rho\rangle} \nabla D_{T}\right]\right\}_{\mathbf{X}^{\frac{1}{2}}}+\left\{\Delta t \frac{2 D_{T}}{\langle\rho\rangle}\right\}_{\mathbf{X}^{\frac{1}{2}}}^{1 / 2} \xi^{\prime}
$$

5. Full step in normalized mass

$$
\mu^{*}(s+\Delta s) \equiv \mu^{0}\left(\frac{d t\left(\mathbf{X}^{1}\right)}{d t\left(\mathbf{X}^{0}\right)}\right)
$$

Two independent Gaussian random vectors, $\xi$ and $\xi$, with properties $\langle\xi\rangle=0$ and $\langle\xi \xi\rangle=I$, are introduced. The species-mixing step is presented in a general form to account for different mixing models. For the IEM mixing model, the term $\alpha$ is

$$
\alpha\left(\mathbf{X}^{\frac{1}{2}}\right)=\exp \left\{\left[\frac{C_{\phi} \Delta t}{\tau_{T}}\right]_{\mathbf{x}^{\frac{1}{2}}}\right\}
$$

The reaction step for the species is represented by the reaction mapping $\boldsymbol{R}$, which is a function of the mean pressure and time step at the mid-step particle position and the mixed composition $\phi^{\mathrm{M}}$. The reaction mapping is here zero, but would be provided from the implementation of chemistry through in situ adaptive tabulation (Pope, 1997). 
The discretized particle algorithm requires properties interpolated to the particle position from mean values specified by the finite-volume code or time-averaged from the particle properties. The algorithm that calculates the particle means and the interpolation to the particles is based on trilinear interpolation, an approach well suited to tetrahedral grids. Particle basis functions $\boldsymbol{L}$ provide the "weighting" for interpolation

$$
q\left(\mathbf{X}^{*}\right)=\sum_{i=1}^{4} L_{i}\left(\mathbf{X}^{*}\right) Q_{i}=Q_{4}+\sum_{i=1}^{3} L_{i}\left(\mathbf{X}^{*}\right)\left(Q_{i}-Q_{4}\right)
$$

and for mean estimation

$$
\tilde{Q}_{n}=\frac{\sum_{\mathbf{x}^{*} \in \Omega_{n}} \mu^{*} L_{n}\left(\mathbf{X}^{*}\right) Q^{*}}{\sum_{\mathbf{x}^{*} \in \Omega_{n}} \mu^{*} L_{n}\left(\mathbf{X}^{*}\right)}
$$

where $\Omega_{\mathrm{n}}$ is the support for vertex $\mathrm{n}$. The basis functions are calculated after each position evolution step from $\mathrm{L}_{\mathrm{i}}$ $\left(\mathbf{X}^{*}\right) \equiv \mathrm{A}_{\mathrm{ij}}\left(\mathrm{X}_{\mathrm{j}}^{*}-\mathrm{x}_{\mathrm{j}}^{(4)}\right)$, where $\mathrm{x}_{\mathrm{j}}^{(4)}$ is the position of the fourth vertex in the tetrahedron and $\boldsymbol{A}$ is the basis function coefficient matrix that is constant within each cell.

\section{Three-Dimensional, Unstructured Grid Algorithms}

An efficient and robust algorithm is required to track the large number of particles as they evolve through the grid; the particles must be located within cells. The algorithm implemented calculates for each cell face the ratio of the face plane perpendicular distances from the initial particle location and the face to the initial and new particle locations. If the minimum non-negative value exceeds one, the particle remains in the cell. Otherwise, the particle exits the cell through the face with the minimum value for the ratio, and the process repeats (a finite number of times) with the initial location moved to the cell face. An example in Figure 2-10 shows a particle leaving cell $\alpha$ and entering cell $\beta$. Difficulties stemming from round-off error or high grid skewness complicate the simple approach, but are handled robustly through error tolerances and identification of lost particles. The lost particles are discarded prior to further processing. In testing of a coarse grid

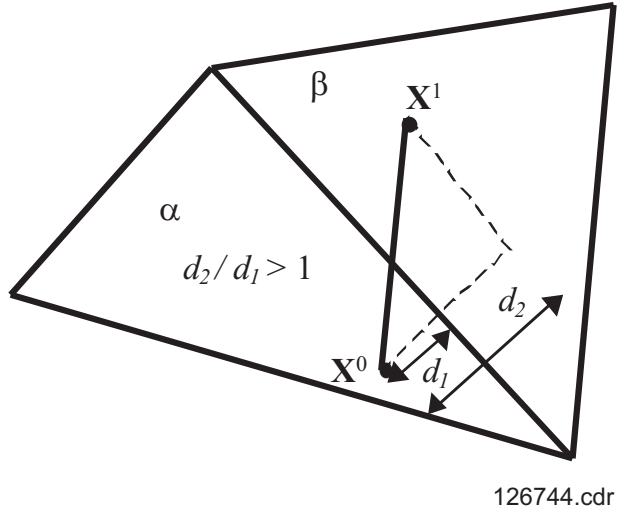

Figure 2-10. Particle Tracking Sketch with a maximum number of face crossings set to 20 , the probability of losing a particle in a given time step was found to be less than $1 e-7$, a value deemed satisfactory.

Parallel processing through domain decomposition is required in finite-volume CFD codes to perform largescale combustor calculations. The ability to track a particle through a grid has to be extended to track a particle as it moves from processor to processor. This algorithm inherently couples to particle tracking and particle boundary conditions. Boundary and domain faces are tagged such that particles trying to cross these faces are specially treated. Particles are reflected from inlet, wall, and symmetry boundaries, while particles are lost upon crossing exit boundaries. Particles crossing periodic or domain boundary conditions are tagged as leaving the domain and positioned on the bounding face. The algorithm is designed so that these particles are bundled and broadcast to the appropriate processor for continued tracking. This process is repeated a fixed number of times prior to labeling the remaining unlocated particles as lost. The coding for the parallel processing and the interdomain face connectivity is highly dependent on the data structures implemented in the finite-volume CFD code. The coding for parallel processing was not performed under this contract, while the framework for the domain-crossing boundary conditions was coded. Therefore, the current composition PDF code is limited to single domain calculations. 
The final algorithm implemented is for the treatment of particles entering through inlet boundary conditions. The algorithm mirrors the two-step, mid-point algorithm by specifying a fixed number of particles to have a mid-point position on the bounding surface. These particles are assumed to have initiated from a location perpendicular to the face plane and at a distance uniformly distributed. These particles then evolve a full particle step. Some of the particles will enter the domain and are kept, while others are lost. The mass of the entering particles is specified so that the inlet mass flow rate is held constant, while the particle species are set to the inlet conditions.

\section{Jet-in-Crossflow Test Case}

A jet-in-crossflow (JIC) test case was constructed to test the implementation of the Composition-PDF code, but not necessarily provide accurate solution to the physics. As such, the grid is rather coarse with $4.5 \mathrm{~K}$ cells and with a plane of symmetry through the jet center. The CFD model is contained in Figure 2-11 with surface grids illustrated. The configuration consists of a fuel jet into a crossflow of air with a momentum ratio of 25. The case is nonreacting, and the species variable may be viewed as a mixture fraction. The CFD mixture fraction profiles are illustrated in Figure 2-12.

Four Composition-PDF cases were run with initially 20, 40, 80, and 160 particles per cell. The results from all four cases were comparable and only those from the 20 particles

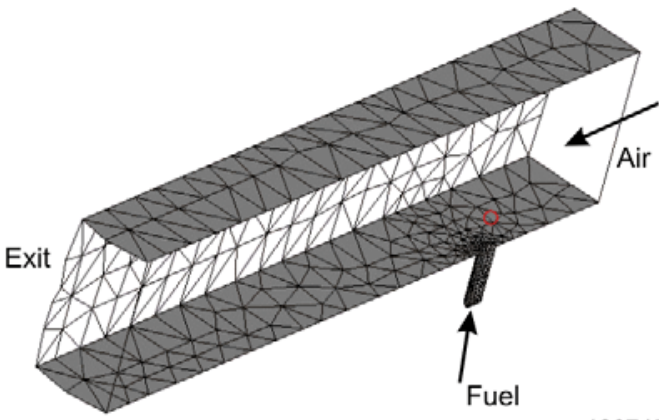

126745.cdr

Figure 2-11. CFD Model and Grid

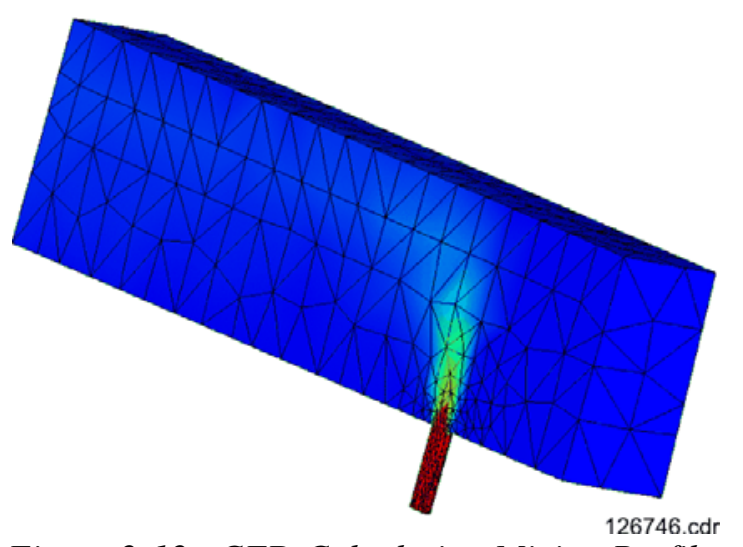

Figure 2-12. CFD Calculation Mixing Profile per cell case are shown here. Figure 2-13 plots, as a function of iteration, the instantaneous exiting particle mass flow rate and its iteration average (range 2000 to 7200), both normalized by the imposed CFD mass flow rate. As expected, the iteration average matches the imposed CFD mass flow rates. The instantaneous mass flow rate oscillated with a standard deviation of 2 percent for the 20 particles per cell case. The standard deviation was found to scale with $1 / N$, the inverse of the number of particles per cell, as expected in the Monte Carlo algorithm. Figure 2-14 and Figure 2-15 contain the mean mixture fraction and mixture fraction variance at a vertex located at the leading edge of the jet about one jet-diameter into the crossflow and slightly off-center (see the red circle in Figure 2-11). Plotted are the instantaneous mean, the running time average over 500 iterations calculated within the

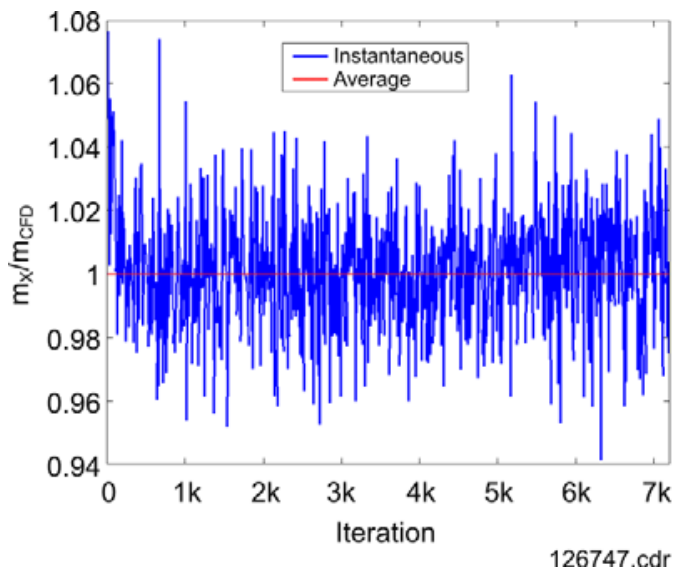

Figure 2-13. Convergence of Exit Mass Flow Rates

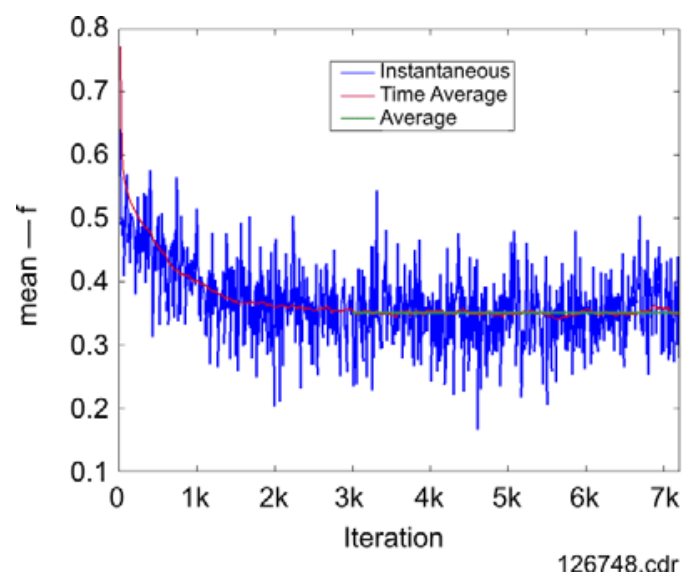

Figure 2-14. Convergence of Mean Mixture Fraction at Selected Vertex 
Composition-PDF code, and the post-processed iteration average (range 3,000 to 7,200). Clearly, a statistically stationary state is reached for this vertex located in an active region of the flow, but a longer time-average scale should be used in the Composition-PDF calculations. In addition, the computational time per particle per time step that was found in these calculations was comparable to the values used in the estimates provided in Figure 2-9. The final results presented are the timeaverage mean mixture fraction contours in Figure 2-16. These results show a significant difference from the CFD calculations in Figure 2-12. A possible explanation for the discrepancy is that the Composition-PDF code is more dissipative than the CFD code, which on such a coarse grid leads to unacceptable errors. This issue must be investigated further.

\subsubsection{Turbine System}

During the NGT Program Phase I study, several concepts were evaluated for the turbine. The major decision to make concerned whether to have a single or two-stage turbine. After detailed aerodynamic studies, and a realization of the commonality requirement between the NGT family of engines, a twostage turbine was selected. A common $50 \mathrm{~Hz}$ and $60 \mathrm{~Hz}$ power turbine was also selected due to the cost savings from eliminating a gear box. The commonality would be achieved by designing to a speed between 3,000 and 3,600 rpm while featuring different sets of airfoils on both applications. A list of technologies has also been identified. The funding for these technologies comes from DOE, NASA, the U.S. Air Force, and P\&W.

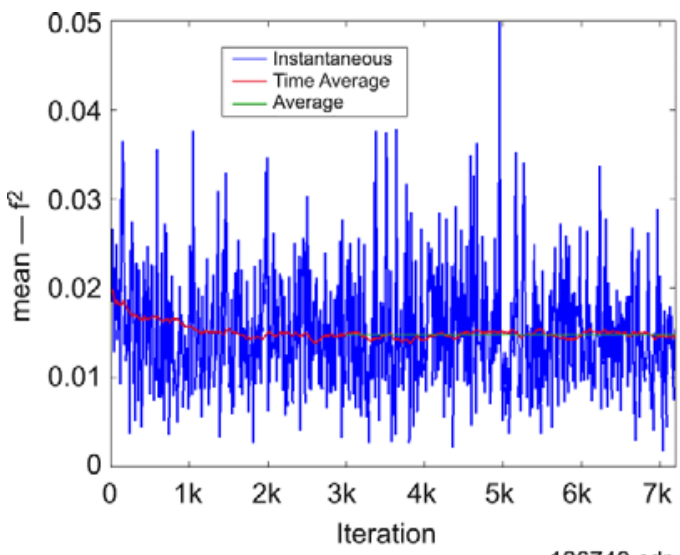

Figure 2-15. Convergence of Mixture Fraction Variance at Selected Vertex

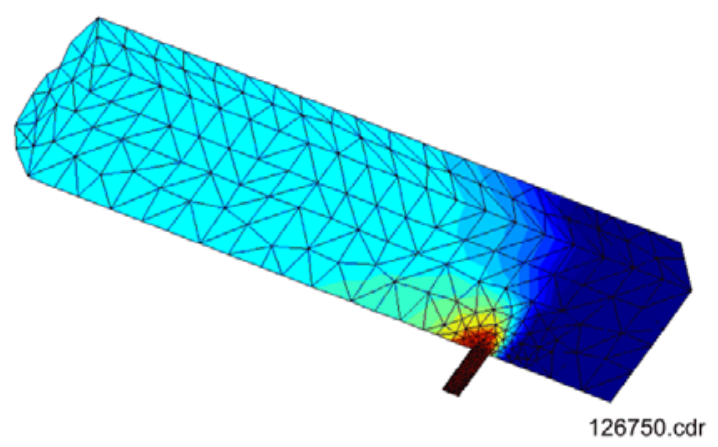

Figure 2-16. Composition-PDF Mixing

\subsubsection{Turbine Material Selection}

Ceramic vane technology will require less cooling flow than conventional metallic vanes and will therefore improve the engine efficiency.

\begin{tabular}{|c|c|c|c|}
\hline Block No. & Stage & Material & Comments \\
\hline \multirow[t]{4}{*}{ Block 1} & 1st-stage vane & Cobalt & \\
\hline & 2nd-stage vane, 3rd-stage vane ds & Nickel & Ceramics not at TRL 6 \\
\hline & 1st-stage blade, 2 nd-stage blade, 3rd-stage blade & DS Nickel & May also use advanced IGT alloy \\
\hline & 4th-stage vane through 7 th-stage blades & EQ Nickel & \\
\hline Block 1.5 & 2nd-stage vane, 3 rd-stage vane & Si3N4 & Uncooled 2nd-stage vane and 3rd-stage vane \\
\hline \multirow[t]{3}{*}{ Block 2} & 2nd-stage vane, 3 rd-stage vane & Si3N4 & Uncooled \\
\hline & $\begin{array}{l}\text { 1st-stage vane, } 1 \text { st-stage blade, } 2 \text { nd-stage blade, } \\
\text { 3rd-stage blade }\end{array}$ & DS Nickel & $\begin{array}{l}\text { May also use advanced IGT alloy, or cooled Si3N4 } \\
\text { 1st- stage vane }\end{array}$ \\
\hline & 4th-stage vane through 7 th-stage blade & EQ Nickel & \\
\hline
\end{tabular}

The HPT disk material will likely be IN 718, although low-cost material such as M152 steel will also be evaluated. LPT disk material will most likely be steel, with Nickel-based alloy as the back up. 


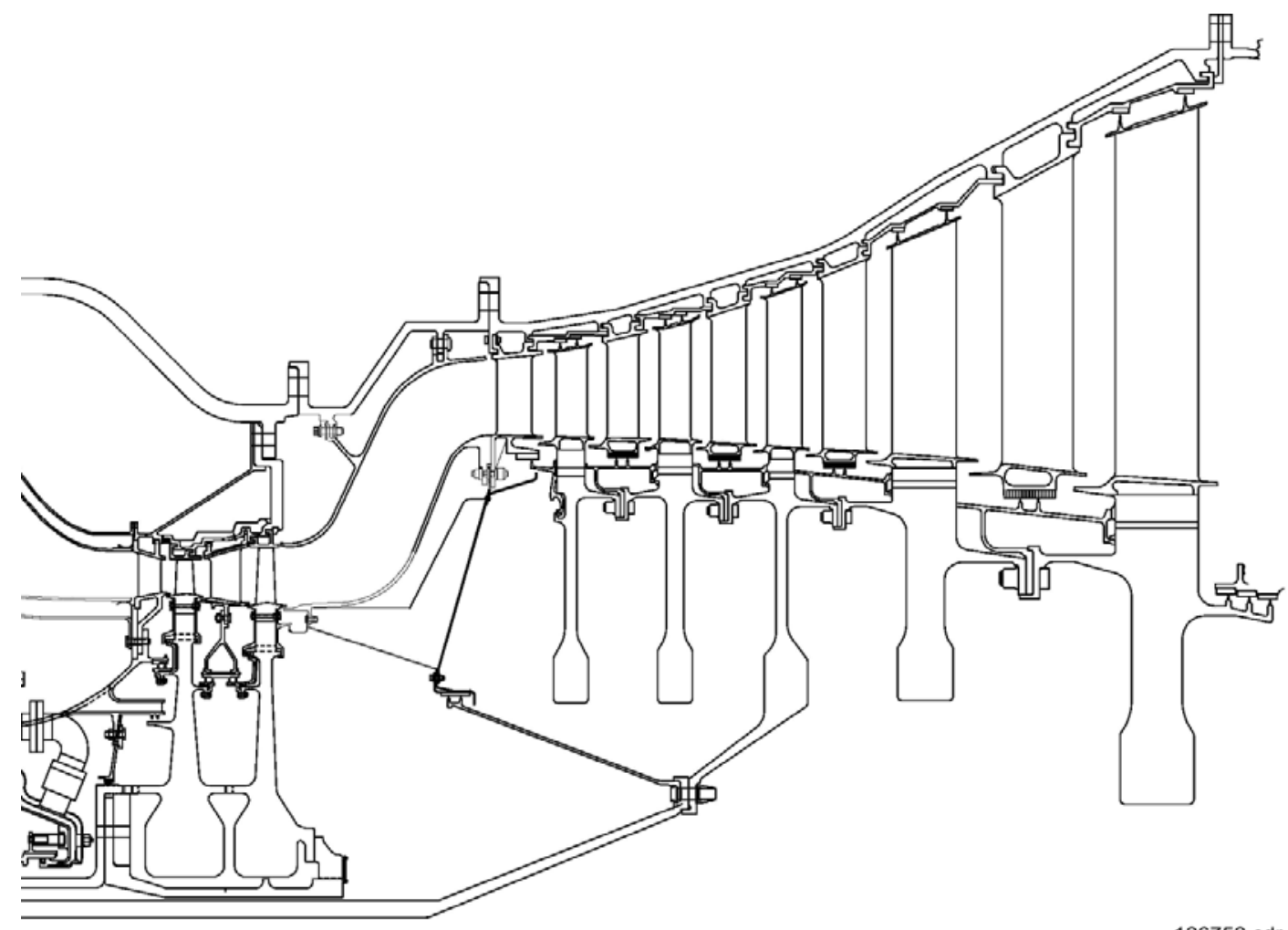

Figure 2-18. FT60IC Turbine Cross-Section

126752.cdr

Table 2-1. NGT Program Turbine Technologies ${ }^{1}$

\begin{tabular}{|c|c|c|c|c|c|}
\hline Technologies & $\begin{array}{c}\text { TRL } 6 \\
\text { Date }\end{array}$ & $\begin{array}{l}\text { Funding } \\
\text { Program }\end{array}$ & $\begin{array}{l}\text { Funding } \\
\text { Source }\end{array}$ & $\begin{array}{l}\text { DOE Funding } \\
\text { Required? }\end{array}$ & $\begin{array}{c}\text { Outside } \\
\text { Resource }\end{array}$ \\
\hline Ceramic Vanes With EBC & 2005 & NGT & DOE & $\mathrm{Y}^{2}$ & \\
\hline Microwave Sensor Active Clearance Control & 2004 & Internal & Internal & Y & Universities \\
\hline $\begin{array}{l}\text { Film Optimization With CFD and Leading Edge Fillet/Endwall } \\
\text { Contouring }\end{array}$ & 2005 & $\begin{array}{l}\text { IHPTET } \\
\text { (PRDA VI) }\end{array}$ & $\begin{array}{l}\text { U.S. Air Force, } \\
\text { Internal }\end{array}$ & $\mathrm{Y}$ & Universities \\
\hline Trailing Edge Optimization & 2003 & Internal & Internal & $\mathrm{Y}$ & \\
\hline Tip Desensitization - Tip Blowing and Bowing & 2005 & $\begin{array}{l}\text { IHPTET } \\
\text { (PRDA IV) }\end{array}$ & $\begin{array}{l}\text { U.S. Air Force, } \\
\text { Internal }\end{array}$ & $\mathrm{Y}$ & Universities \\
\hline Advanced IGT Alloy & 2006 & & & $?$ & \\
\hline CMC Blade Outer Airseals & & & & $?$ & \\
\hline Aggressive T-Duct & 2005 & UEET & NASA & $\mathrm{N}$ & \\
\hline Hi-Life Airfoils & 2005 & UEET & NASA & $\mathrm{N}$ & Universities \\
\hline Multidiscipline Optimization & 2002 & Internal & Internal & $\mathrm{N}$ & \\
\hline Low-Conductivity Thermal Barrier Coating & 2005 & Internal & Internal & $\mathrm{N}$ & \\
\hline
\end{tabular}

${ }^{1}$ DOE funding is required for all technologies, except for advanced IGT alloy and CMC BOAS whose requirements are currently unknown.

${ }^{2}$ Funded through 2001. 


\subsubsection{Ceramic Turbine Vanes and Ceramic Matrix Composite Liners}

Under Phase I of the NGT Program, UTRC supported $\mathrm{P} \& \mathrm{~W}$ by studying incorporation of ceramic turbine vanes and CMC combustor liners/transition ducts in the FT60 IC engine. A cross-section of the FT60 IC combustor and turbine sections is presented in Figure 2-19. The results of this initial study show that ceramic turbine vanes and $\mathrm{CMC}$ combustor liners/transition ducts will help the FT60 IC meet the 25,000-hr/4,000-cycle life requirement. The performance and cost benefits of using ceramics and CMCs over metallic systems are discussed below.

\subsubsection{Ceramic Turbine Vanes}

During Phase I, ceramic turbine vanes were identified as an advanced material technologies that is key to the high efficiency and high performance of the FT60 IC. The Phase I

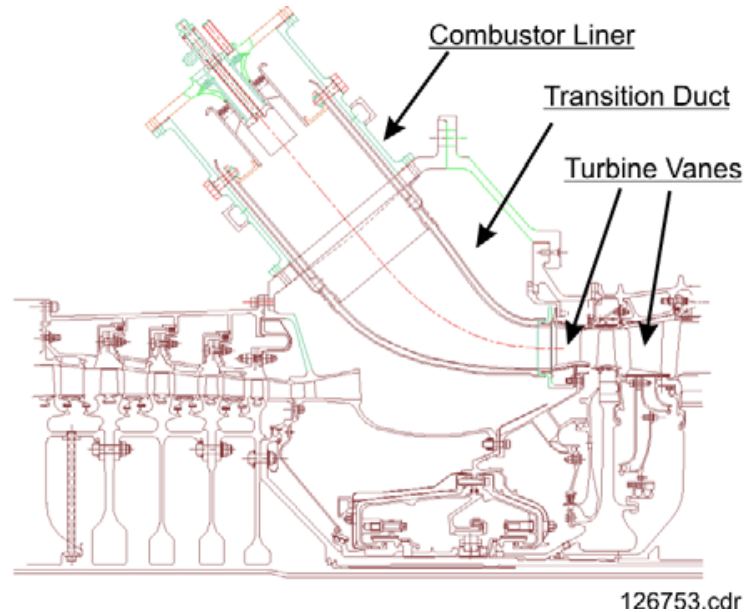

Figure 2-19. FT60 IC Combustor and Portion of the Turbine objective was to assess the feasibility, benefits, and risks of using ceramic 1st-, 2nd-, and 3rd-stage turbine vanes. A material database was first established to summarize the thermal and mechanical performance of silicon nitride. Secondly, a durability study was carried out to assess the cooling flow required by ceramic turbine vanes, as well as their metallic counterparts, based on the material properties and the temperature envelope defined by the conceptual design of the turbine section. Following the durability study, a business case study identified the benefits associated with the cooling flow saved as a result of using ceramic turbine vanes.

\section{Material Database}

Thermal and mechanical properties of the potential turbine vane materials are required in order to perform a durability study. Therefore, the first part of the work was to collect thermal and mechanical data of commercially available silicon nitride that was developed for high temperature structural applications. The candidate silicon nitride materials were AS800 from Honeywell Ceramic Components and SN281 and SN282 from Kyocera Industrial Ceramics Corporation. Thermal and mechanical properties were gathered by collecting data from vendors, from literatures, and from research institutes (such as Oak Ridge National Laboratory, University of Dayton Research Institute, and NASA Glenn Research Center) that have been studying these materials. With the existing mechanical properties and the temperature envelope defined by the conceptual design of the turbine section, a preliminary analysis was carried out to identify the stress envelope in which the material would meet the 25,000-hr life goal. It was concluded that with a design specified for the ceramic material, it is possible to manage the thermal stress in the turbine vane within the stress envelope (less than $30 \mathrm{ksi}$ ). Mechanical properties that are critical to ceramic turbine vane design and life prediction were also identified. It was recognized that additional slow crack growth and long-term creep rupture data was required. Such findings have been communicated to the teams at ORNL, UDRI, and NASA that are currently conducting mechanical testing on structural ceramics.

\section{Durability Study}

According to the temperature envelope defined by the conceptual design of the turbine section and the material properties, it became clear that the 2nd- and 3rd-stage ceramic turbine vanes in FT60 IC would not require cooling. About 8 percent of the total turbine cooling flow could be saved by replacing the 2nd- and 3rd-stage metallic turbine vanes with ceramic turbine vanes. The 1st-stage ceramic turbine vane still requires cooling due to the highoperation temperature. A durability study was carried out to assess the cooling flow requirement for the 1st-stage ceramic turbine vane versus its metallic counterpart. The analysis of the cooled 1st-stage ceramic turbine vane was largely based on the knowledge and experience gained under previous programs that developed the cooled silicon nitride FT8 turbine vane, while the analysis on the cooled 1st-stage metallic vane was based on existing P\&W turbine airfoil designs. It was found that a cooled 1st-stage ceramic turbine vane would require only convective cooling, while a state-of-the-art metallic turbine vane requires film cooling. The cooling flow required by a cooled 1st- 
stage ceramic turbine vane was only one-fourth to one-third of what was needed by a metallic turbine vane, as shown in Figure 2-20. Using cooled 1st-stage ceramic turbine vanes could save about 33 percent total turbine cooling flow. Overall, a turbine section with ceramic 1st-, 2nd- and 3rd-stage vanes will use only the equivalent of 60 percent of the cooling airflow a turbine with state-of-the-art metallic vanes will use. A preliminary business case study has indicated that such savings in turbine cooling flow could result in more than a 0.4 percent improvement in overall thermal efficiency and increase the power output by the equivalent of 7 percent.

\subsubsection{CMC Combustor Liner and Transition Duct}

CMC combustor liners and transition ducts have been

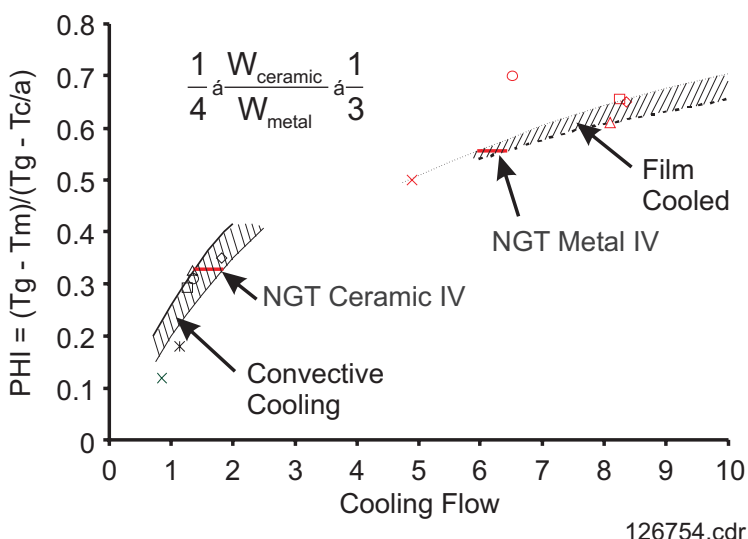

Figure 2-20. Cooling Flow evaluated for the FT60 IC combustor, as shown in Figure 2-19. The CMC system being evaluated is melt-infiltrated silicon carbide fiber-reinforced silicon carbide (MI SiC/SiC) because it is the most mature CMC system and has the temperature capability and conductivity required in combustor environments. $\mathrm{MI} \mathrm{SiC} / \mathrm{SiC}$ has demonstrated long-term stability at temperatures up to $1204^{\circ} \mathrm{C}\left(2200^{\circ} \mathrm{F}\right)$, and efforts are underway to extend the use temperature of $\mathrm{MI} \mathrm{SiC} / \mathrm{SiC}$ to $1316^{\circ} \mathrm{C}\left(2400^{\circ} \mathrm{F}\right)$. In order to inhibit recession of the $\mathrm{SiC}$ in the high-temperature, high-moisture combustor environment, an environmental barrier coating (EBC) is applied to the hot surface of the SiC CMC combustor components. The current MI $\mathrm{SiC} / \mathrm{SiC} \mathrm{EBC}$ system has a use temperature of $1316^{\circ} \mathrm{C}\left(2400^{\circ} \mathrm{F}\right)$, and work is being conducted to extend the use temperature to $1482^{\circ} \mathrm{C}\left(2700^{\circ} \mathrm{F}\right)$.

\section{Thermal Analysis}

Heat transfer, surface temperature, and pressure drop calculations for the preliminary design of the FT60 IC combustor liner were performed using the P\&W P783 General Internal Flow Solver Program. The purpose of this preliminary design study was to examine the tradeoff between the temperature capability of a number of potential liner materials and the associated coolant-channel pressure drop required to maintain acceptable material temperatures. In other words, liners with higher temperature capability will require less cooling which, in turn, implies lower velocities and reduced pressure drop in the cooling channel. The key result is that the CMC liners had a 5 percent higher static pressure than the metal liners, which translates into a 1 percent pressure drop savings for the CMC liner based upon $\mathrm{P} \& \mathrm{~W}$ design analysis. This 1 percent pressure drop savings translates into a $0.5 \mathrm{MW}$ increase in power according to the P\&W Engine Performance Group.

The maximum interface temperature for the $\mathrm{MI} \mathrm{SiC/SiC} \mathrm{liner} \mathrm{was} \mathrm{approximately} 982^{\circ} \mathrm{C}\left(1800^{\circ} \mathrm{F}\right)$. There is a large margin of operating temperature safety for $\mathrm{MI} \mathrm{SiC} / \mathrm{SiC}$ at $982^{\circ} \mathrm{C}\left(1800^{\circ} \mathrm{F}\right)$, since this system has demonstrated long-term durability at $1204^{\circ} \mathrm{C}\left(2200^{\circ} \mathrm{F}\right)$. The interface temperatures for the metal liners are $815^{\circ} \mathrm{C}$ $\left(1500^{\circ} \mathrm{F}\right)$ to $871^{\circ} \mathrm{C}\left(1600^{\circ} \mathrm{F}\right)$. These are close to the temperature limit for the various metals, once a $38^{\circ} \mathrm{C}\left(100^{\circ} \mathrm{F}\right)$ safety margin is included for hot spots.

\section{Durability Analysis}

A preliminary durability analysis has been performed on candidate designs and materials for the combustor liner and transition duct. Several materials were considered, including MI SiC/SiC, Nickel B-1900 (PWA1455), and Nickel SC2000 (PWA1487). To improve life, the CMC and metal components featured EBC and TBC coatings, respectively. The candidate design and materials were analyzed to determine:

- An operational stress-temperature envelop

- A relative comparison of inner/outer wall strains

- $\quad$ EBC durability. 
The operational stress-temperature analysis produced a $B$-basis life curve that predicted that $\mathrm{MI} \mathrm{SiC/SiC} \mathrm{can}$ operate continuously for 25,000 hours under combined temperatures and stress conditions of up to $1148^{\circ} \mathrm{C}$ $\left(2100^{\circ} \mathrm{F}\right)$ and $15 \mathrm{ksi}$. Calculation of the hoop stresses resulting from through-thickness thermal gradients indicates that the CMC liner/EBC system will have approximately one-third the stress of metal liner/TBC systems. Analysis of the operating stress for the CMC liner/EBC system and the various metal liner/TBC systems indicates that all systems will achieve the 25,000-hr goal; however, the CMC liner/EBC has a larger margin of safety.

The relative strain due to thermal expansion differences between the combustor liner and the shell was approximately half the value for a CMC liner, compared to a metal liner. The actual stress in the liner will be a function of the attachment scheme; however, the lower relative strain has the potential for resulting in lower liner stress and simplified attachment design.

The EBC coating should meet the 25,000-hr life goal for the FT60 IC, and EBC development work at UTRC is expected to further reduce the recession rate. The recession rate of 0.012 microns per hour was measured on an EBC-coated MI SiC/SiC liner in a Solar Turbines Centaur 50S engine run at the Texaco site in Bakersfield, California, from 1999 to 2000. Therefore, 300 microns of EBC would be recessed in 25,000-hr, which is less then the thickness of the coating.

\section{Business Case Study}

As discussed above, ceramic turbine vanes and CMC combustor liners/transition ducts required less cooling and increase engine efficiency. This increased efficiency means that the same basic engine will produce more power and be able to be sold at a higher price. However, the ceramic components are projected to cost more then metallic components. Figure 2-1 shows the business case study results.

The increased revenues shown in Figure 2-1 are slightly offset by the increased fabrication cost on manufacturing ceramic and CMC components. Even with this increased fabrication expense, a significant revenue increase is projected for the FT60 IC with all ceramic turbine vanes and CMC combustors/transition ducts.

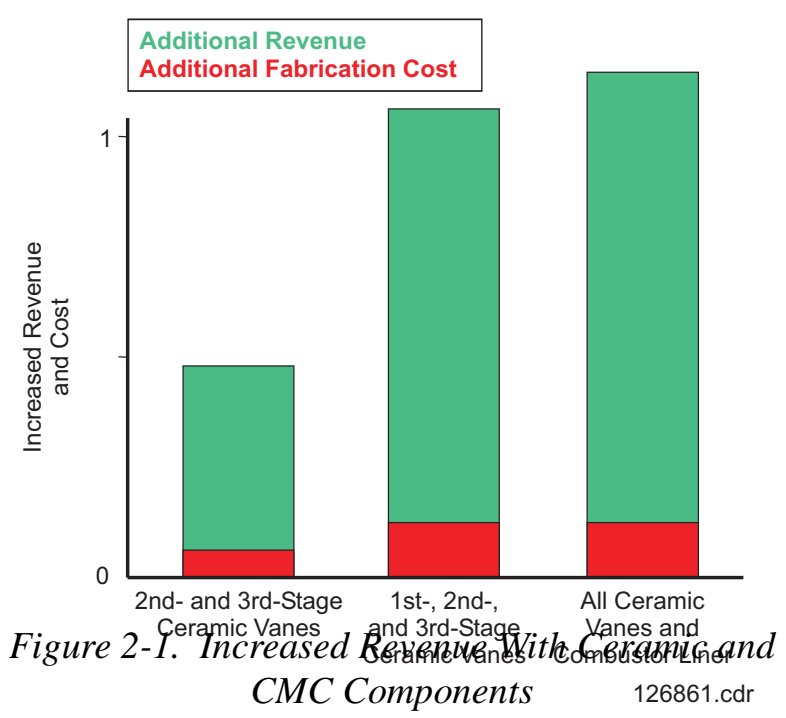

\subsubsection{Mechanical Systems}

Initially, when the gas turbine was to be derived from an aircraft engine, the bearings were to be a rolling element. The high axial thrust load, caused by the high pressure level of the intercooled cycle, would have required the development of advanced tapered roller bearings for the low-pressure rotor. When the size of the gas turbine was increased, so that the airflow was in the same class as older (E-class) direct-drive frame-type gas turbines, the bearing choice became conventional hydrodynamic bearings, with journal bearings for the radial load, and tilting pad bearings for the axial load. This decision is favorable for long life (RAM) and reduces risk in the NGT Program.

\subsubsection{Balance of Plant Summary}

PWPS is studying the development of an intercooled gas turbine derived from P\&W's FTX engine program. This PWPS development program has identified the land-based intercooled gas turbine generator set as the FT60 IC. Several intercooler configurations and corresponding piping alternatives were investigated in support of this development program. These studies determined FT60 IC performance and simple-cycle equipment installed costs for various intercooler configurations. 


\subsubsection{Lubrication}

The FT60 lube oil system contains the engine lube oil system together with necessary filters, cooler, and reservoir.

Components not integral to the gas turbine are mounted as a pre-engineered package on the ancillary skid. This package, located adjacent to the gas turbine enclosure, contains the combined reservoir, duplex filters, air-tooil cooler, and the turbine supply and scavenge pumps.

The turbine lube oil system lubricates and cools the main bearings and bearing seal assemblies. Lubrication is provided by identical three-element pumps, which provide primary and auxiliary flow functions. The primary and auxiliary pumps are alternating current motor driven at 3,600 rpm, while the emergency pump is a direct current motor driven at $1,800 \mathrm{rpm}$. The auxiliary pump automatically starts in case of trouble with the primary pump. The direct current pump is used for emergency shutdown when alternating current power is lost.

\subsubsection{Gas Fuel System}

The customer-furnished fuel gas supply is provided at a minimum pressure. After flowing through a fire valve, the gas flows through two shutoff valves and the modulating valve to the gas manifold, where it is injected through the gas fuel nozzles. The modulating valve meters fuel in response to signals from the electronic gas turbine control.

\subsubsection{Liquid Fuel System}

In the liquid system, fuel in a flooded suction line from the fuel storage tanks is pumped by the customer-supplied fuel forwarding system to the filtering skid. After flowing through a fire stop valve, the fuel is boosted by fuel pump, and sent to the modulating valve. The modulating valve meters fuel in response to a signal from the electronic gas turbine control. The fuel then flows through two fuel shutoff valves and a flow divider, into the manifold and through the liquid fuel nozzles.

\subsubsection{Dual Fuel System}

The dual fuel system uses the same components as the gas and liquid fuel systems, plus additional valves to allow switching from one fuel to the other.

At startup with liquid fuel selected, the fuel pump is started and liquid fuel flows through the liquid modulating valve and liquid shutoff valve into the liquid fuel manifold to the nozzles. At shutdown, the pump is disengaged, the liquid modulating valve and liquid shutoff valves are closed, the liquid drain valves are opened to prevent pressure buildup downstream of the shutoff, and the manifold drain valve is opened to drain the manifold.

When gas fuel operation is selected, gas flows from the supply through two shutoff valves, through the modulating valve to the gas manifold. A small amount is sent through the liquid system purge valve to the liquid fuel manifold for continuous purging of all liquid fuel from the manifold and nozzles to prevent coking of the nozzles. At shutdown, the shutoff valves are closed the vent line between shutoff valves is opened to relieve pressure.

The gas turbine has the capability to burn liquid and gaseous fuels simultaneously or to transfer from one fuel to the other during operation.

\subsubsection{Water Injection System}

The water injection system (used for liquid fuel) introduces demineralized water with the fuel into the nozzles of the gas turbine to assist in achieving required exhaust gas emission levels. The system operation is automatically controlled by electronic gas turbine control.

The demineralized water is delivered by the customer to the water injection skid located just outside the gas turbine enclosure. The skid contains the alternating current motor driven pumps to boost the water to the required pressure and necessary valving.

When operating on liquid fuel, the water is mixed with the fuel and sent through the liquid fuel nozzles. When running on gas fuel, the water is sent through the liquid fuel nozzles and the gas through the gas fuel nozzles. When 
running on both fuels, the water is mixed with the liquid fuel and injected through the nozzles via the liquid fuel manifold, while the gas flows through the as fuel nozzles.

\subsubsection{Starting System}

The starting system consists of an electric starter mounted on the gas turbine.

When the operator initiates a start, the power is supplied to the starter motor geared to the high-compressor rotor shaft of the gas generator. The starter converts the fluid pressure to shaft torque and rotates the high-speed rotor to ignition speed.

After fuel is admitted to the gas turbine combustion section and ignition is achieved, the gas turbine accelerates to its self-sustaining speed and the starter is disengaged from the shaft. If any problems are detected during the start cycle, the control shuts off fuel flow and hydraulic fluid flow, causing the starter to disengage and the gas turbine to coast down.

The starting system is also used to rotate the gas turbine rotors for water wash/gaspath purge. When water wash is selected, the start system is used to motor the gas generator while water, with or without detergent, is sprayed into the bellmouth. During a purge operation, fumes and other flammable gases accumulated in the gas turbine are purged by motoring the gas generator with the starting system to above $1,500 \mathrm{rpm}$, with the ignition and fuel systems off.

\subsubsection{Fire Protection System}

The fire protection system provides independent fire detection and $\mathrm{CO}_{2}$ total flooding fire suppression systems for the gas turbine enclosure and is available as an option for the generator and control enclosures.

Automatic fire detection is provided by rate compensated thermal detectors. Facilities for manual (electric and mechanical) initiation of the fire systems are also provided. The $\mathrm{CO}_{2}$ tanks, solenoids, and manifold are located outside the enclosures, with the system's control module located in the control room.

The control system monitors and displays the status of all fire system inputs and provides outputs to activate audible and visual alarms, discharge $\mathrm{CO}_{2}$, close fuel fire safety valves, and signal turbine and unit control systems for required responses. The system operates on $24 \mathrm{~V}$ of direct current and contains its own internal power supply and battery backup.

Immediately upon actuation of the system, the turbine enclosure secondary air supply fans are de-energized and the fuel supply is shut off. A 20-sec time delay permits rundown of the gas turbine and generator before a solenoid valve releases the pressurized $\mathrm{CO}_{2}$ into its distribution manifold. A pneumatic cylinder, actuated by the pressurized $\mathrm{CO}_{2}$, releases a pair of guillotine-type dampers (just forward of the fan blades), closing off the secondary air path. Simultaneously, a series of nozzles floods the enclosures to a 34 percent $\mathrm{CO}_{2}$ concentration, sufficient for inerting the combustion process.

The $\mathrm{CO}_{2}$ supply to the manifold is fed from pressurized tanks. The first tank is quick emptying, while the second slow-emptying tank maintains the five percent level required to overcome dilution from air leakage. This $\mathrm{CO}_{2}$ concentration is maintained for approximately 30 minutes, sufficient time to allow combustibles to cool below their autoignition temperatures.

$\mathrm{A} \mathrm{CO}_{2}$ status display board is provided near each protected enclosure entry to visually indicate the status of the fire protection system $\left(\mathrm{CO}_{2}\right.$ armed or disarmed).

Disarming may be accomplished by disabling the $\mathrm{CO}_{2}$ discharge system either electrically by means of a keyswitch and/or blocking the flow of $\mathrm{CO}_{2}$ by a manually-activated safety block valve in the $\mathrm{CO}_{2}$ piping discharge system. When disarmed, the detection alarm system will remain active while the $\mathrm{CO}_{2}$ discharge capability will be disabled. Continuous alarm signals are sent to the monitoring system, notifying the operator while the system is disarmed. Additional safety features include a suppressant release delay and audible and visual alarms inside and outside the enclosure. 


\subsubsection{Gas Detection}

Gas detection in the gas turbine enclosure is provided by a resistance-type combustible gas sensor. When the gas concentration reaches 20 percent lower flammable level (LFL), the gas hazard alarm will be displayed in the fire control panel and warning alarms will be activated at the enclosure. When a 60 percent LFL is reached, an automatic trip of the fuel and gas turbine will be initiated. The enclosure's ventilation system will remain inoperation to reduce the gas hazard.

\subsubsection{Gas Turbine Dehumidifier System}

The gas turbine dehumidifier maintains the internal parts of the gas turbine at a temperature above the dew point of the ambient air during nonoperation periods. Dry air forced into the compressor section and out through the exhaust ducts prevents condensation, which can cause corrosion.

The operation of the humidifier system is fully automatic for unattended operation.

\subsubsection{Water Wash System}

The gas turbine requires periodic washing of its aerodynamic components that have accumulated deposits that could affect performance.

A water wash circuit, when activated by the operator, energizes a solenoid valve in the water wash line. The water flows through a nozzle located inside the inlet air plenum, directed toward the gas turbine's inlet. While the gas turbine is rotated on the starter, the sprayed water is pulled through the compressor section of the gas turbine and is drained through drain valves. After washing, the gas turbine is started to dry out any remaining water.

\subsubsection{Electric Generator}

The electric generator is an open ventilated, two-pole, air-cooled unit rated to BS/IEC standards with Class F insulation, but limited to Class B temperature rises on a total temperature basis. It includes shaft-mounted overhung main and pilot-brushless exciters complete with rotating-fused diodes, and all required support auxiliaries, instrumentation, protective devices, and controls.

The rotor is an integral forging of nickel chromium molybdenum alloy steel. Axial slots are milled on the periphery of the body of the rotor to carry the winding and for ventilation. The rotor winding conductor material is conventional silver bearing copper. The conductor is in the form of a strip and each rotor coil is preformed to the shape required. All insulation materials are suitable for Class F operation.

The preformed coils are inserted into the slots, each turn being insulated from the next. After the completion of the winding, the conductors are heated electrically and pressed to the correct depth using pressing rings. A fully interconnected damper winding is then fitted into the tops of the slots and the retaining wedges are inserted. The rotor endwinding is braced with packing blocks between the conductors, after which the nonmagnetic manganese chromium steel endcaps are shrink fitted to spigots at each end of the rotor body. All rotors are tested at 20 percent overspeed and balanced.

The main bearings are conventional circular profile, white metal lined, hydrodynamic cylindrical bearings. Pressurized oil seals are fitted at each end of the bearings. Temperature detectors are provided for the bearing metal and oil drains. Noncontact vibration sensors are provided for both bearings.

The generator features integral axial flow fans which supply a large volume of filtered cool air flowing through the frame and over the stator and rotor coil ends and winds through interslot ventilation ducts and discharging at the top of the frame. The exciter is self-ventilated.

A separate air-cooled lubrication system is provided, including a storage tank with radiator and cooling fan, two alternating current motor driven lube oil pumps, and a direct current motor driven emergency backup pump for emergency coastdown or black start.

The generators are fitted with a brushless excitation system, where the excitation power is derived from a small alternating current generator driven by the generator shaft. The alternating current power produced by this exciter 
is rectified to direct current by a shaft-mounted rotating rectifier assembly that is connected to the main field through conductors inside the shaft; thus, the need for sliprings is eliminated.

\subsubsection{Electrical/Control System}

The electrical/control system contains all of the equipment necessary for local control of the FT8 60 IC together with the switchgear and generator protectives.

The equipment contains the gas turbine and generator controls, motor control center, low voltage alternating and direct current distribution, station batteries, metal-clad switchgear, station auxiliary transformer, protectives relaying, and master terminal board. These controls and instruments are mounted on the following cabinets:

- Protective Relay Cabinet

- Instrument Cabinet

- Operator Cabinet

- Motor Control Center

- Monitoring Cabinet

- Master Terminal Board Cabinets.

\subsubsection{Control System}

The control system contains an integrated gas turbine and unit control. This integrated controller acts as a central processing point for all input/output serial and ethernet communications associated with the FT60 IC. Data from this control is sent to a user-friendly ICE operator interface to display pertinent information.

The Woodward controller performs both fuel control and sequencing functions. This system incorporates a digital programmable microprocessor that optimizes turbine safety and efficiency. The programmable features of this control enhance the ability of the end user to incorporate the latest features in gas turbine technology.

This integrated control performs all of the gas turbine control functions including:

- Speed Control

- Temperature protection and control

- Acceleration and deceleration limiting

- Fuel valve control

- Inlet guide vane control

- Variable stator vane control

- Water injection

- Gas turbine performance monitoring

- $\quad$ Start sequencing

- Unit synchronization

- Alarm and shutdown protection

- Monitoring System.

The ICE monitoring system package operates on a Pentium-based industrial computer and serves as the operator interface. This system interfaces to the gas turbine and unit control through an Ethernet local area network. The monitoring system performs such functions as:

- Data logging and trending

- Alarm monitoring

- Alarm and event logging

- Sequence-of-events recording 
- First-out alarm indication

- X-Y plotting

- Calculation functions

- Event storage, archiving, and redisplay

- Operator control functions

- Process animation

- Control system diagnostics.

\subsubsection{Gas Turbine Enclosure}

The gas turbine enclosure protects the gas turbine and other ancillaries located within it from the environment and provides noise attenuation. It provides a protected working environment and inside lighting for maintenance with the unit in a nonoperating condition. It protects outside workers from the high component temperatures in an operating system.

The gas turbine enclosure includes the inlet plenum and the exhaust enclosure. The inlet plenum channels the air from the inlet air silencer to the gas turbine bellmouth to minimize the inlet air pressure loss. The exhaust enclosure houses the exhaust diffuser/collector that delivers the power turbine exhaust gases to the exhaust transition duct and silencer. The enclosure serves as a mounting structure for the inlet and exhaust air systems, and as a duct for passing secondary air over the gas turbine for cooling. The enclosure also provides a limited containment volume for the fire protection system.

\subsubsection{Gas Turbine Enclosure Secondary Air System}

The gas turbine enclosure secondary air system provides cooling air flow throughout the length of the enclosure. Air is drawn into the intake assembly, through the silencer chamber, and blown into the gas turbine enclosure. It passes along the length of the gas generator and power turbine, around the exhaust collector and up into the exhaust air silencer, where it joins with the gas turbine exhaust.

A pair of alternating current motor driven fans are mounted low on the front bulkhead of the enclosure to take in atmospheric air through a louvered opening mesh screen and a silencer module.

If a gas turbine enclosure fire is detected, the fans are deenergized and a pair of guillotine-type gates are released to block the inlet air supply ports.

\subsubsection{Inlet Air Filtration}

The primarily inlet filtration system has a filtration efficiency of 99.7 percent for particles down to 5 microns, and 95 percent for particles down to 2 microns. Clean elements flow about $86 \mathrm{~kg}(190 \mathrm{lb})$ of air per second with a maximum pressure drop of approximately $1 \mathrm{in.}(2.54 \mathrm{~cm})$ of water.

The filter house is constructed of mild steel and rests atop (with its flange bolted to) the inlet air silencer module. Air enters both endwalls of the filter house. Each endwall is configured to have filter elements and 6,000 half sized elements in individual galvanized frames.

The high-efficiency, replaceable fiberglass filters are preceded by a prefilter. The two filters are kept together by a pair of extended spring clips.

Filter elements can be replaced from inside the filter house. The doors can be accessed from a full-length external catwalk with safety railing and fixed-end ladder.

\subsubsection{Inlet Air Silencer}

The inlet air silencer module attenuates noise over a broad band of frequencies.

Module walls, configured for sound attenuation, consist of equally-spaced, transversely-mounted vertical acoustic baffles. The baffles, which have a 16-gage perforated galvanized steel shell and are filled with 3 in. of mineral wool, may be removed for servicing. 


\subsubsection{Intercooler Description}

Two types of heat exchange systems were investigated:

1. Water-cooled intercoolers with heat rejection to a cooling tower

2. Air-cooled intercoolers.

The cost of a heat exchanger is a function of the heat transfer surface area and the materials of construction. The amount and type of heat transfer of a surface used impacts:

- The pressure drop of the fluid streams passing through the exchanger

- The temperature differences between these streams.

For pressure drop optimization, engine air side intercooler pressures drops of 3 percent, 4.5 percent, and 6 percent were investigated. The pinch temperature difference between the cooling medium and the intercooler outlet (or the HPC inlet) was held constant for each of the intercooler pressure drop cases studied. As expected, the intercooler installed costs were the highest for the 3 percent pressure drop case, since this configuration contained the most surface area and required more steel and concrete to complete the installation than did the others. However, the corresponding engine output for this 3 percent case was significantly greater than that of the other two cases studied. This performance improvement more than offset the increases in associated installed costs resulting in the lowest dollars $/ \mathrm{kW}$ value of all the cases investigated.

At the completion of the pressure drop investigation, an HPC inlet temperature optimization study was undertaken. The pinch temperature difference between the cooling medium and the intercooler outlet was varied, and the resulting impact on engine performance was calculated. For this study, three HPC inlet temperatures of $31^{\circ} \mathrm{C}$ $\left(88^{\circ} \mathrm{F}\right), 46^{\circ} \mathrm{C}\left(115^{\circ} \mathrm{F}\right)$, and $60^{\circ} \mathrm{C}\left(140^{\circ} \mathrm{F}\right)$ were investigated, while holding the intercooler system pressure drop constant at 3 percent for each of these study cases. As expected, the intercooler installed costs were the highest for the $31^{\circ} \mathrm{C}\left(88^{\circ} \mathrm{F}\right) \mathrm{HPC}$ inlet case. The engine output attributable to the lowest HPC inlet temperature case was significantly better than that for the other cases. As before, the configuration which produced the most power also had the highest installed capital cost. Once again, the configuration which produced the most power also resulted in the lowest installed cost per $\mathrm{kW}$.

Figure 2-21 through Figure 2-24 show isometric and plan views of the plant layout with water-cooled and aircooled intercoolers. 


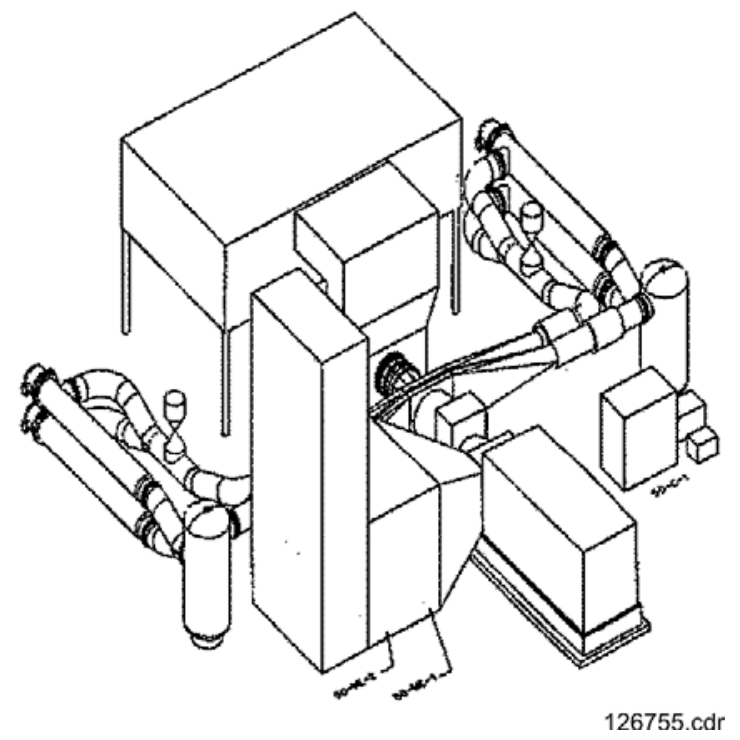

Figure 2-21. Isometric View of the FT60 IC With a Water-Cooled Intercooler

As

shown in these drawings, a simple header design was chosen to minimize the pressure drop through the supply and return portions of the piping system. Care should be taken during detailed design to provide an even distribution of the air flow through each of the cooler bodies or bays to the interconnecting header. Orifice plates may be have to be located in the flanges connecting the headers to each cooler inlet to ensure this. A second option, using a candelabra-header design with three levels of subheaders, was also investigated for the aircooled intercooler case.

This candelabra-header design option does ensure even engine-air flow distribution to each of the intercooler banks. However, this design option results in a higher-pressure drop, due to the need for more fittings and the additional linear feet of pipe required completing the assembly. Table 2-2 presents the data comparing the pressure drops calculated for these two header options:

Table 2-2. Data Comparing the Pressure Drops Data Calculated for These Two Header Options

\begin{tabular}{lcc}
\hline & Simple-Header Design & Candelabra-Header Design \\
\hline Pressure Drop Without Turning Vanes (pi) & 0.76 & 2.53 \\
Pressure Drop with Turning Vanes (pi) & 0.69 & 0.74 \\
\hline
\end{tabular}

Therefore, although the candelabra arrangement is technically feasible, it is not the best alternative when its pressure drop is weighed against the orifice plate option. 
The type of intercooler selected depends upon the availability of cooling water at the chosen site. If sufficient water is available, the water-cooled intercooler is the preferred choice. Whether a cooling tower is applied or not depends upon access to sea, river, or other open body of water.

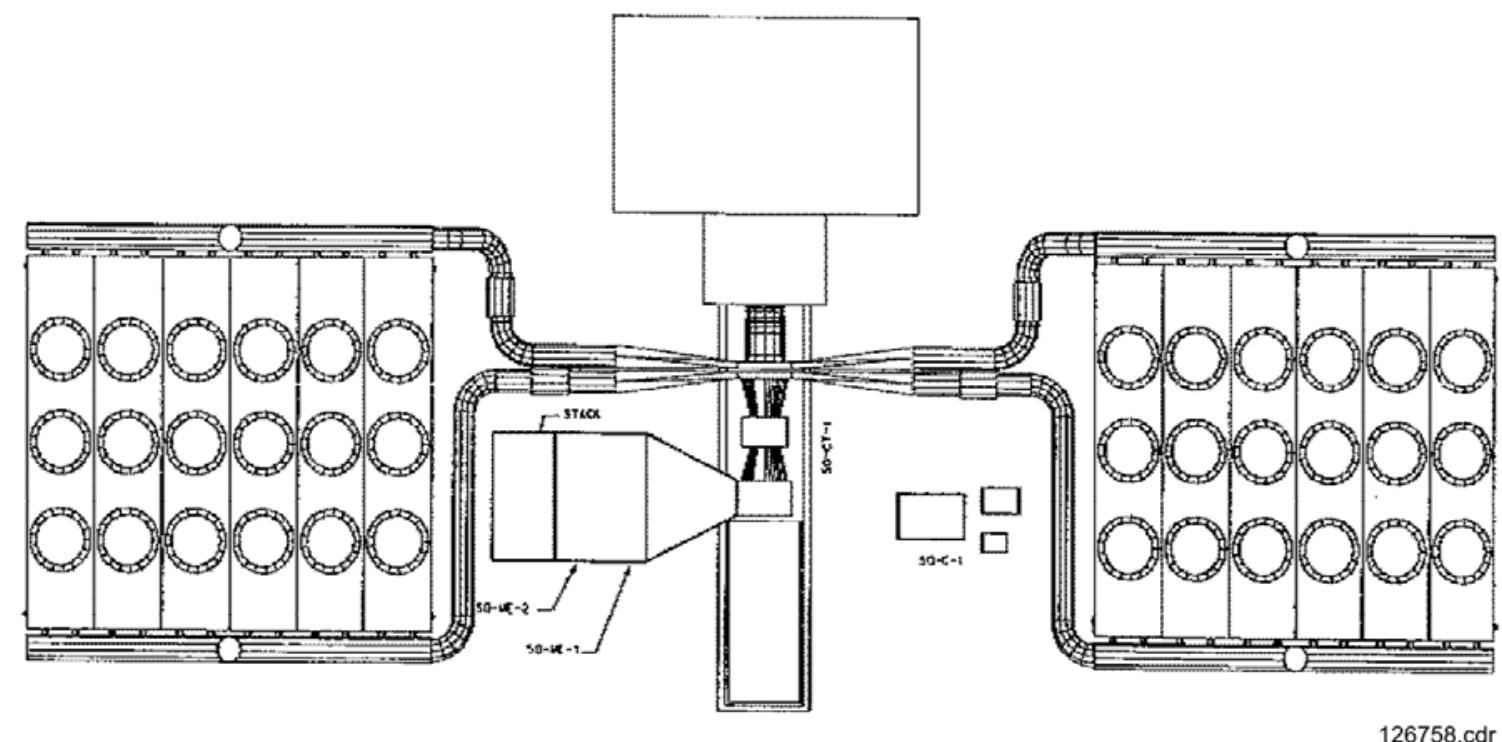

Figure 2-24. Plan View of the FT60 IC With an Air-Cooled Intercooler

\subsection{COMBINED CYCLE}

A combined cycle version of the FT60 IC was evaluated, using a biphase bottoming cycle. This cycle is well suited to recover energy from low-temperature exhausts. The biphase combined cycle is shown schematically in Figure 2-25. Exhaust heat from the gas turbine flows through a superheater section and two-phase economizer, transferring heat to a once-through working fluid. The two-phase mixture from the economizer flows into a biphase turbine where the two-phase mixture is expanded in the first stage of the biphase turbine to produce power. 


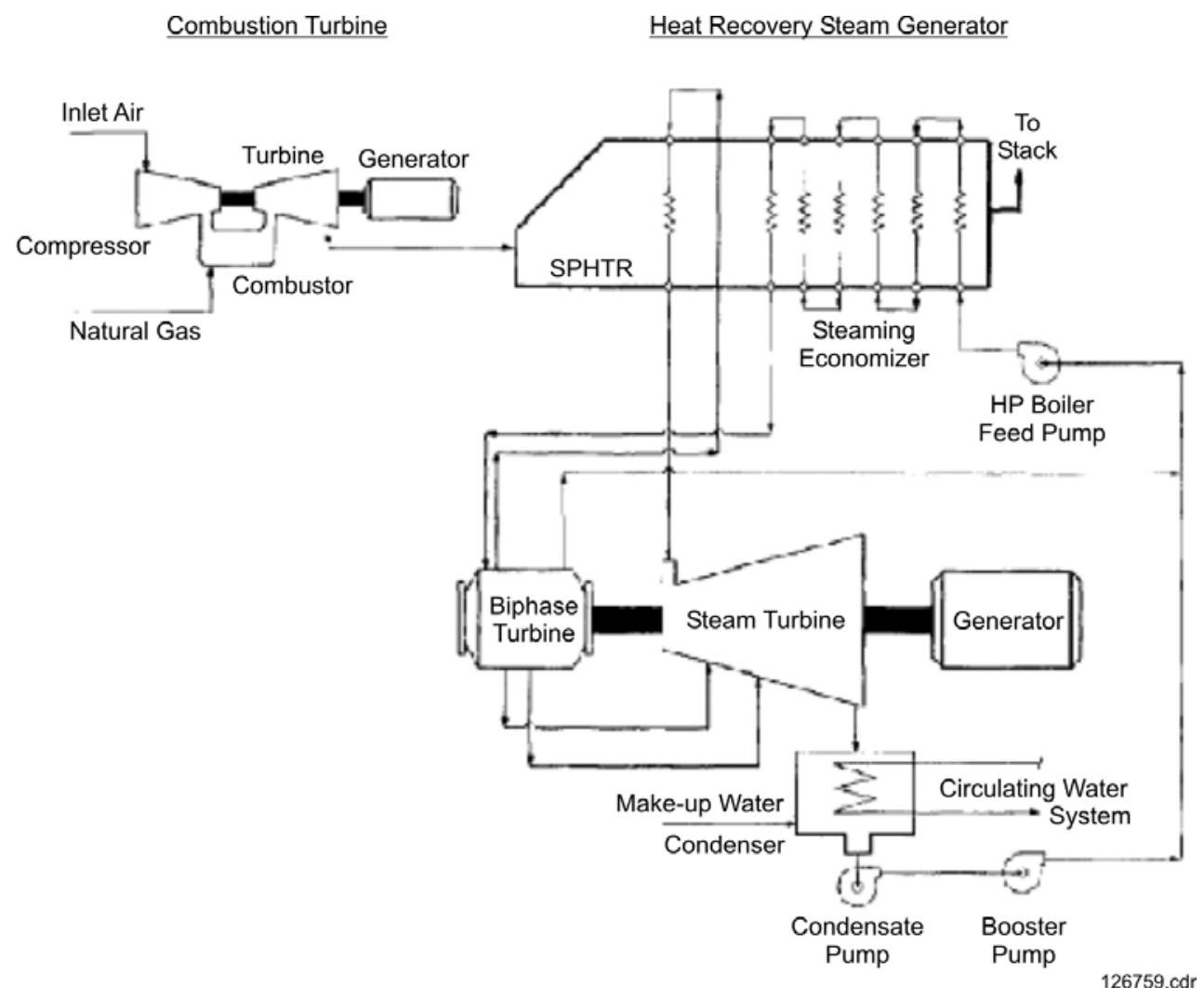

Figure 2-25. Biphase Combined-Cycle Boasts System Efficiency

Separated steam from the first stage flows through the superheater to the inlet of a steam turbine (in a biphase turbine, the superheated steam enters the structure through a port downstream of the initial biphase stage). Separated water from the first stage of the biphase turbine is flashed in a second biphase stage, producing additional power and intermediate pressure steam and water. The intermediate pressure steam flows to another inlet port of the steam turbine. The intermediate pressure hot water is then flashed in the third biphase stage, producing additional power and low-pressure steam and water. The low-pressure steam flows to the third inlet port of the steam turbine. The separated water has its pressure increased in an internal diffuser and flows back to the inlet of a feedwater pump. The mixed-steam flows are expanded in the steam turbine, producing power. Steam leaves the steam turbine at the lowest pressure of the cycle and forms condensation in the condenser. The condensation pump pressurizes the condensation and pumps it to the boiler feed pump. The combined hot water stream at high pressure flows into the biphase economizer to complete the cycle. 
The following two factors increase the efficiency of the two-phase bottoming cycle relative to a conventional steam bottoming cycle:

- The thermodynamic energy loss due to constant temperature steam vaporization is reduced. Figure 2-26 shows the heat transfer from the turbine exhaust into the biphase working fluid for the biphase bottoming cycle. The majority of the heat transfer is gas to liquid, with no pinch point. A small pinch point exists at the exit of the biphase economizer as the wet steam-water mixture is generated. However, this pinch point is much lower than that realized in a conventional steam bottoming cycle.

- Mixing hot water leaving the biphase turbine with

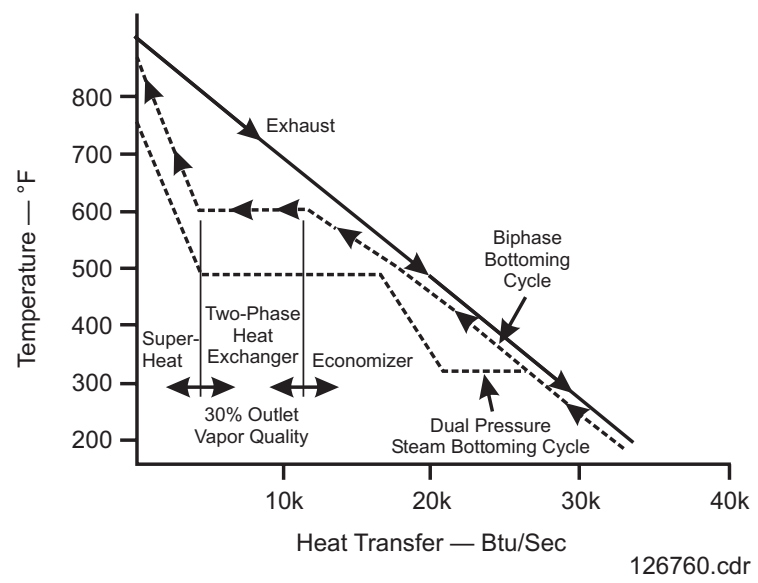

Figure 2-26. Heat Transfer for the Biphase Bottoming Cycle condensate produces regenerative heat of the feedwater that is not available in a conventional bottoming cycle.

In 1995, P\&W commissioned an engineering study of the biphase combined cycle that compared a conventional FT8 gas turbine to a proposed FT4000 gas turbine, which has similar characteristics to the FT8000 IC.6 The efficiency of the biphase bottoming cycle was improved by 30 percent over an optimized bistage steam turbine bottoming cycle. The major reason for this was that minimization of the pinch point loss enables more heat to be extracted from the gas turbine exhaust. The exhaust temperature reached in the biphase cycle was $82^{\circ} \mathrm{C}\left(180^{\circ} \mathrm{F}\right)$, versus a minimum of $168^{\circ} \mathrm{C}\left(335^{\circ} \mathrm{F}\right)$ found possible with a two-stage steam bottoming cycle. In the current contract, Douglas Energy and MPPT did a conceptual design of the biphase bottoming cycle.

The performance of a single FT60 IC Block 2 gas turbine and one biphase bottoming cycle was about 200 MW and 59 percent efficiency. This is considerably higher than any current combined cycle at this small an output. According to the Gas Turbine World 2000-2001 Handbook, the highest efficiency combined cycle in the 150 to 250 MW size class is 53.7 percent for $2 \times 1$ combined-cycle 6 FAs.

In the economic analysis, a single FT60 IC combined cycle was not as cost effective as the FT60 IC, without bottoming, at the baseline gas price of $\$ 3.90$ per $10^{6} \mathrm{Btu}$. If gas prices become extremely high, $(\$ 13.50$ was chosen as an example), combined cycles were the economic choice starting at 2,000 to 2,500 hr/year. Also, one $200 \mathrm{MW}$ FT60 IC combined cycle was slightly less cost effective than the 590 MW 7FX-2 combined cycle, due to economies of scale. 


\section{CONCLUSION}

\subsection{MARKET STUDIES}

A market study for the FT60 IC was performed by the ADL and by P2 Energy. The market study consisted of stakeholder interviews, economic analyses, and a market forecast. PWPS provided the attributes of the FT60 IC and conducted some of the interviews. The economic analyses were discussed earlier in the description of system attributes. The approach and other key results of the market study are summarized in this section. The high output of the FT60 IC precludes its application in any market except electric power generation; there is assumed to be no market demand for mechanical drive or marine propulsion applications.

ADL evaluated the market opportunity for the NGTs being developed at P\&W. This market evaluation consisted of:

- Stakeholder interviews

- Economic analysis

- Market forecast.

\begin{tabular}{|c|c|}
\hline ADL's Task & Our Approach/Actions \\
\hline $\begin{array}{l}\text { - See stakeholder input regarding: } \\
\text { - Their future power generation needs } \\
\text { - Importance of GT performance attributes. }\end{array}$ & $\begin{array}{l}\text { - Conducted a mini-workshop with P2 Energy to identify and select } \\
\text { key stakeholders for interviews. } \\
\text { - ADL designed the interview guides and reference material. } \\
\text { - Jointly with P2 Energy, conducted key stakeholder interviews with } \\
21 \text { large players in the power generation business. } \\
\text { - ADL compiled and analyzed the feedback and its implications for the } \\
\text { NGT development team. }\end{array}$ \\
\hline $\begin{array}{l}\text { Determine Market Potential for NGT's } \\
\text { - Economic analysis } \\
\text { - Estimate target market for NGTs } \\
\text { - Sensitivity analysis top assist the development team. }\end{array}$ & $\begin{array}{l}\text { - ADL analyzed the business conditions and trends in global and U.S. } \\
\text { power generation markets to identify the overall size of the market } \\
\text { and opportunities for using gas turbines under development. } \\
\text { - ADL created three scenarios to identify key drivers and establish a } \\
\text { framework for economic analysis and market forecasts. } \\
\text { - We used ADL's market forecast model to assess the U.S. market } \\
\text { opportunity for NGT's by accounting for planned additions, load } \\
\text { growth, and future plant requirements for the next } 20 \text { years. } \\
\text { - ADL estimated global market potential for NGT's. We used insights } \\
\text { from our U.S. analysis to forecast the market potential globally. }\end{array}$ \\
\hline
\end{tabular}

The NGT (FT60 IC) is an intercooled gas turbine rated at $170 \mathrm{MW}$. The design targets for this turbine are significantly better than any other turbine on the market today. The targeted efficiency, in simple cycle application, is greater than 50 percent, while the best comparable turbine on the market is at 38 percent. The commercial availability date of this NGT is projected to be 2007.

ADL performed their analysis within the framework of the scenarios show in Figure 3-1. The greatest drivers for the NGT market are load growth and gas prices. 


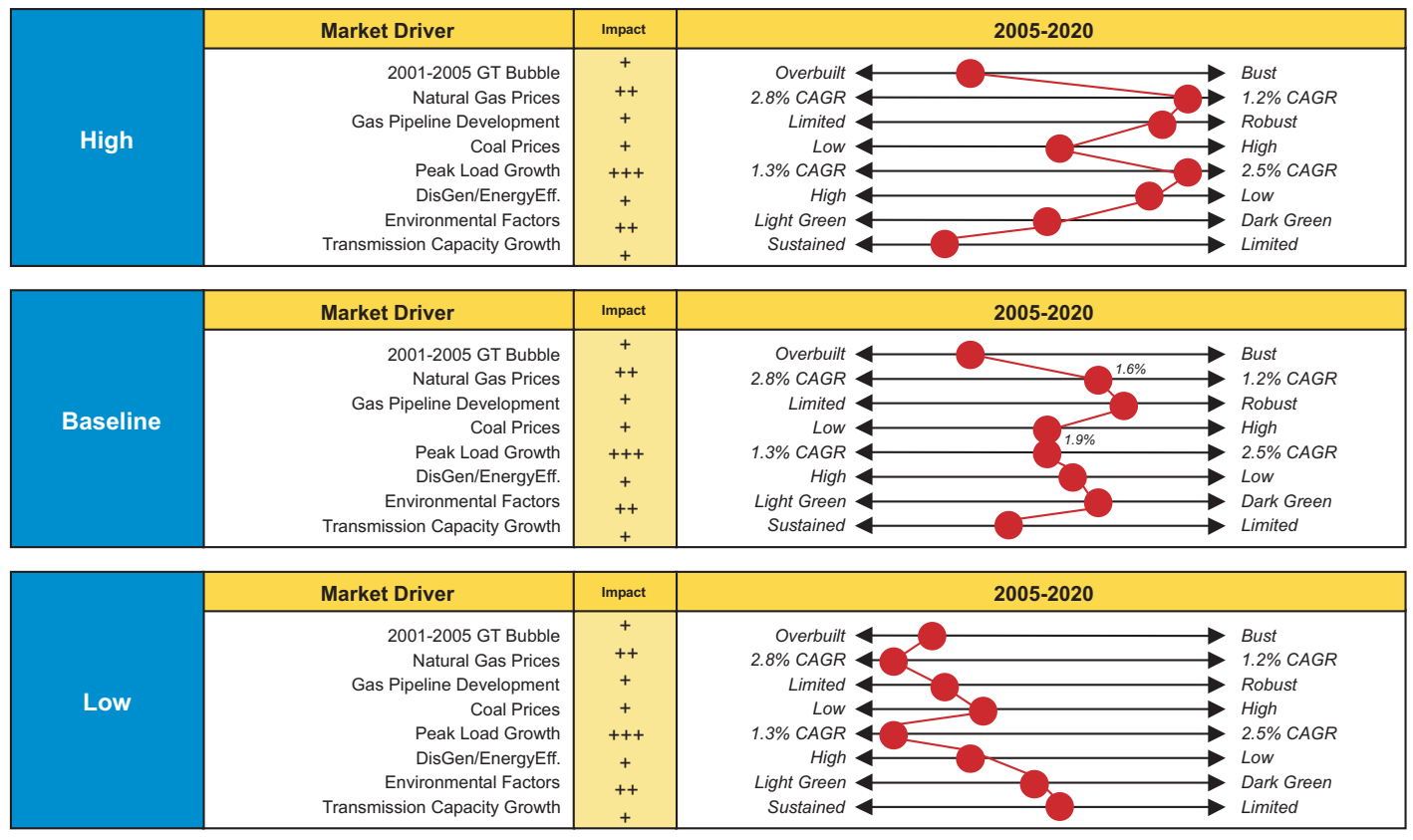

Figure 3-1. Framework of the Scenarios for the ADL Analysis

We interviewed 21 large players in the global power generation market to seek their perspectives on the overall generation markets and the new turbine(s) under development. ${ }^{1}$ Most respondents did not distinguish between base load and intermediate duty plants. Many of the interviewees were merchant plant developers who believed that capacity factor of the plant will vary with market dynamics. Even though the specific needs of customers vary between combined cycle owners and those owning peakers, both groups selected the same top three desirable attributes (availability, reliability, and economics). In general, they all saw a continuation of the trend towards building large combined cycle projects based on 7F and 501G technology. However, they did not see any need for even larger gas turbines. They seem to prefer a relatively smaller peaking unit size equivalent to $100 \mathrm{MW}$ installed in banks of four or eight at a location. Presently, the 7EA seems to be the most popular choice for a peaker.

Leading energy trading companies tend to use peaking units as a financial hedge. They view them as a conversion device to pump electricity into the grid at a very short notice. They prefer a large peaking unit equivalent to 175 MW. Reliability is a bigger concern for this group.

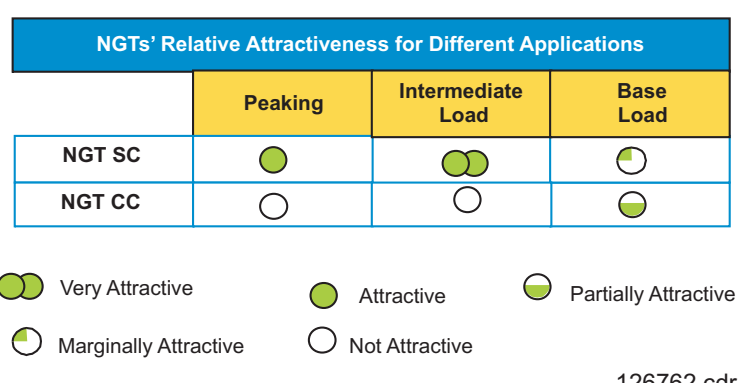
critical to succeed in the merchant power market. However even operational considerations or noneconomic factors have a quantifiable impact on the economics (dollars/MW/ hr), thereby blurring the distinction between the two.

Comparative economic analysis shows that NGT simple cycle will be attractive for both peaking and intermediate duty applications. The combined cycle, however, is only partially attractive for baseload applications (Figure 3-2).

The market for new generating capacity in the U.S. was estimated based on supply-demand growth projections. Overbuilding the retirement over the years is also taken into account (Figure 3-3).

\footnotetext{
${ }^{1}$ Large gas turbines (greater than $60 \mathrm{MW}$ ) constitute more than 85 percent of the total turbines sold in the U.S. during the last 10 years.

Large turbines are also expected to maintain the percentage in the future.
} 


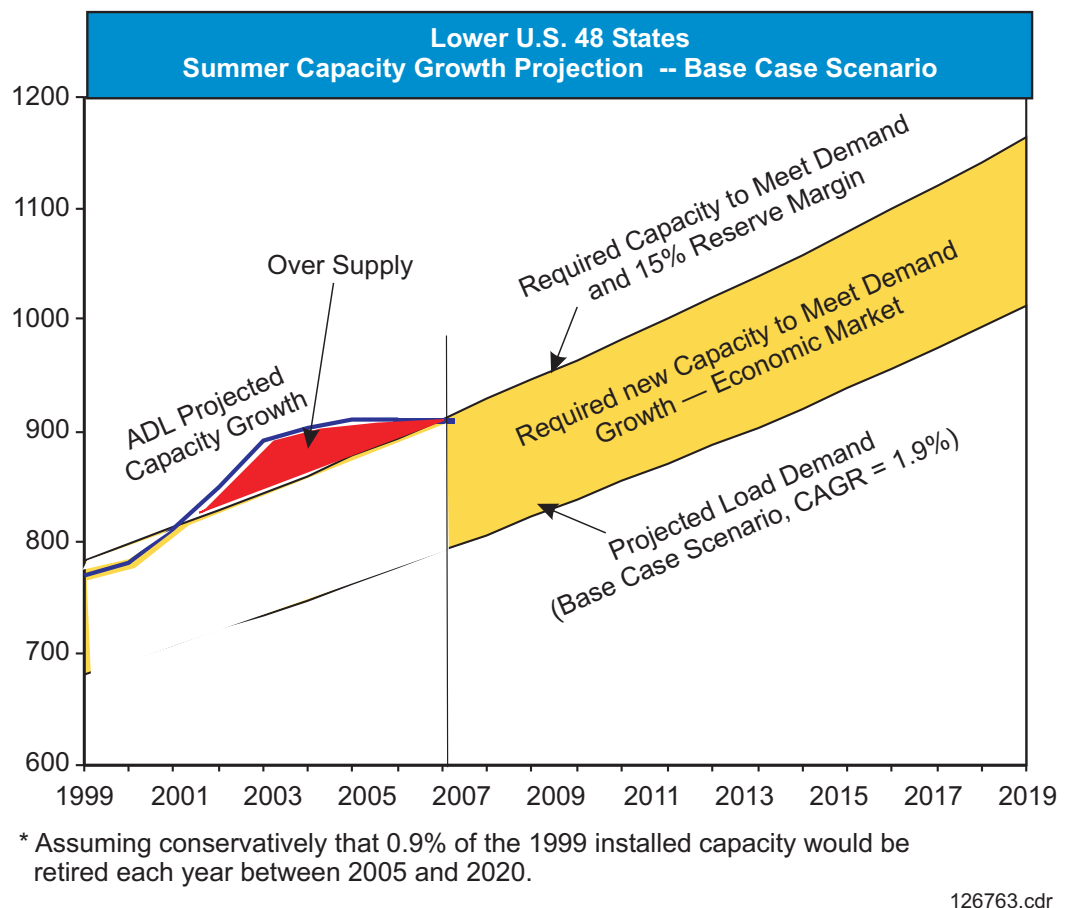

Figure 3-3. Market for New Generating Capacity in the U.S.

About $370 \mathrm{GW}$ of new generating capacity would be required in the U.S. between 2005 and 2020 to keep pace with demand growth and to offset estimated plant retirements. It is widely believed that gas turbine-based simple-cycle and combined-cycle powerplants will account for about 90 percent of the new generating capacity additions in each scenario (Figure 3-4).

The global market for NGTs is estimated to be over $\$ 30$ billion and is almost equally divided between the U.S. and the rest of the world (Table 3-1 and Table 3-2).

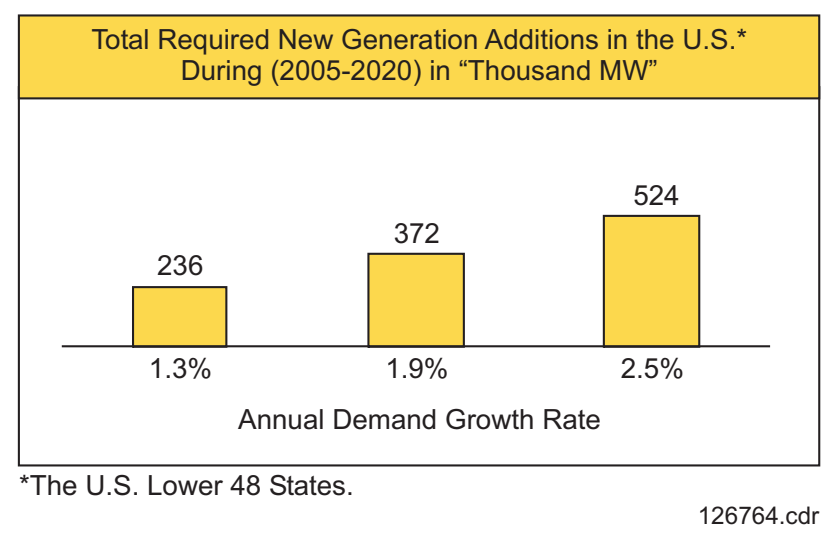

Figure 3-4. Generation Additions in the U.S.

Table 3-1. NGT Market Potential in U.S. (2007 to 2020)

\begin{tabular}{lcccc}
\hline & Total Market for Gas Turbines & \multicolumn{2}{c}{ NGT Projected Market } \\
\multicolumn{1}{c}{ Scenario } & MW & $\begin{array}{c}\text { Percent } \\
\text { Share }\end{array}$ & MW & $\begin{array}{c}\text { Billions of } \\
\text { Dollars }\end{array}$ \\
\hline Low growth at 1.3 percent CAGR & 213,000 & $22.3 \%$ & 47,500 & $\$ 10.5$ \\
Base case at 1.9 percent CAGR & 335,000 & $19.9 \%$ & 66,500 & $\$ 14.6$ \\
High Growth at 2.5 percent CAGR & 420,000 & $19.5 \%$ & 81,900 & $\$ 18.0$ \\
& OEM price used in computations above dollars/kW: & $\$ 220.0$ \\
\hline
\end{tabular}


Table 3-2. NGT Market Potential in the Rest of World (2005 to 2020) ${ }^{1}$

\begin{tabular}{ccccc}
\hline & Total Market for Gas Turbines & \multicolumn{3}{c}{ NGT Projected Market } \\
Scenario & MW & $\begin{array}{c}\text { Percent } \\
\text { Share }\end{array}$ & MW & $\begin{array}{c}\text { Billions of } \\
\text { Dollars }\end{array}$ \\
\hline Rest of world at 2.7 percent CAGR & 476,000 & $14.9 \%$ & 71,100 & $\$ 15.6$ \\
\hline
\end{tabular}

${ }^{1}$ We have not made any allowances for: a) any delayed adoption of new technology, and b) plant retirements in the rest of the world.

NGTs could generate total sales of more than $\$ 15$ billion over the planning horizon based on its $\$ 220 / \mathrm{kW}$ price. While significant additional sales will result from services and spare parts, their impact is not included here (Figure 3-5).
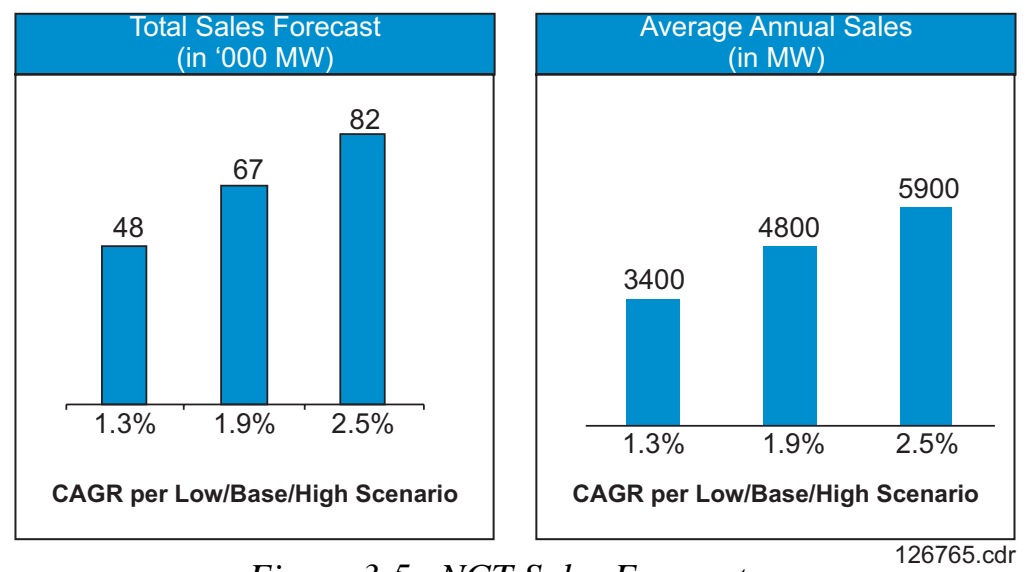

Figure 3-5. NGT Sales Forecasts

The attributes of the FT60 IC, combined with the market forecast above, will generate a considerable amount of public benefits, as indicated in Figure 3-6. Adoption of NGTs will lead to substantial economic, environmental, and societal benefits.

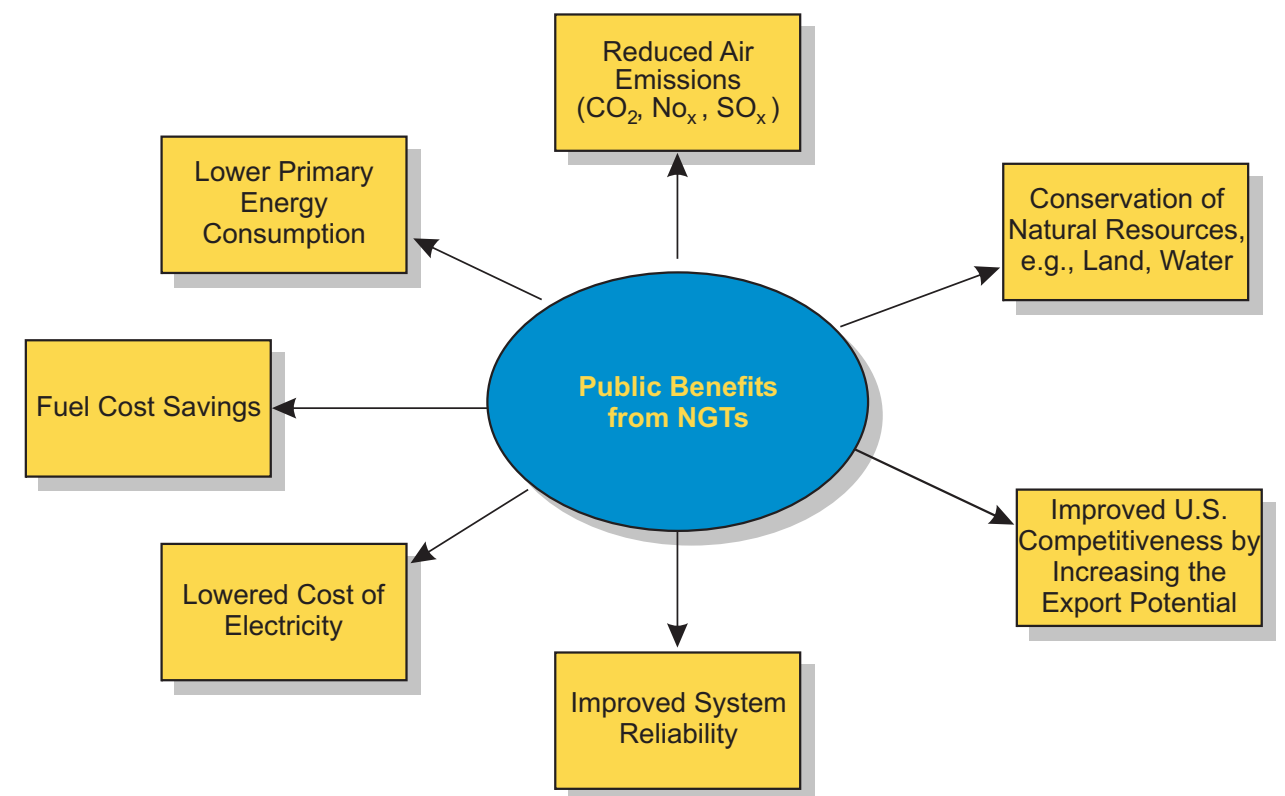

Figure 3-6. Benefits of Adopting NGTs 


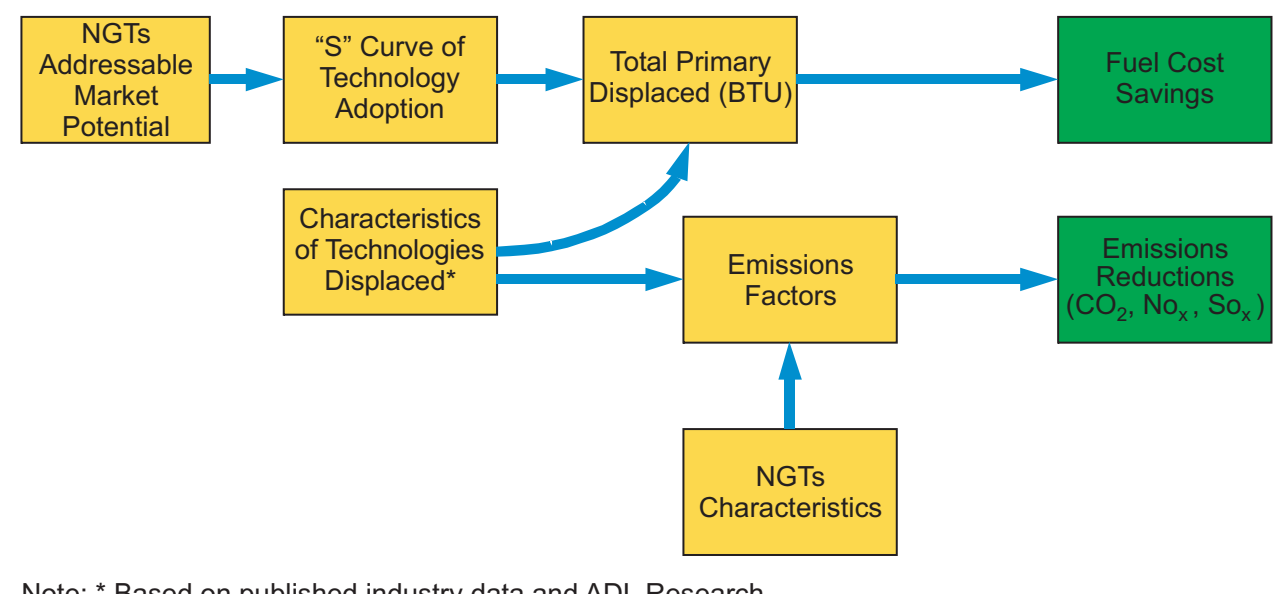

Note: * Based on published industry data and ADL Research

Figure 3-7. Savings Were Generated Using Market Projections

Energy savings, electricity cost savings, fuel savings, and emissions reductions were calculated using the base case NGT market projections (Figure 3-7). The public benefit calculations are based on our market forecast assumptions and projections for NGTs. NGTs are projected to displace some old generating plants and future GT plants based on E\&F technology. Existing units are those oil-fired and gas-fired, intermediate duty, steam-turbine plants that would be displaced by NGTs. Among the total capacity of this segment, gas-fired plants account for about 75 percent of the total, whereas oil-fired account for the other 25 percent. ${ }^{1}$ Heavy oil prices are used to represent prices of oil as they account for more than 95 percent of the total fuel oil consumption. Future plants that would be displaced by NGTs are mostly composed of gas turbine simple-cycle powerplants for peaking and intermediate load applications (Figure 3-8).

Economic benefits are dependent on the future fuel oil prices of gas and oil. Gas prices were taken from our study and oil prices forecasted by EIA (Figure 3-9).

The efficiencies and emission factors for NGTs and generation technologies are shown in Figure 3-10.

Annual fuel saving from the adoption of NGTs would reach almost 190 trillion Btu in 2020, which is enough to fuel a 3,000 MW plant for 1 year (Figure 3-11).

\footnotetext{
${ }^{1}$ Percentage assumptions are based on RDI PowerDAT.
}

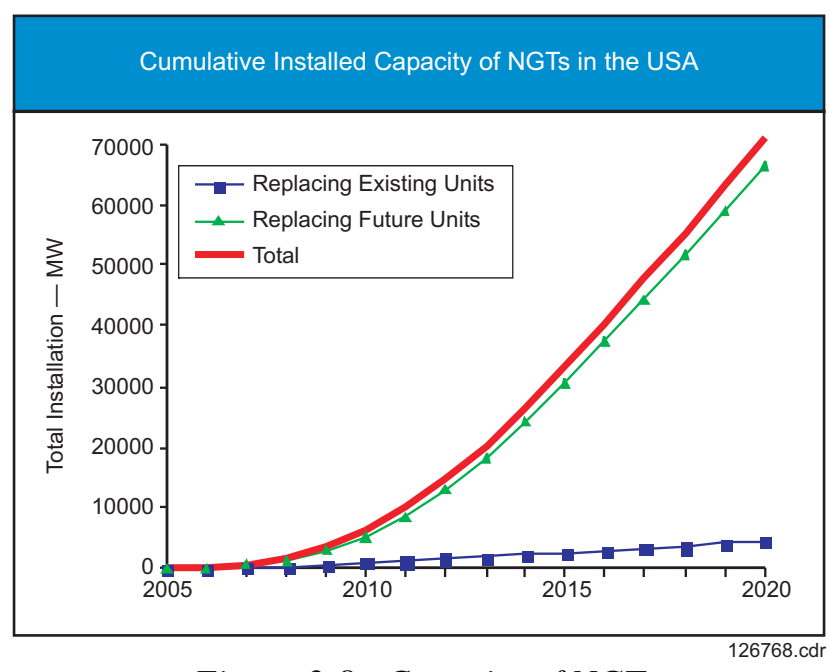

Figure 3-8. Capacity of NGTs

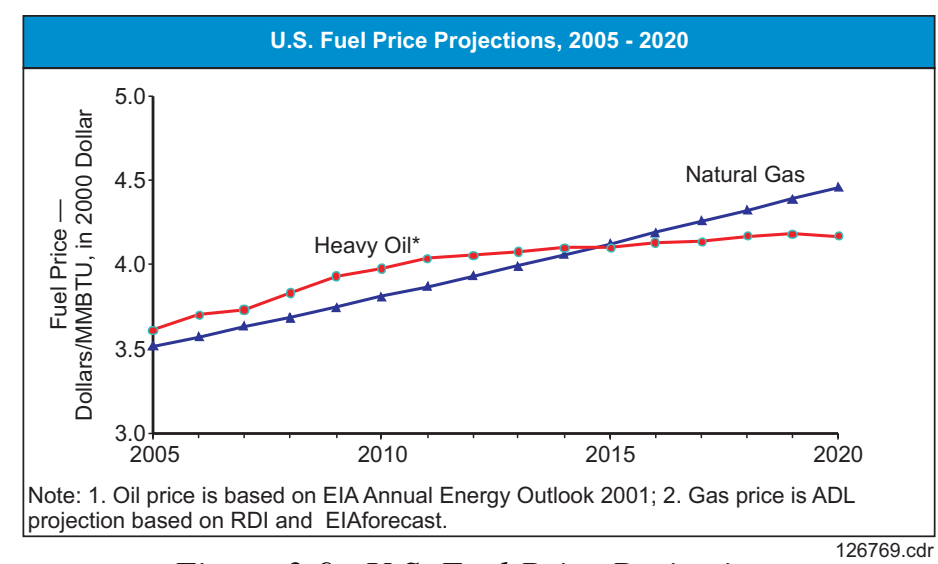

Figure 3-9. U.S. Fuel Price Projections 


\begin{tabular}{|c|c|c|c|c|}
\hline & \multicolumn{2}{|c|}{$\begin{array}{c}\text { Existing Technology that Would } \\
\text { Be Displaced by NGTs }\end{array}$} & \multirow{2}{*}{$\begin{array}{l}\text { Future Technology } \\
\text { that Would Be } \\
\text { Displaced by NGTs }\end{array}$} & \multirow{2}{*}{ NGTs } \\
\hline & Gas -Fired & Oil -Fired & & \\
\hline LHV Efficiency & $35 \%$ & $35 \%$ & $39 \%$ & $50.2 \%$ \\
\hline $\begin{array}{c}\mathrm{CO}_{2} \text { Emission Factor } \\
\text { (lbs/MWh) }\end{array}$ & 1151 & 1463 & 1030 & 800 \\
\hline $\begin{array}{l}\mathrm{SO}_{2} \text { Emission Factor } \\
\text { (lbs/MWh) }\end{array}$ & 0.006 & 8.4 & 0.005 & 0.004 \\
\hline $\begin{array}{l}\mathrm{NO}_{\mathrm{x}} \text { Emission Factor } \\
(\mathrm{lbs} / \mathrm{MWh})\end{array}$ & 1.8 & 3.7 & 0.31 & 0.24 \\
\hline
\end{tabular}

Source:

1. EPA E-GRID Database

2. New Energy Market Power

3. ADL Study

126770.cdr

Figure 3-10. Efficiencies, Emission Factors, and Displaced Generation Technologies

\section{Annual NGTs Fuel Saving in the USA due to Adoption of NGTs, in Trillion BTU}
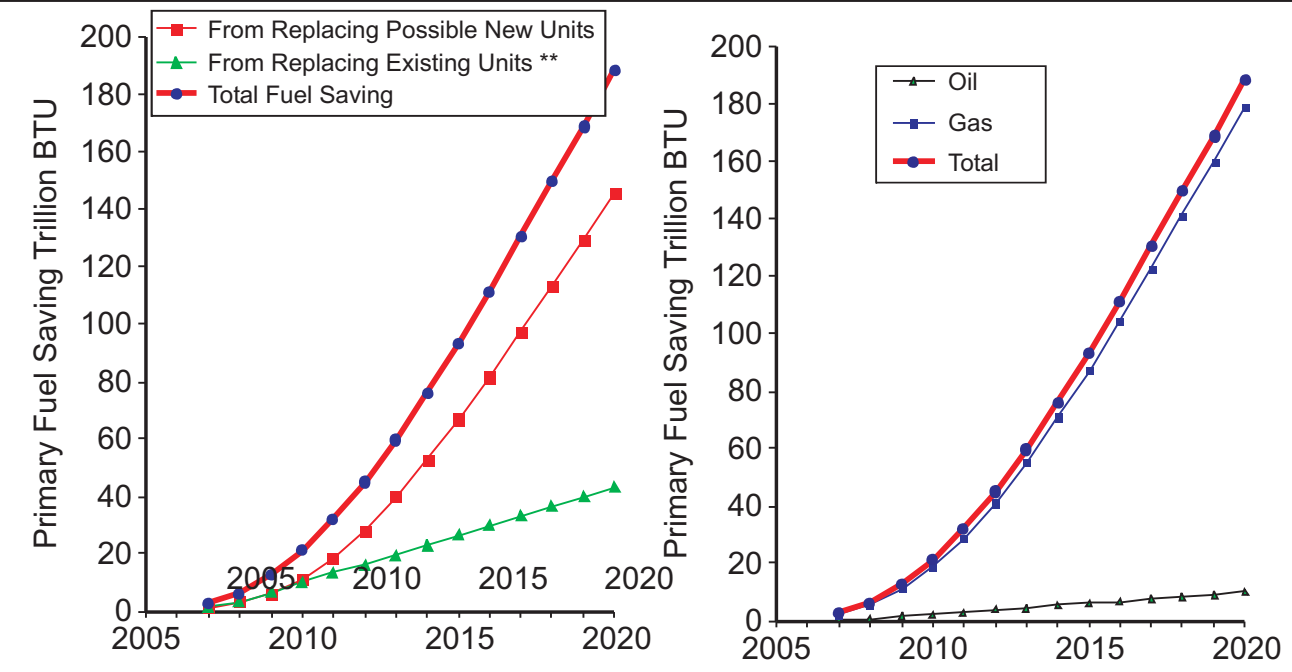

* Existing units that would be displaced are mainly oil-fired or gas-fired steam turbine power plant. 126771.cdr

Figure 3-11. Fuel Savings 


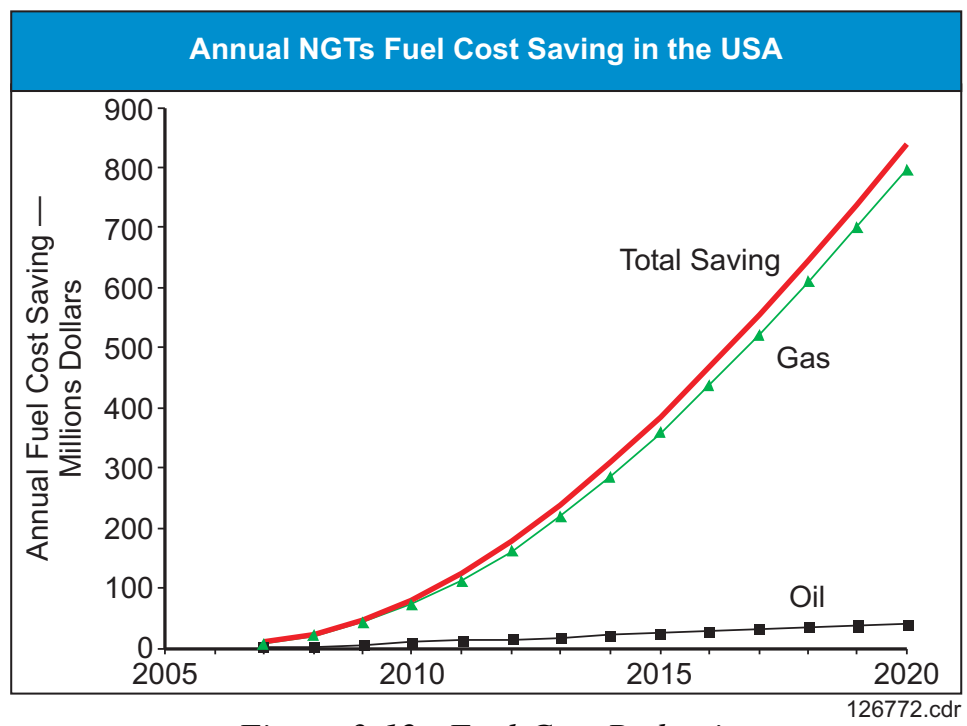

Figure 3-12. Fuel Cost Reduction

Annual fuel cost reduction from the adoption of NGTs would reach 800 million dollars in year 2020 (in year 2000 dollars) (Figure 3-12).

Adoption of NGTs will lead to substantial reduction in $\mathrm{CO}_{2}$ emissions (Figure 3-13). Annual reduction in $\mathrm{CO}_{2}$ emissions would be over 26 million tons per year in 2020. This is equivalent to:

- Total emission of $14 \times 300 \mathrm{MW}$ coal-fired steam-turbine powerplant (assuming a 75 percent capacity factor

- Total emissions of $50 \times 300 \mathrm{MW}$ gas-fired steam-turbine powerplant (assuming a 40 percent capacity factor).

The adoption of NGTs will lead to a reduction in $\mathrm{NO}_{\mathrm{x}}$ and $\mathrm{SO}_{\mathrm{x}}$ emissions as well (Figure 3-14). The majority of the $\mathrm{SO}_{2}$ and $\mathrm{NO}_{\mathrm{x}}$ savings is from the displacement of existing gas-fired and oil-fired steam turbine plants. In 2020, the annual $\mathrm{NO}_{\mathrm{x}}$ and $\mathrm{SO}_{2}$ savings are estimated to be 21,000 tons and 14,000 tons,

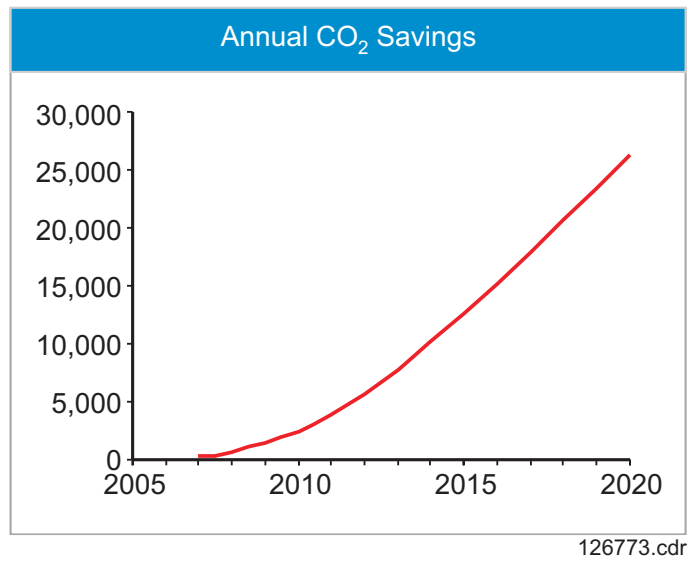

Figure 3-13. Reduction in $\mathrm{CO}_{2}$ Emissions respectively. The $\mathrm{NO}_{\mathrm{x}}$ emission savings are equivalent to the total emissions of approximately 3 to 6 units of $300 \mathrm{MW}$ coal-fired powerplant. The $\mathrm{SO}_{\mathrm{x}}$ emissions savings are equivalent to the total emission of approximately 1 to 2 units of $300 \mathrm{MW}$ coal-fired powerplant. $\mathrm{NO}_{\mathrm{x}}$ and $\mathrm{SO}_{2}$ are not significant as that of $\mathrm{CO}_{2}$ because NGTs would be primarily used to displace the conventional gas turbine technology, which already has limited emissions of $\mathrm{NO}_{\mathrm{x}}$ and $\mathrm{SO}_{2}$.

The cumulative energy and emissions savings could be substantial especially in the later years when NGTs become widely adopted (Figure 3-15).

The use of all types of gas turbines will reduce the need for land and water resources as compared to the steam plants they might displace (Figure 3-16).

Total sales of NGTs in the rest of the world is projected to be $\$ 15$ billion, about the same as in the U.S. (Figure 3-17).

U.S. turbine manufacturers would capture a significant portion of the global market of NGTs, as well as other service business opportunities. Assuming U.S. manufacturers could gain 60 percent of the export of the rest of the 
world market, this would result in $\$ 9$ billion of U.S. exports. U.S. companies will also earn revenues from ancillary services, spare parts, and other business related to NGTs. As a result, the competitiveness of the U.S. turbine manufacturers will be improved. In addition, export of NGTs would create new jobs in the U.S.

There are significant other benefits realized from the adoption of NGTs, although they may be difficult to quantify. NGTs would help the U.S. address the global warming issue more easily. There will be a significant amount of $\mathrm{CO}_{2}$ reductions in the U.S. resulting from the use of NGTs (as calculated previously). The U.S. may also benefit from the credits of $\mathrm{CO}_{2}$ reductions from other countries use of NGTs. NGTs would also have other environmental benefits such as reduced particulate emissions. U.S. customers may benefit from reduced retail electricity prices resulting from low-cost power generated by NGTs. The NGTs' higher performance and availability would also improve the system reliability of equipment owners and the power grid.

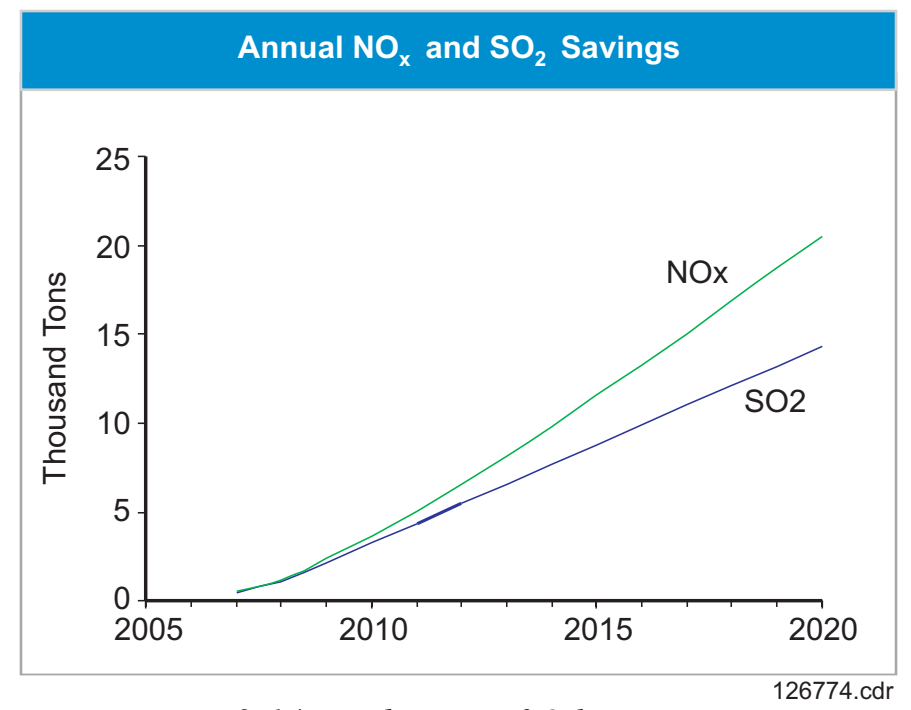

Figure 3-14. Reduction of Other Emissions

\begin{tabular}{|c|c|c|c|}
\cline { 2 - 4 } \multicolumn{1}{c|}{} & \multicolumn{3}{c|}{ Cumulative Savings from 2007 } \\
\cline { 2 - 4 } \multicolumn{1}{c|}{} & 2010 & 2015 & 2020 \\
\hline $\begin{array}{c}\text { Primary Energy } \\
\text { (Trillion BTU) }\end{array}$ & 44 & 350 & 1,100 \\
\hline $\begin{array}{c}\text { Fuel Costs Savings } \\
(\text { MM 2000\$) }\end{array}$ & 165 & 1,400 & 4,640 \\
\hline $\begin{array}{c}\mathrm{CO}_{2} \\
\text { (Thousand Tons) }\end{array}$ & 5,020 & 45,000 & 148,000 \\
\hline $\begin{array}{c}\mathrm{SO}_{2} \\
\text { (Thousand Tons) }\end{array}$ & 7 & 50 & 100 \\
\hline $\begin{array}{c}\mathrm{NO}_{\mathrm{x}} \\
\text { (Thousand Tons) }\end{array}$ & 7 & 52 & 133 \\
\hline NGTs Installation \\
(MW)
\end{tabular}

Figure 3-15. Cumulative Energy and Emissions Savings 


\begin{tabular}{|c|c|c|c|c|}
\hline & & Gas Turbine & Steam Plant* & $\begin{array}{l}\text { Percent } \\
\text { Reduction }\end{array}$ \\
\hline & Land (Acres) & $5-15$ & $25-50$ & $60 \%-90 \%$ \\
\hline \multirow{4}{*}{$\frac{\frac{1}{\Phi}}{\frac{1}{\pi}}$} & $\begin{array}{l}\text { Service and Plant Water } \\
\text { (mgd) }\end{array}$ & $1-2$ & $0.5-1$ & \\
\hline & $\begin{array}{l}\text { Cooling Tower Makeup } \\
\text { Water (mgd) }\end{array}$ & $0-8$ & $12-15$ & \\
\hline & $\begin{array}{l}\text { Waste Water Discharge } \\
\text { (mgd) }\end{array}$ & $1-8$ & 8-14 & \\
\hline & Overall (mgd) & $2-18$ & $20-30$ & $30 \%-90 \%$ \\
\hline
\end{tabular}

*: Gas and Oil (100MW-300 MW).

Source: ADL Estimate

126775.cdr

Figure 3-16. Advantages of NGTs Over Steam Plants

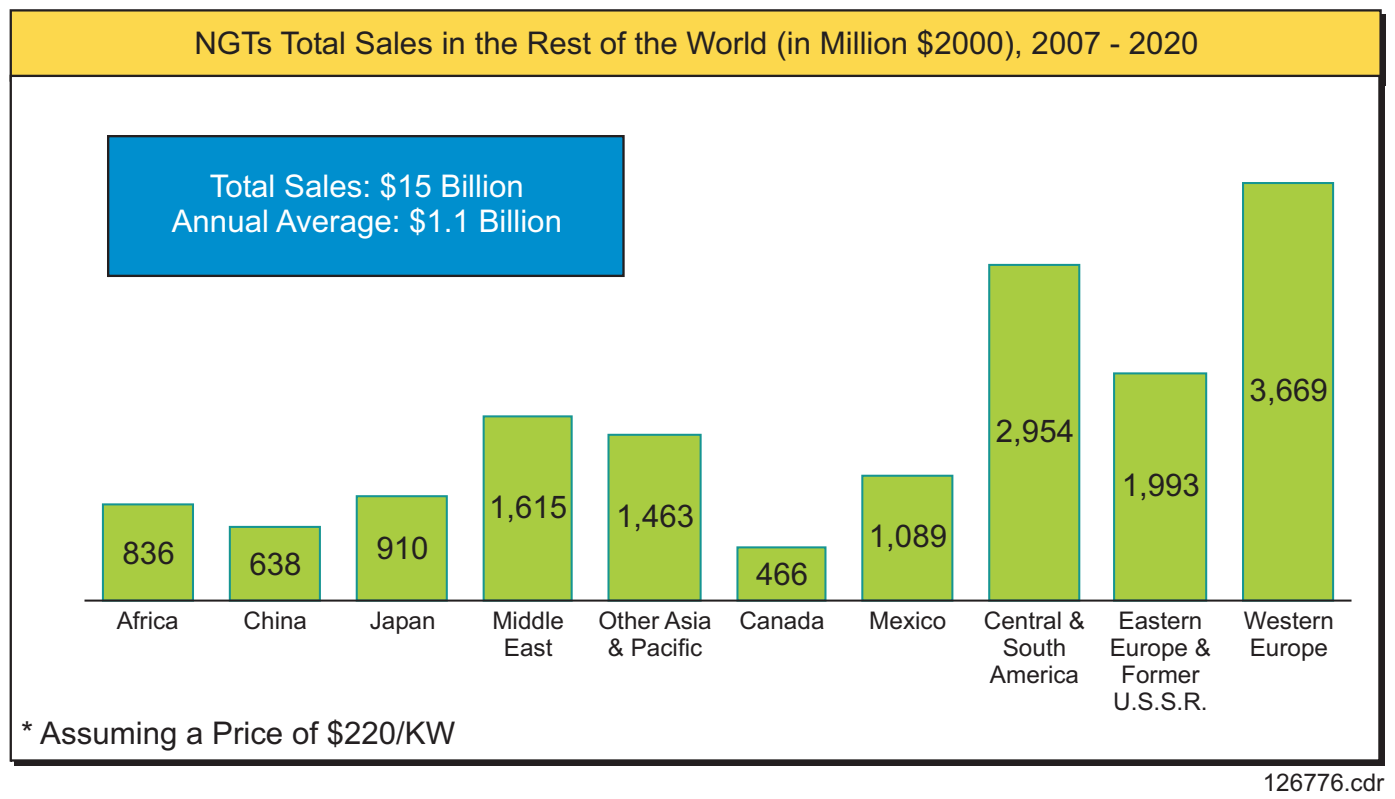

Figure 3-17. Projected Sales of NGTs Worldwide 


\subsection{PUBLIC BENEFITS}

\subsubsection{The System's Ability to Serve Multiple Uses}

KraftWork Systems carried out analyses to identify the NGT engine system's ability to serve multiple uses. The majority of these uses are based on employing the NGT system in conjunction with a coal-fired plant, or on using coal as the system fuel. Also identified was the ability of the NGT system to serve as the basis of an advanced performance cycle, the HAT cycle. The HAT cycle is also is used with coal gasification in an IGHAT. The NGT systems to be identified are:

- Feedwater heating retrofit to an existing coal-fired steam plant, which could supply both heat and peaking power (Block 2 engine)

- $\quad$ Repowering of an older coal-fired plant (Block 2 engine)

- Gas-fired HAT cycle (Block 1 and 2 engines); integrated gasification HAT (Block 1 and 2 engines).

In addition, results from a recent study funded by DOE (contract DE-AC22-95PC95144) concerning application of the intercooled aeroderivative engine technology in an indirectly fired gas turbine will be included to round out the potential cycle/fuel flexibility of this technology.

\subsubsection{New Coal-Fired Plant with Feedwater Heating}

The NGT can enhance the performance and flexibility of new coal-fueled powerplants. For example, in the near term, the NGT could be used with conventional coal-fired steam plants. The heat from the intercooler and the exhaust of the natural gas fired NGT can be used for feedwater preheating in coal fired steam plants. This increases the output and efficiency of the coal-fired plant, because steam does not need to be extracted from the steam turbine for

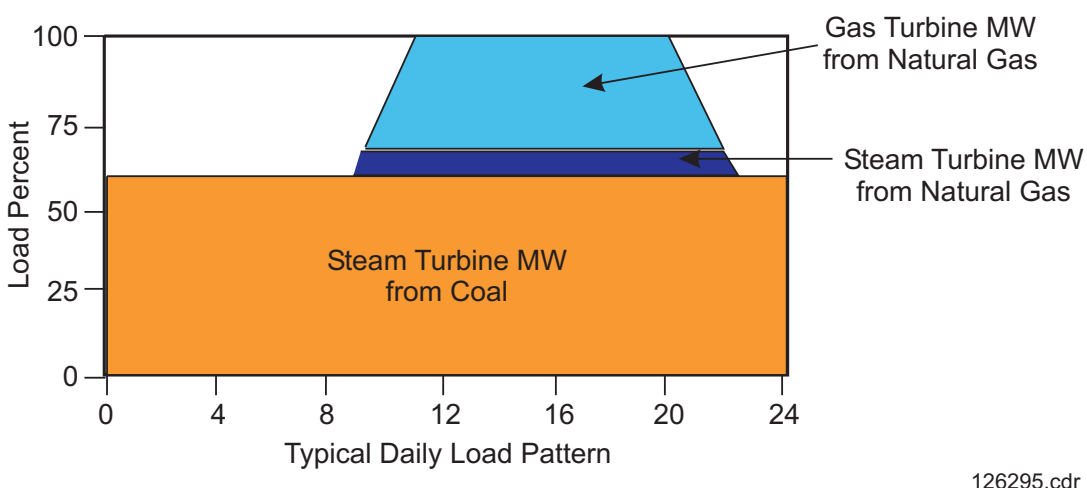

Figure 3-18. Typical Daily Load Factor for Feedwater Heating Plant feedwater preheating. The gas turbine is operated on natural gas fuel during times of peak demand. The plant operator sells power only into the base load market with the coal plant when the gas turbine is not operating and sells both the power from the gas turbine and the increased output of the steam plant in the on-peak market when he operates the gas turbine. If needed, the remaining heat from the gas turbine exhaust can be used to heat water for process or district heating. This equipment can be added to existing coal-fired plants as well as new plants. The cycle arrangement and the plant output during a 24-hour period are shown in Figure 3-18 and Figure 3-19.

As an example of this approach, the steam system shown in Figure 3-20 has been investigated. This basic steam plant operates at $3500 \mathrm{psi} / 537^{\circ} \mathrm{C}\left(1000^{\circ} \mathrm{F}\right)$. With extraction for seven feedwater heater stages, the heat rate is $9,077 \mathrm{Btu} / \mathrm{kW} / \mathrm{hr}$ and the output is slightly over $800 \mathrm{MW}$. The plant is designed to accept full throttle flow during periods when peak power is needed. During this peak demand period, the feed water is heated by the exhaust from five NGT engines, which supply a further 842 MW of power (Figure 3-21).

The performance of this feedwater-heating cycle is quite impressive. The output of the system has been increased from $800 \mathrm{MW}$ to 1,850 MW. Similarly, the heat rate has been reduced from 9,077 Btu/kW/hr to 7,155 $\mathrm{Btu} / \mathrm{kW} / \mathrm{hr}$, a decrease of over 21 percent. At full peak output, gas supplies 47 percent of the system energy. The incremental gas efficiency in this system is 57 percent (steam MW from gas and GT MW)/gas energy lower heating value [LHV]). While analyses were performed only for the case when all of the extraction steam is expanded, it is possible to operate with partial extraction and use only selected gas turbines to obtain the desired power output. This gives great operating flexibility to the concept. In Figure 3-21, the extraction heaters and the necessary valves and piping have been omitted for clarity. 


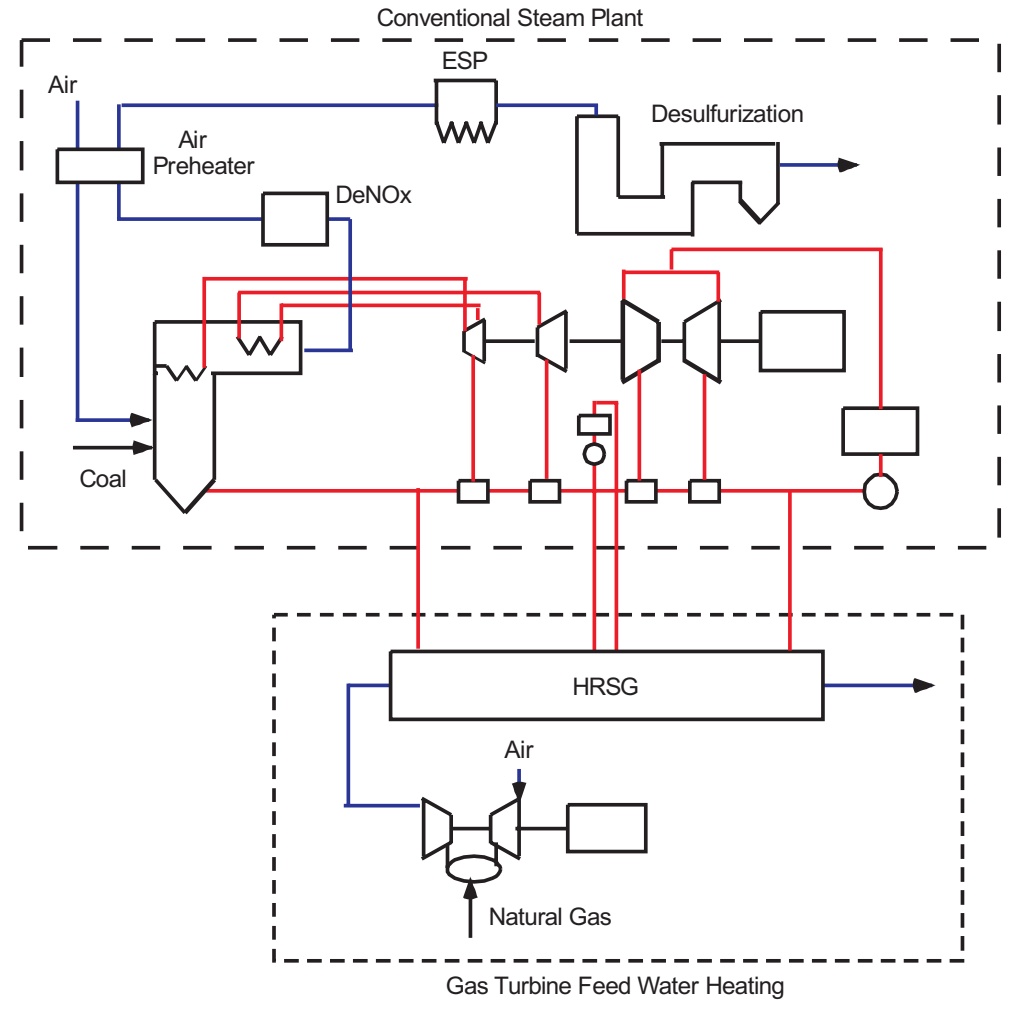

Figure 3-19. Diagram of Feedwater Heating Cycle

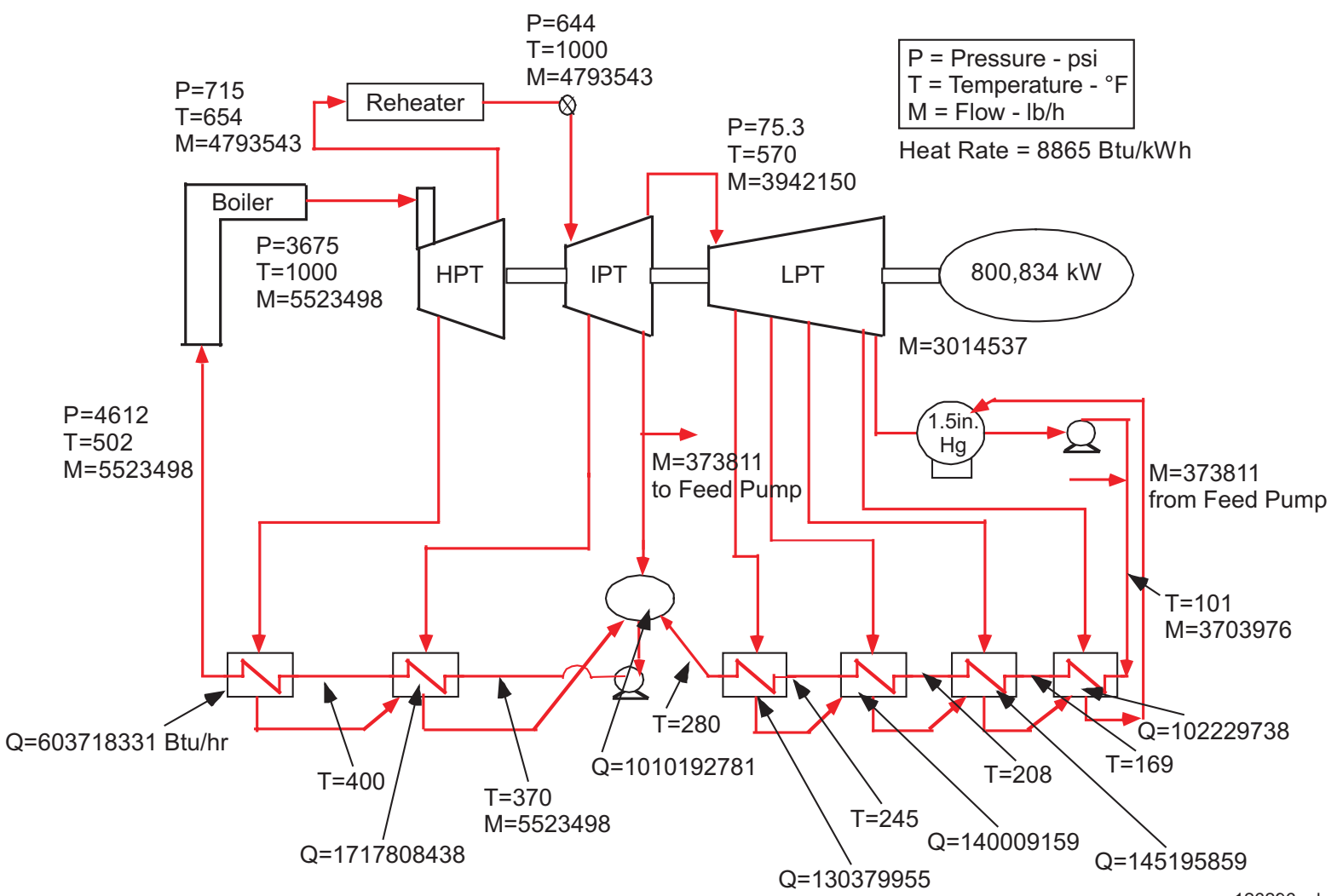

Figure 3-20. Base-Load Supercritical Steam Plant 


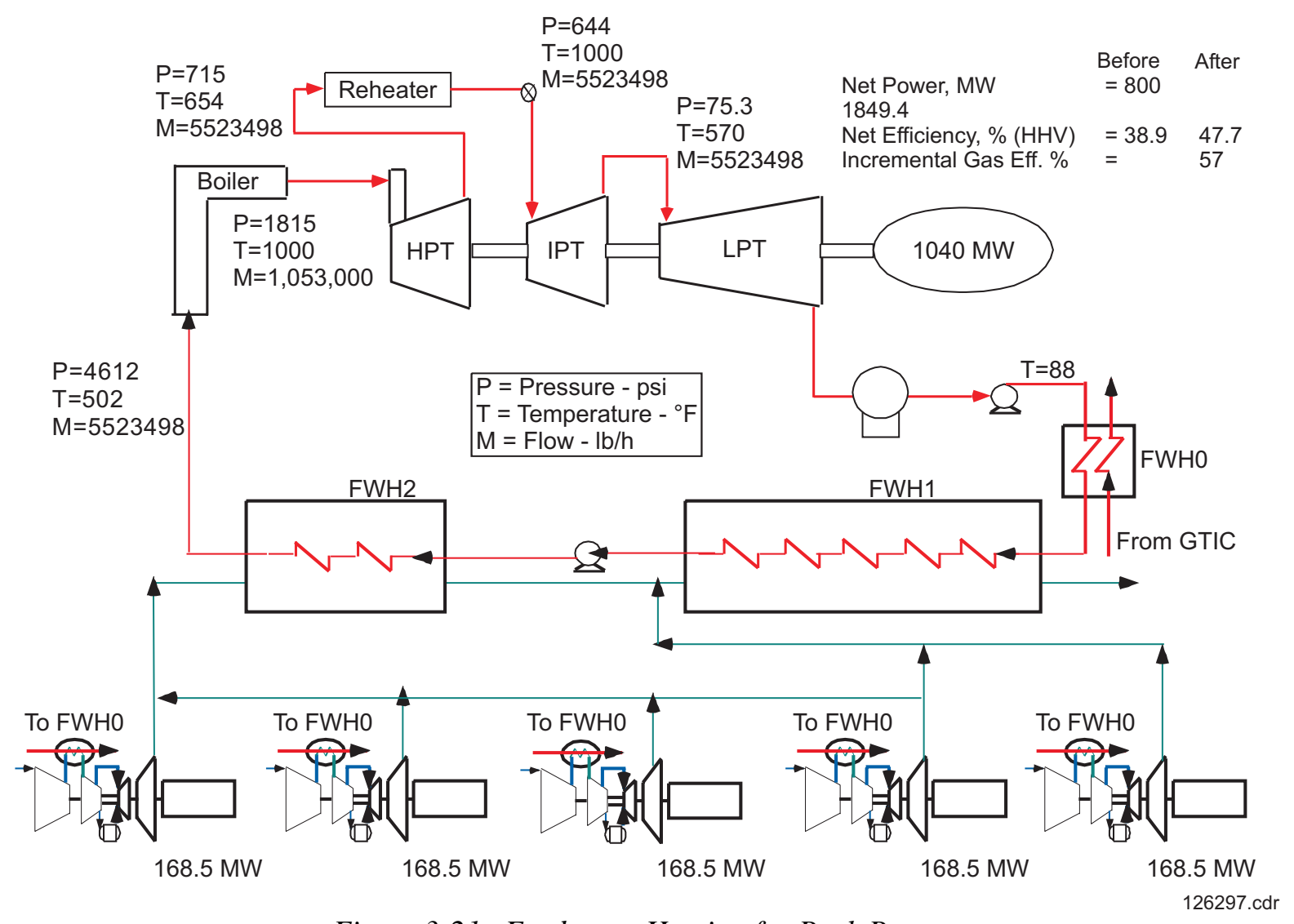

Figure 3-21. Feedwater Heating for Peak Power

\subsubsection{Repowering of a Coal-Fired Powerplant}

In the next two decades, it is estimated that over 400,000 MW of capacity addition will be needed to meet increased electrical demand and to replace aging units. This includes approximately 73,000 MW of current coalfired power scheduled to be retired during this period. Many of the plants currently scheduled for retirement could be successfully repowered using NGT technology, thereby reducing the required capital investment in generating capacity while also reducing energy use and environmental impact including greenhouse gases.

The repowering of aging steam stations with modern gas turbines may now present a better opportunity to provide the additional power that is required for the future. The ability to use existing facilities and infrastructure and, in many cases, use locations near to load centers that already have needed environmental permitting makes repowering attractive. A concept definition study was performed to identify the alternative gas turbine configurations to be used for repowering. The intercooled aeroderivative-type engine was selected to allow the widest flexibility in operation and also to minimize the footprint of any repowering additions. A specific steam powerplant was selected to be the basis for a repowering study to estimate potential performance using an actual steam power system.

The steam system selected for repowering is shown in Figure 3-22. As can be seen, the system uses modest steam conditions of $1,815 \mathrm{psi} / 537^{\circ} \mathrm{C}\left(1000^{\circ} \mathrm{F}\right)$. There are a number of approaches to repowering, the most common being to replace the existing boiler by a heat recovery steam generator (HRSG), which uses the gas turbine exhaust as the heat source. This means the entire plant capacity is now gas fueled. This approach would not be suitable for the NGT engine as the exhaust temperature is too low (the equivalent of $426^{\circ} \mathrm{C}\left[800^{\circ} \mathrm{F}\right]$ ). The repowering method that makes the best use of the low-temperature exhaust would use this heat to replace the feedwater heating normally done by steam extracted from various points in the steam cycle; for example, in the steam system selected for analysis, there are seven extraction points. While this approach, shown in Figure 3-23, allows retention of the original steam generator, there would be significant modifications necessary to the steam turbine. 


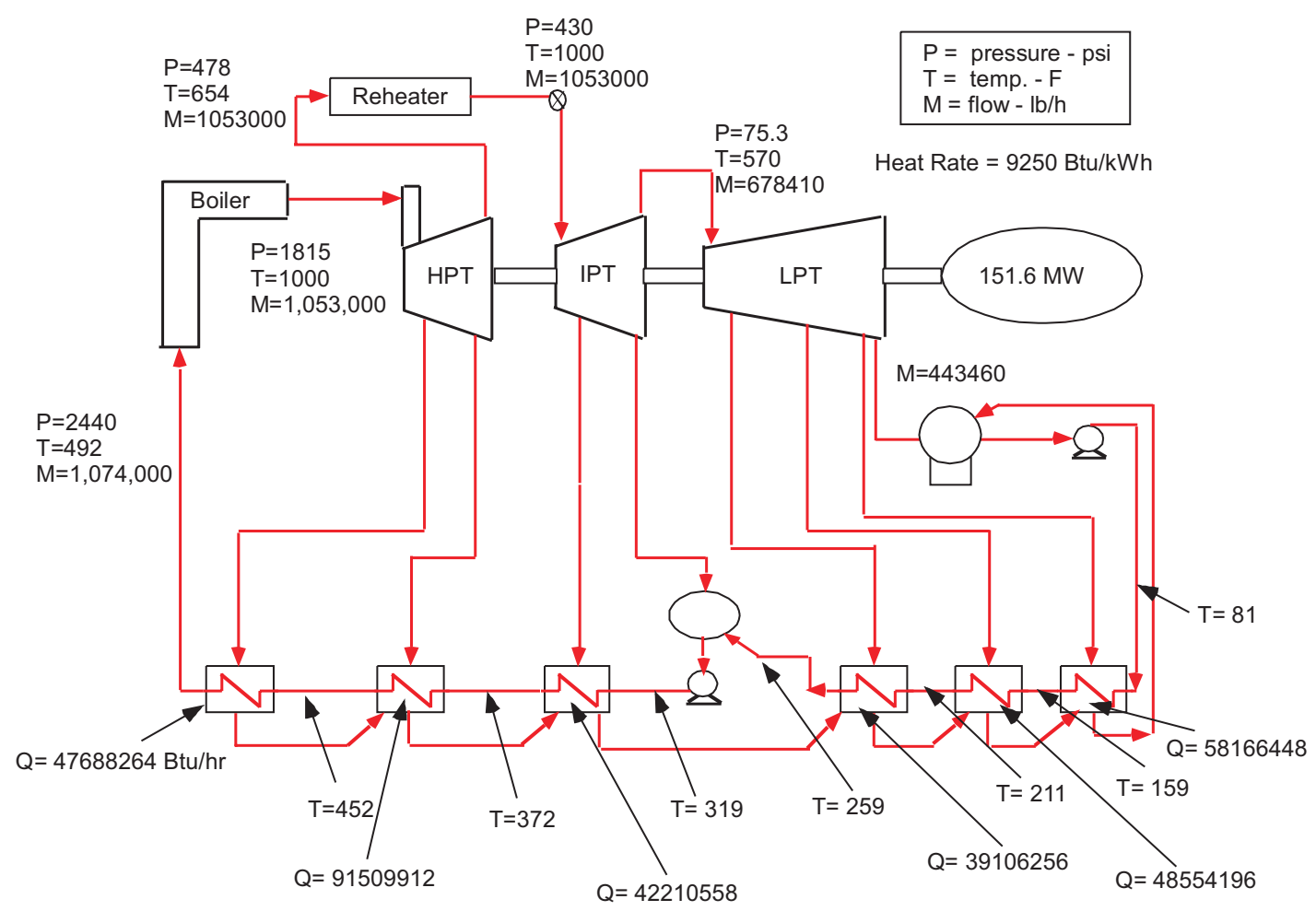

Figure 3-22. Schematic of Steam System

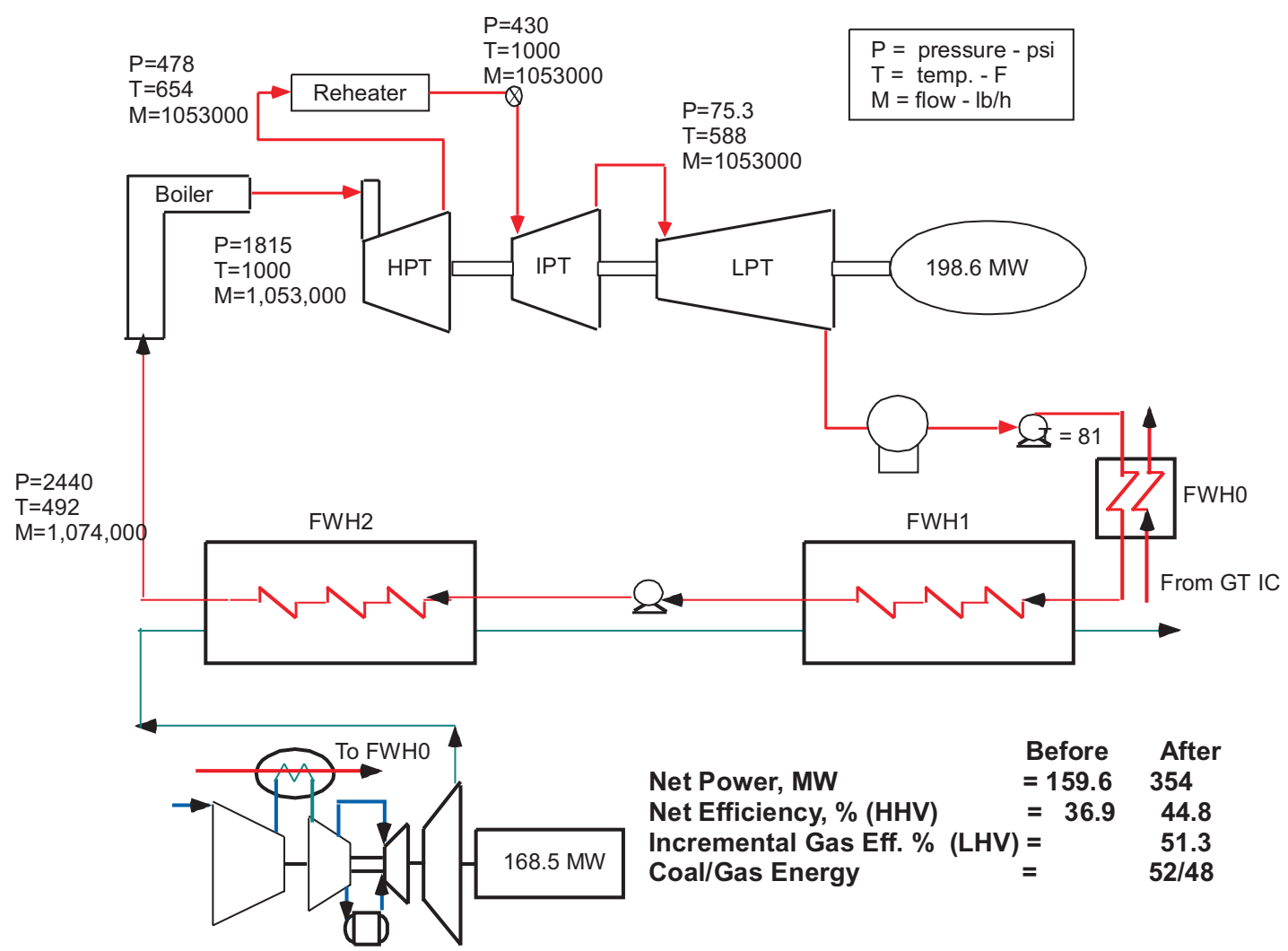

Figure 3-23. Schematic of Repowered Plant 
As designed, the flow of the steam passing through the turbine sections is reduced at each extraction point until the flow from the LPT to the condenser is only a fraction of the throttle flow into the HPT. When the extractions are eliminated, modifications to the HPT and LPT will be needed to accommodate the increased flow. Additionally, the generator will have to upgraded or replaced by one of a higher capacity. When the full throttle flow is expanded, the steam turbine output is $198.6 \mathrm{MW}$, nearly 40 MW higher than previously. One NGT is needed to supply the feedwater heating. Three heat exchangers are used: a low-pressure and a high-pressure feedwater heater and the engine intercooler. To simplify the Figure 3-23 schematic, the water/steam circuits are not shown in full detail. The repowered system now has a net output of $354 \mathrm{MW}$ and a heat rate, based on the high heat value (HHV) of the combined coal and gas fuel, of 7,618 Btu/kW/hr, a 17 percent reduction. Coal furnishes 52 percent of the cycle heat. The emissions of $\mathrm{CO}_{2} / \mathrm{kW} / \mathrm{hr}$ will be essentially halved compared to the original plant (due to increased efficiency and use of gas for nearly one-half the energy input). The gas fuel is used at an incremental efficiency (additional power/gas energy) of 51.3 percent (LHV).

In cases where it is not economically feasible to upgrade the steam turbine and generator for increased output, the replacement of the extraction by gas turbine heat recovery could result in savings in coal flow of 20 to 25 percent (the feed water represents about 25 percent of the heat input, depending on the actual cycle parameters.) This also represents about a 10 to 12 percent reduction in $\mathrm{CO}_{2}$ emissions compared to the all-coal case.

\subsubsection{Humid Air Turbine Cycle}

In addition to being a worthwhile product on its own, NGT is the first step to an HAT cycle (Figure 3-24). In the HAT cycle, the compressor discharge air is humidified in a tower, recuperated, and sent to the combustor. This results in a much higher mass flow and a higher efficiency. The higher mass flow would require a redesign of the turbine gaspath, but would retain the much more expensive compressor gaspath. The HAT cycle offers equal or better performance than a combined cycle in a package that would also be less expensive, due to the elimination of the HRSG, steam turbine-generator, cooling tower, and condenser. This more than compensates for the cost of the saturator, recuperator, and economizer in the HAT cycle. At the Block 1 design point, temperature $\left(\mathrm{CET}=1330^{\circ} \mathrm{C}\right.$ $\left[2426^{\circ} \mathrm{F}\right]$ ), the NGT HAT would have an output of $242.5 \mathrm{MW}$ and an efficiency of 54.3 percent (LHV). At the Block 2 combustor exit temperature of $1510^{\circ} \mathrm{C}\left(2750^{\circ} \mathrm{F}\right)$, the output is $288.1 \mathrm{MW}$ and the efficiency is 57.0 percent (LHV). Because the moisture addition suppresses $\mathrm{NO}_{\mathrm{x}}$ emissions, higher turbine temperatures are possible and at 
$1704^{\circ} \mathrm{C}\left(3100^{\circ} \mathrm{F}\right)$, the NGT HAT has an estimated output of approximately $321 \mathrm{MW}$ and an efficiency of 60.4 percent (LHV).

\subsubsection{Indirectly Heated Gas Turbine Cycles Using Coal}

The following paragraphs describe power systems that use advanced technology coal-fired air heaters to heat the discharge air from the compressor of aeroderivative gas turbines using technology similar to the NGT engines. These systems were examined as part of DOE-funded (contract DE-AC22-95PC95144) Engineering Development of Coal-Fired High-Performance Power Systems (HIPPS), Phases II and III. Its inclusion here is to identify the potential capability of the NGT-type turbine to use coal as a major fuel source.

In the HIPPS application, (Figure 3-25) the compressor discharge air is heated to $954^{\circ} \mathrm{C}\left(1750^{\circ} \mathrm{F}\right)$ or higher in the high temperature advanced furnace (HITAF), first in a convective heater and then in a specially designed radiator. From there, it goes to a special duct burner where gas is burned to raise the temperature to the desired level (equivalent to $1371^{\circ} \mathrm{C}\left[2500^{\circ} \mathrm{F}\right]$ and higher). The gas turbine exhaust is then sent to a HRSG. When used in the basic HIPPS configuration, essentially a combined cycle, with technology similar to the Block 1 NGT, the output of the system is nominally $275 \mathrm{MW}$ with an overall efficiency, based on the HHV of the coal and gas, of 48.8 percent. Coal provides 65 percent of the system energy input. An advanced system using gas turbine technology similar to the Block 2 NGT combined with an advanced ultracritical steam system would bring the overall cycle efficiency to 53 percent (combined HHV).

As in the case of the gas-fired NGT, the HIPPS can benefit from the HAT-cycle configuration. An NGT-technology based HIPPS/HAT is shown in Figure 3-26. In this configuration, which uses a coal-fired reheater and steam injection before the power turbine, the HAT output is over $395 \mathrm{MW}$ and the estimated efficiency is 54.1 percent (combined HHV) while burning 62 percent coal.

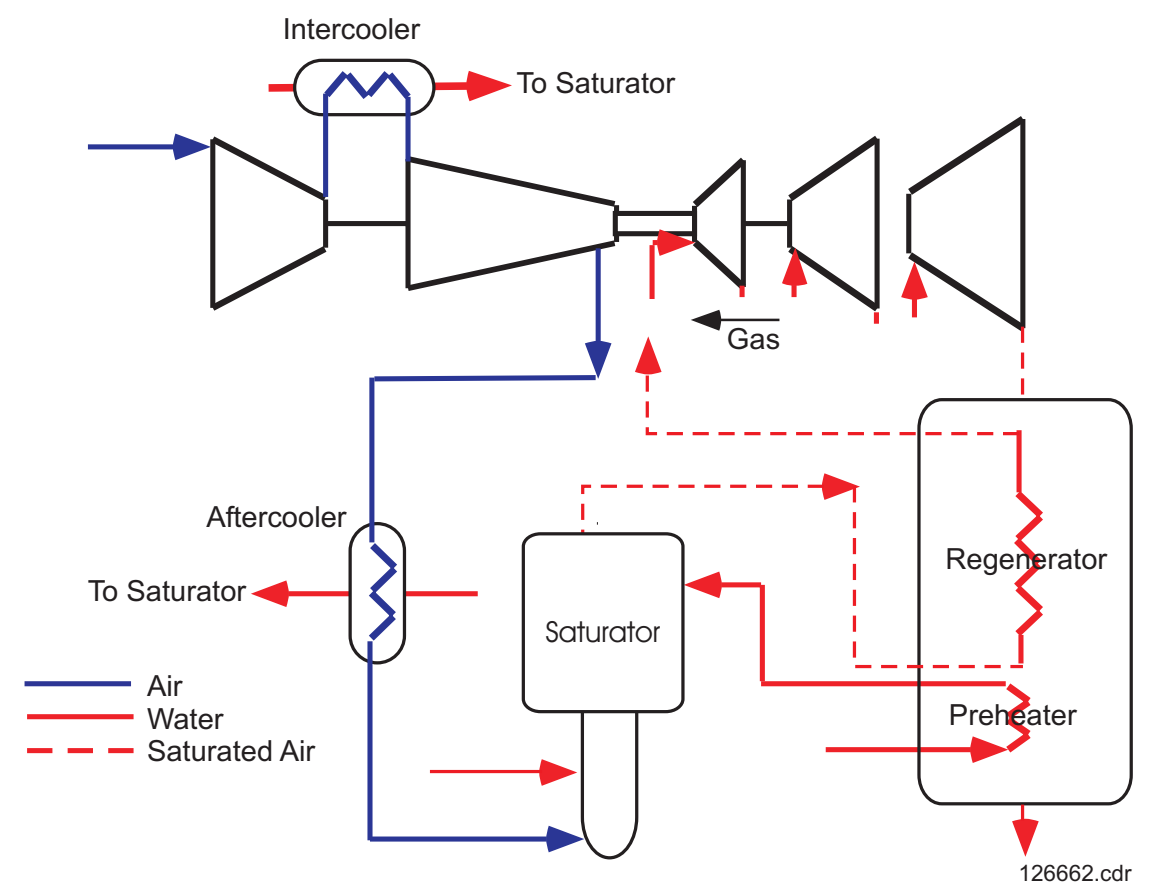

Figure 3-24. Simplified Diagram of HAT Cycle 


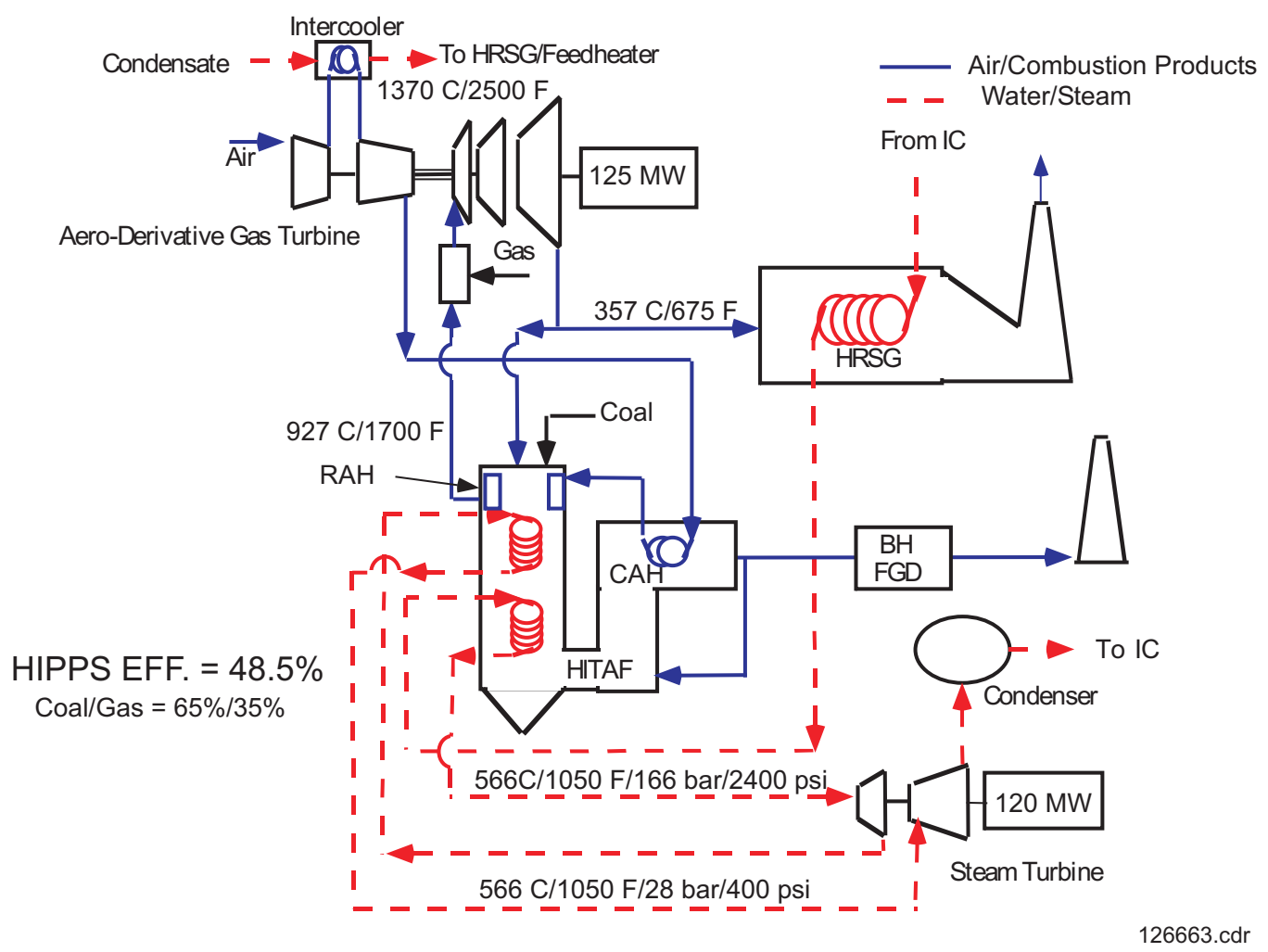

Figure 3-25. HIPPS With NGT-Type Gas Turbine 


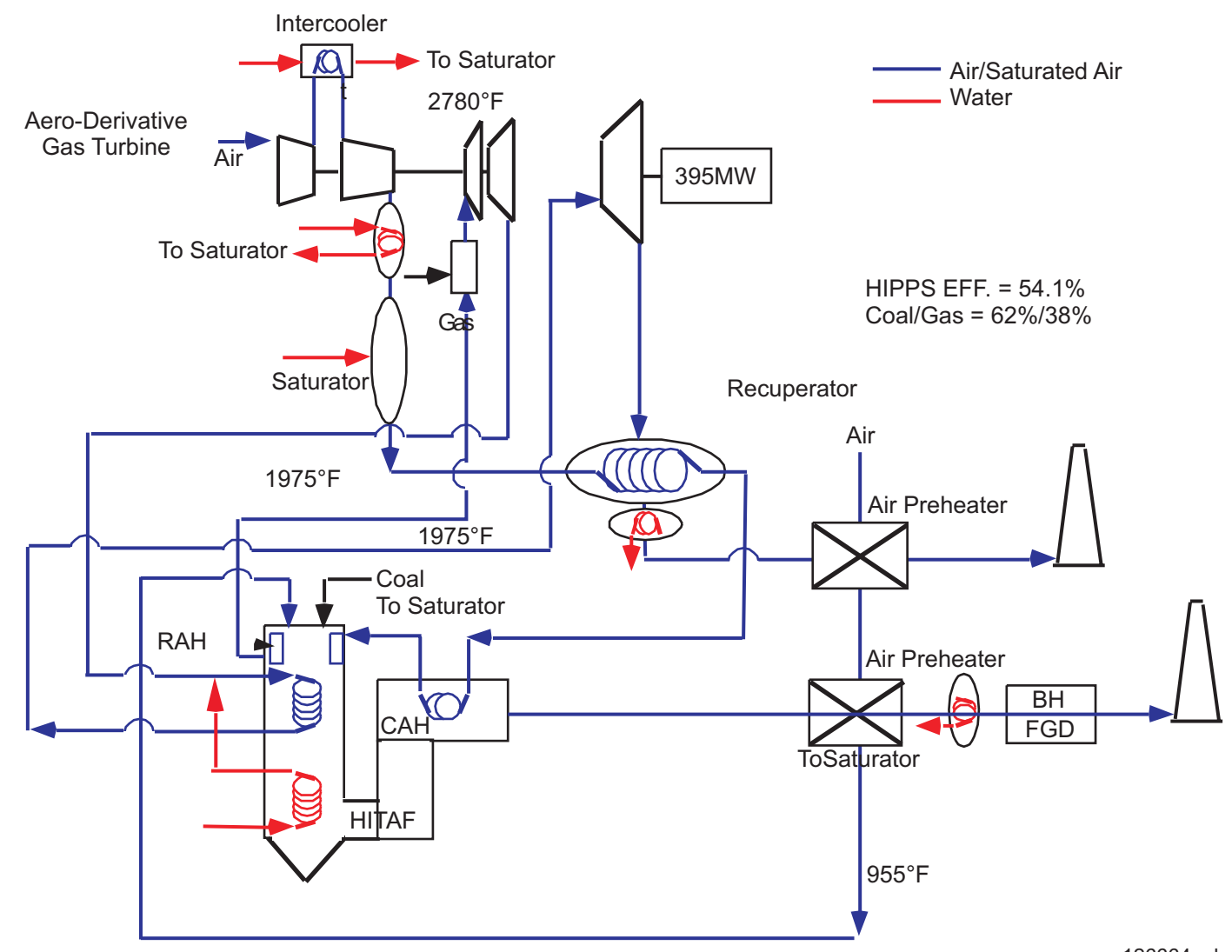

Figure 3-26. A HIPPS/HAT System

\subsubsection{Integrated Coal Gasification Humid Air Turbine Cycles}

When integrated with a coal gasification system, the NGT HAT has the further advantage that it can be developed to achieve the same attributes as the integrated combined-cycle powerplant, with the additional advantage of lower capital cost. An IGHAT configuration is shown in Figure 3-27.

Based on studies done in cooperation with Texaco, Fluor Daniel, and EPRI for a HAT cycle based on an aeroderivative version of the PW4000 aircraft engine, estimates indicate an IGHAT would have an efficiency comparable to that of a heavy-frame engine integrated combined-cycle powerplant. The IGHAT has the potential for lower cost than the integrated combined-cycle powerplant because it could operate without a steam turbine system and its accompanying equipment.

Performance for Block 1 and Block 2 versions is given in Table 3-3. The IGHAT analyzed used a Texaco highefficiency quench (HEQ) gasifier. The reason for using this gasifier was to give a basis of comparison to the $H$ engine integrated combined-cycle powerplant performance given in the literature (43 percent HHV). As can be seen in the following table, the estimated efficiencies of both the Block 1 and Block 2 IGHAT systems are higher than those given for the H-class integrated combined-cycle powerplant, even though they use some steam-system components to recover the lower grade heat in the HEQ system. Based on prior analyses of integrated combinedcycle powerplants and HAT cycles, it is expected that the IGHAT would benefit more than an integrated combinedcycle powerplant when employed in conjunction with a dry-feed gasifier coupled to a high temperature gas cleanup system. An IGHAT with a NGT operating with combustor exit temperature of $1676^{\circ} \mathrm{C}\left(3050^{\circ} \mathrm{F}\right)$ was also analyzed. The powerplant output was $479 \mathrm{MW}$ at an estimated efficiency of 50.1 percent (HHV). 
Table 3-3. FT60 IGHAT Performance Estimates (Texaco HEQ Gasifier)

\begin{tabular}{lrr}
\hline & Block 1 & \multicolumn{1}{c}{ Block 2 } \\
\hline HAT Power (MW) & 299 & 359.9 \\
Steam Power (MW) & 54.6 & 69.6 \\
Expander Power (MW) & 4.3 & 5 \\
Total Gross Power (MW) & 357.9 & 434.5 \\
Auxiliary Power (MW) & 43.6 & 51.4 \\
Net Power (MW) & 314 & 383.1 \\
Overall Efficiency Percent (HHV) & 44.1 & 46 \\
\hline
\end{tabular}

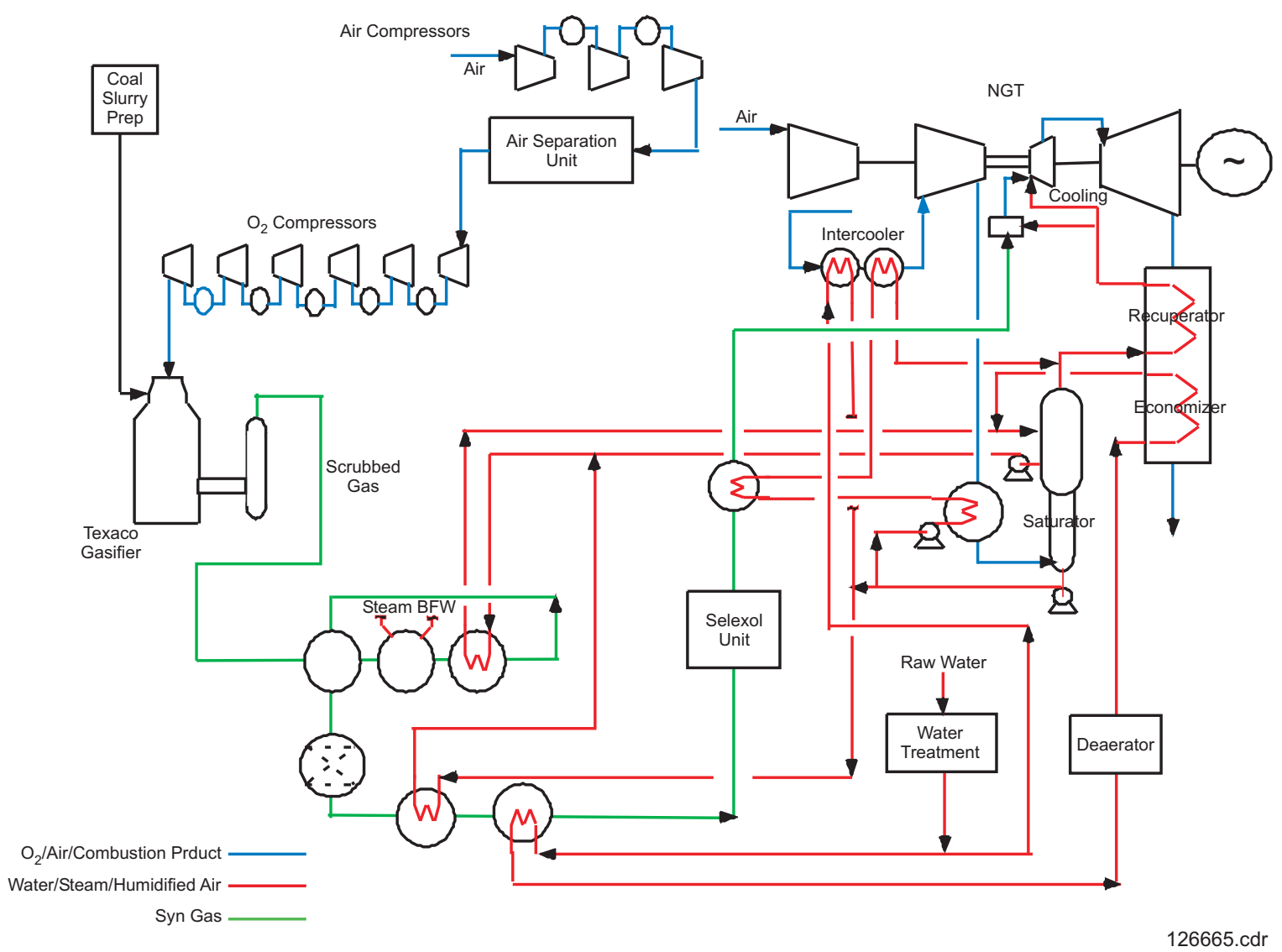

Figure 3-27. IGHAT Schematic 


\subsubsection{Support of Vision 21}

KraftWork Systems carried out analyses to identify how the NGT engine system could be integrated into Vision 21 plants. Vision 21 identifies the DOE plan for advanced coal-and gas-based power systems for introduction in the 2015 time frame. The Vision 21 goals include electrical efficiencies of 60 percent (HHV) on coal and 75 percent (LHV) on gas. These very high efficiencies are to be attained with systems having near zero emissions of pollutants including greenhouse gases. Program funding limitations only allowed consideration of gas-fired systems. Comments of the public benefits that could accrue with the NGT-based Vision 21 plants are also included.

\subsubsection{Next Generation Turbine/Fuel Cell Hybrids}

As previously described, the highest efficiencies for NGT systems were those of the gas-fired NGT HAT, which could reach efficiencies equivalent to 58 to 60 percent using Block 2 technology and beyond. To reach the lofty DOE goal of 75 percent (LHV), use of new technology in areas other than the NGT would have to be investigated. The fuel cell/gas turbine hybrid offers this opportunity.

At this time, solid oxide fuel cells (SOFC) have been demonstrated in the greater than $200 \mathrm{~kW}$ size range. The SOFC operates at high temperature, approximately $1000^{\circ} \mathrm{C}\left(1800^{\circ} \mathrm{F}\right)$, and has been pressurized to as much as 1.01 Mpa (10 atm). This technology can be used in a new type of hybrid cycle in which the SOFC tops the gas turbine. This hybrid cycle is thermodynamically similar to a gas turbine/steam turbine combined cycle in that the highest cycle efficiency is attained when all of the fuel into the system is used first in the topping portion. The SOFC, like other fuel cells, converts hydrogen to water while producing electricity. Since the fuel available is methane, a reformer, which converts much of the methane to carbon monoxide and hydrogen, is necessary. The fuel cell is then fed a fuel mixture of hydrogen, carbon monoxide, and unreformed methane. The SOFC does not fully use all of the input fuel; typical utilization factors are in the 70 to 80 percent range. Thus, the SOFC exhaust contains small fractions of the input fuel. This mixture can be combusted to raise the temperature of the exhaust from the $1000^{\circ} \mathrm{C}\left(1800^{\circ} \mathrm{F}\right)$ range to values up to $1204^{\circ} \mathrm{C}\left(2200^{\circ} \mathrm{F}\right)$. This temperature is well below the combustor exit temperature for the Block 1 NGT. The hybrid system, however, does benefit from the higher compressor and turbine efficiencies of the NGT and also from the higher power density resulting from intercooling. An NGT-based hybrid is shown in Figure 3-28. The performance is outstanding, with an estimated efficiency of 77.8 percent (LHV).

High Pressure GT/SOFC Hybrid

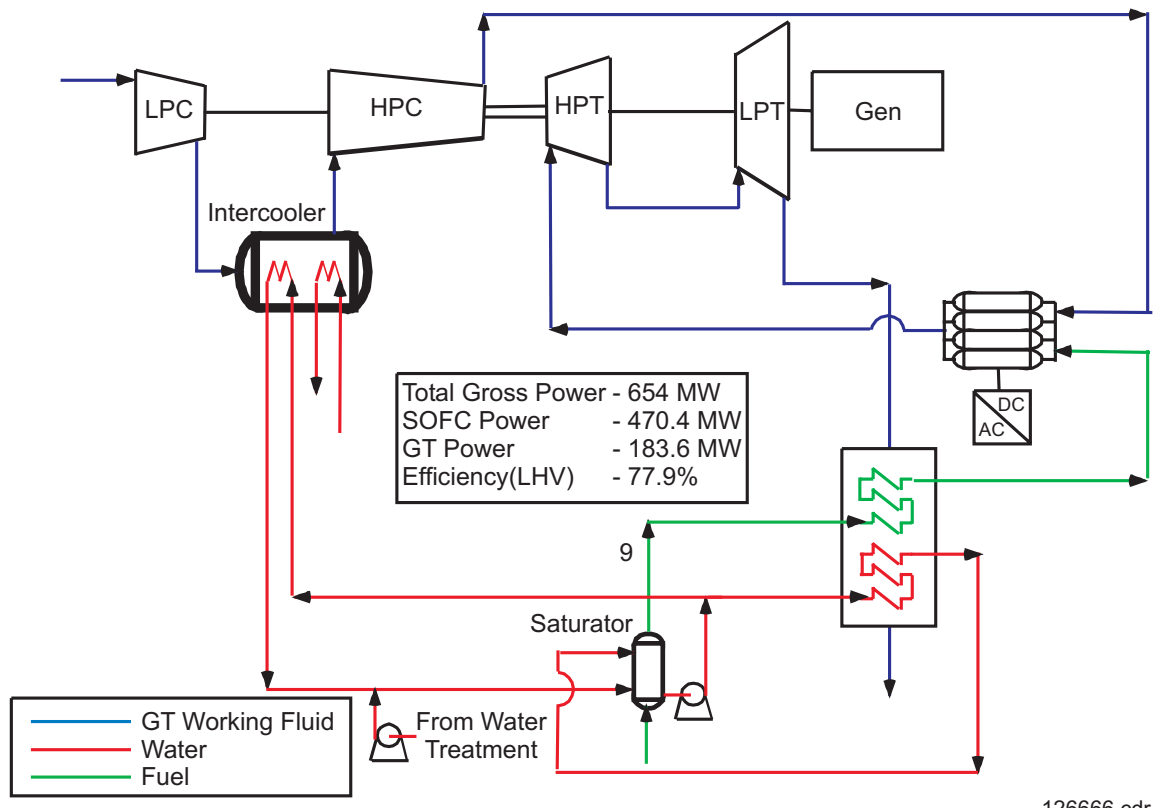

Figure 3-28. NGT/SOFC Hybrid 
The combustor exit temperature for this system is $1167^{\circ} \mathrm{C}\left(2134^{\circ} \mathrm{F}\right)$, a value far below the Block 1 value. The use of the ceramic 1st-stage vanes means that the turbine can run essentially uncooled in hybrid mode. Although the turbine temperature is down, the output is still over $180 \mathrm{MW}$, mostly do to the additional flow of steam from the fuel cell. It is, in effect, a steam injected engine. Operation at near 6.08 Mpa (60 atm) and, at a size of $470 \mathrm{MW}$, is far beyond current SOFC planning. Nonetheless, the very high efficiency of the hybrid makes this approach a very desirable subject for further research and development.

\subsubsection{Comments on Public Benefits of the Vision 21 Application}

A system with an efficiency of over 77 percent could offer a number of benefits to the general public. Even with higher cost gas, versus lower cost coal, the cost of electricity (COE) has an opportunity to be reasonable, if not actually more attractive. The cost of the SOFC has yet to be determined. The DOE goal is for fuel cell costs to be below $\$ 1,000 / \mathrm{kW}$. If this ambitious goal can be met, then the COE would indeed be significantly lower than most coal-fired alternatives.

This potential for low COE is accompanied by an extremely low pollution profile. The only source of sulfur is the natural gas. It is desulfurized prior to entering the reformer with recovery possible as elemental sulfur. There is essentially no production of $\mathrm{NO}_{\mathrm{x}}$ as the fuel cell produces electricity through electrochemical reactions and the combustion in the fuel cell exhaust is at low temperature and in the presence of a high fraction of water. The production of $\mathrm{CO}_{2}$, a greenhouse gas is also quite low, approximately $75 \mathrm{~g}$ carbon $/ \mathrm{kW} / \mathrm{hr}$, some 3 to 5 times lower than current coal-fired stations, and nearly 25 percent lower than the gas-fired $\mathrm{H}$-class combined cycle.

The NGT/SOFC hybrid could, of course, be integrated with coal gasification to give a very high performance coal-based system. This would give additional fuel flexibility to an already attractive power generation system. 


\section{REFERENCES}

Hogg, S. and Leschziner, M. A., "Computation of Highly Swirling Confined Flow With a Reynolds Stress Turbulence Model," AIAA J. 27(1): 57 (1989).

Jenny, P., Pope, S. B., Muradoglu, M., and Caughey, D. A., "A Hybrid Algorithm for the Joint PDF Equation of Turbulent Reactive Flows," J. Comput. Phys. 166: 252 (2001).

Malecki, R. E., Rhie, C. M., McKinney, R. G., Ouyang, H. Syed, S. A., Colket, M. B., and Madabhushi, R. K., "Application of an Advanced CFD-Based Analysis System to the PW6000 Combustor To Optimize Exit Temperature Distribution - PART 1: Description and Validation of the Analysis Tool," Proc. ASME TURBO EXPO 2001, 2001-GT-0062 (2001).

Muradoglu, M., Jenny, P., Pope, S. B., and Caughey, D. A., “A Consistent Hybrid Finite-Volume/Particle-Method for the PDF Equations of Turbulent Reactive Flows," J. Comput. Physics 154:342 (1999).

Muradoglu, M., Pope, S. B., and Caughey, D. A., "The Hybrid Method for the PDF equations of Turbulent Reactive Flows: Consistency Conditions and Correction Algorithms," J. Comput. Physics 172: 841-878 (2001).

Muradoglu, M., Pope, S. B., "A Local Time Stepping Algorithm for Solving the PDF Equations for Turbulent Reacting Flows," AIAA Journal (submitted 2001).

Pope, S. B., “PDF Methods for Turbulent Reactive Flows,” Prog. Energy Combust. Sci. 11: 119 (1985).

Pope, S. B., "Computationally Efficient Implementation of Combustion Chemistry Using In-Situ Adaptive Tabulation," Combust. Theory Modeling 1, 41 (1997). 